\title{
Evaluation of opacity, particulate matter, and carbon monoxide from heavy-duty diesel transient chassis tests
}

\author{
Ronald Page Jarrett \\ West Virginia University
}

Follow this and additional works at: https://researchrepository.wvu.edu/etd

\section{Recommended Citation}

Jarrett, Ronald Page, "Evaluation of opacity, particulate matter, and carbon monoxide from heavy-duty diesel transient chassis tests" (2000). Graduate Theses, Dissertations, and Problem Reports. 1075. https://researchrepository.wvu.edu/etd/1075

This Thesis is protected by copyright and/or related rights. It has been brought to you by the The Research Repository @ WVU with permission from the rights-holder(s). You are free to use this Thesis in any way that is permitted by the copyright and related rights legislation that applies to your use. For other uses you must obtain permission from the rights-holder(s) directly, unless additional rights are indicated by a Creative Commons license in the record and/ or on the work itself. This Thesis has been accepted for inclusion in WVU Graduate Theses, Dissertations, and Problem Reports collection by an authorized administrator of The Research Repository @ WVU. For more information, please contact researchrepository@mail.wvu.edu. 


\title{
EVALUATION OF OPACITY, PARTICULATE MATTER, AND CARBON MONOXIDE FROM HEAVY-DUTY DIESEL TRANSIENT CHASSIS TESTS
}

\author{
BY \\ RONALD P. JARRETT
}

Thesis

Submitted to

The College of Engineering and Mineral Resources

at

West Virginia University

in partial fulfillment of the requirements

for the degree of

Master of Science

in

Mechanical Engineering

Nigel N. Clark, Ph.D., Chair

Christopher M. Atkinson, Sc.D.

Mridul Gautam, Ph.D.

Thomas R. Long, Ph.D.

Department of Mechanical and Aerospace Engineering

Morgantown, West Virginia

2000

Keywords: Opacity, particulate matter, diesel, heavy-duty, emissions, transient chassis testing 


\section{ABSTRACT \\ EVALUATION OF OPACITY, PARTICULATE MATTER, AND CARBON MONOXIDE FROM HEAVY-DUTY DIESELTRANSIENT CHASSIS TESTS}

\section{By Ronald P. Jarrett}

Diesel particulate matter (PM) is a significant contributor to ambient air $\mathrm{PM}_{10}$ and $\mathrm{PM}_{2.5}$ particulate levels. In addition, recent literature argues that sub-micron diesel PM is a pulmonary health hazard. There is difficulty in attributing PM emissions to specific operating modes of a diesel engine, although it is acknowledged that PM production rises dramatically with load and that high PM emissions occur during rapid load increases on turbocharged engines. Stringent regulations now limit PM emissions at the manufacturing level, but do not govern in use PM emissions. Many states have established roadside snap-acceleration tests accompanied with peak opacity readings to identify high PM emitting diesel engines. The accuracy of this testing method to quantify PM is in question, casting doubt on their validity as a basis for regulation.

To evaluate snap-acceleration/opacity testing, the West Virginia University (WVU) Transportable Heavy Duty Vehicle Emission Testing Laboratories were used to collect emission and opacity data from vehicles exercised on a chassis dynamometer. The primary data for this research were obtained from a fleet of 1996 New Flyer buses in Flint, Michigan, equipped with electronically controlled Detroit Diesel Series 50 engines, with additional data from Cummins, Caterpillar, and Navistar heavy-duty diesel engines. In addition to snap-acceleration tests, the 
following chassis driving cycles were used; the Central Business District (CBD) cycle, the WVU 5-Peak Truck cycle, the WVU 5-Mile route, the EPA Urban Dynamometer Driving Schedule for Heavy Duty Vehicles (Test D), and the New York City Bus (NYCB) cycle. Peak opacity data were collected from the Wager 650CP full flow opacity meter and the Bosch RT 100 partial flow opacimeter. Continuous opacity data were also collected from the Wager opacity meter. Since carbon monoxide $(\mathrm{CO})$ and $\mathrm{PM}$ are attributed to rich combustion, $\mathrm{CO}$ data were also collected. Data were evaluated in terms of the opacity/PM relation, the PM/CO relation, and the CO/opacity relation. A dispersion model was developed and applied to continuous opacity data to simulate the axial dispersive effects of the laboratory's exhaust gas transport system. This was necessary for comparing continuous opacity with continuous $\mathrm{CO}$.

Results showed that the Bosch opacimeter consistently displayed higher peak opacity values than the Wager. The Bosch also showed slightly better correlation with peak CO data, but neither meter showed good results when compared to filter-captured PM. Integrated opacity data from the Wager also showed little correlation with filter-captured PM. It was also found that snap-acceleration tests did not identify PM due to engine loading, which is a significant contributor to PM formation. It was observed that the relation between $\mathrm{CO}$ and PM is consistent for the same engine under similar operating conditions, but will vary for different operating conditions (i.e. speed and load requirements) and probably for different fuels and environmental conditions. Good results were observed when comparing dispersed continuous opacity with continuous CO data. The dispersion model may have other applications, such as comparing engine data (such as speed, torque or power) with other engine emissions. 


\section{ACKNOWLEDGMENT}

There are so many people who deserve credit and/or recognition for their efforts which have aided me in accomplishing this goal. I will attempt to acknowledge the majority. For those that feel they should be mentioned and are not, my apologies. For those that I've mentioned who do not want to be, again my apologies.

I dedicate this work to my mother who did a hell-of-a job in raising my sister and I by herself, taught me to be independent, and instilled in me a respect for all others regardless of race, religion, or any other category that people manage to come up with. I only wish she could have lived to see the fruits of her effort. I also thank all of my other family members who have given me support throughout the years. My aunts and uncles, Penny and Johnny Jones and Roy and Miriam Angel; my cousins David \& Tori, Carter \& Jo Anne, Patricia, and Aleda, and my sister, Carol Anne. Their support has been a great asset.

I thank the Department of Energy for their research funding which has helped me further my education and improve my research skills. I would like to think that their investment will be fruitful.

I thank all the technicians and engineers with the WVU Transportable Heavy Duty Vehicle Emission Testing Laboratory and the WVU Transient Engine Test Cell who assisted with test execution and data collection. Their working knowledge of the laboratories helped provide quality data necessary for this research.

Then there is Nigel (excuse the wart) Clark, who's high expectations of quality and hands-off guidance has helped me further develop a self-guided quest towards excellence in research. His cynical wit provided a humorous guide to questioning everything. With that being said, I question his wisdom in funding me towards a Ph.D. and mine in pursuing it. 
I thank Chris Atkinson for his persistence and insistence to consistency and detail, Mridul Gautam for his unconditional support, and Tom (TR) Long for his friendly guidance throughout this ordeal. Thanks also goes out to Debbie Willis, Jean Kopasko, Marilyn Host, and Fern Wood for their tireless work in keeping the department running.

Then there are my friends who have supported and encouraged me every step of the way. My dearest friend, Helen, who's confidence and faith in me helped to keep me going, and to her husband, David and mother, Jan, who's additional confidence made me think that Helen's might not be unfounded. Thanks to Patti and Richard, Bruce and Janis, June and Denise, and also Susan. Much thanks also goes to Wendy to whom I'm greatly indebted. And finally to Sara, who came into my life in the middle of all this and has stuck with me throughout. Thank you all for being such dear friends. 


\section{TABLE OF CONTENTS}

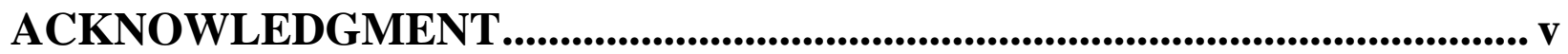

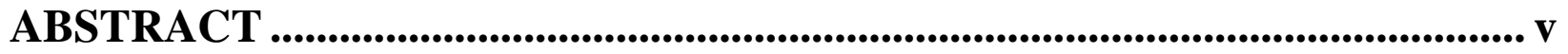

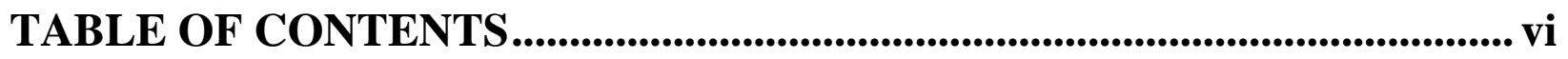

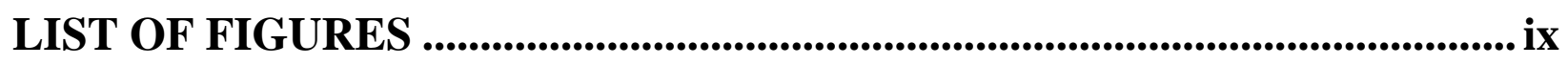

LIST OF TABLES ….............................................................................................

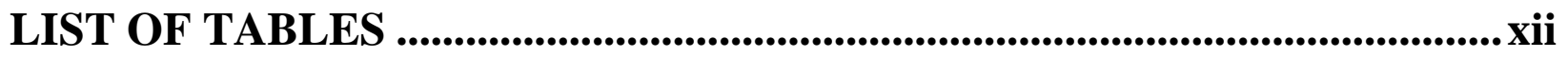

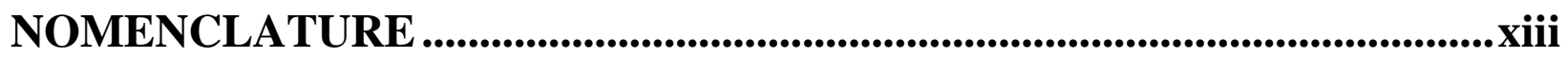

NOMENCLATURE ....................................................................................................... xiii

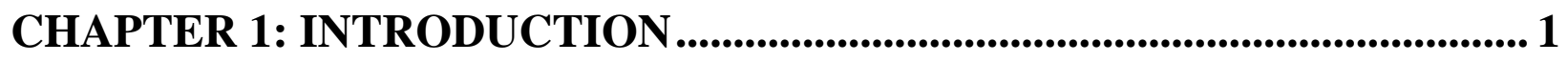

CHAPTER 2: OBJECTIVE .......................................................................

CHAPTER 3: DATA COLLECTION ........................................................9

3.1 Transportable Heavy Duty Vehicle EMission TeSting Laboratory ................. 9

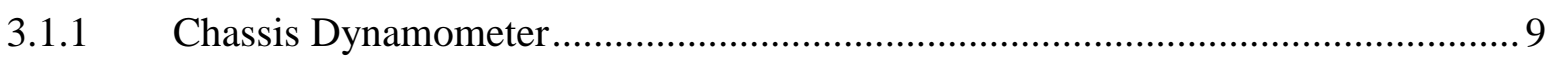

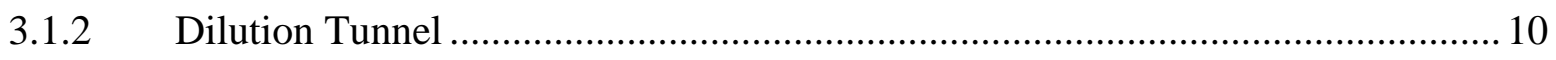

3.1.3 Emissions Gas Collection and Measurement ................................................ 12 
3.1.4 Particulate Matter Collection and Measurement ............................................... 13

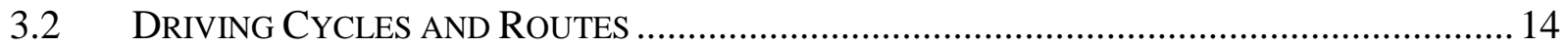

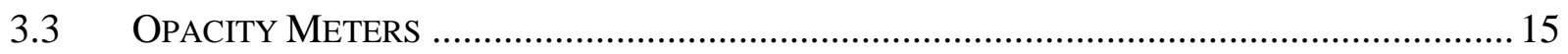

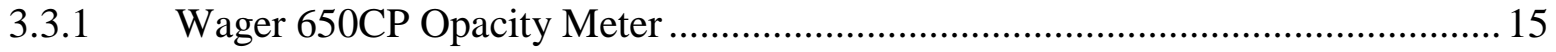

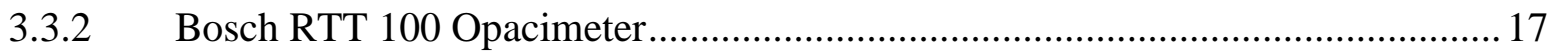



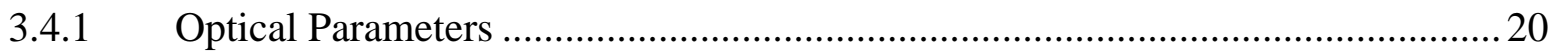

3.4.1.1 Clearance-To-Wavelength Ratio............................................................. 21

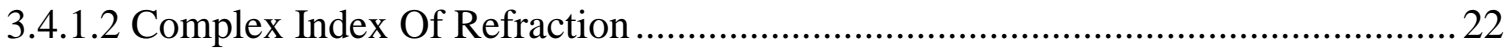

3.4.1.3 Size Parameter......................................................................................... 24

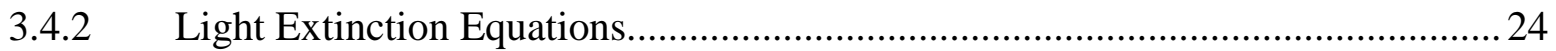

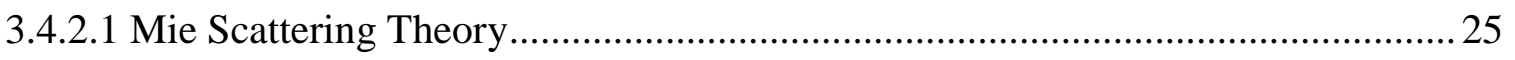

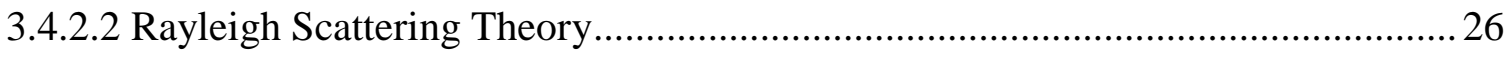

CHAPTER 4: DATA EVALUATION .............................................................. 29

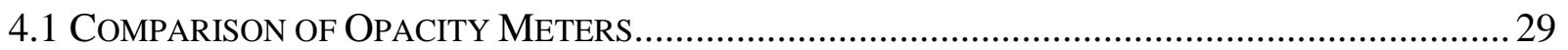

4.2 W AGER Opacity Meter ModificAtions.......................................................... 36

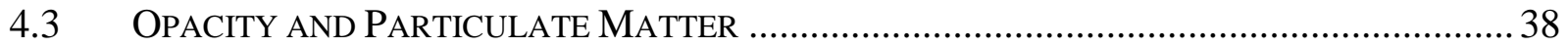

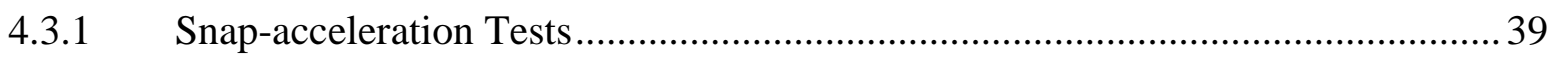

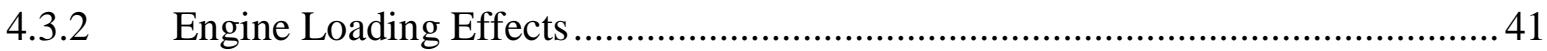

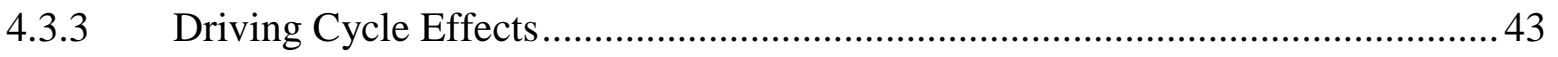

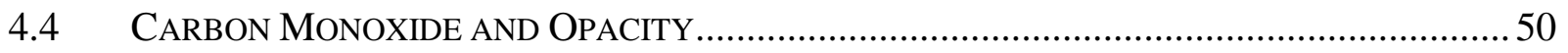

4.4.1 Evaluation of Peak Carbon Monoxide and Peak Opacity Values ........................50

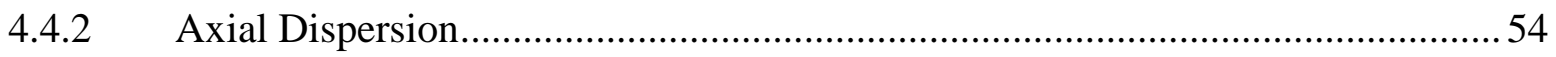


4.4.3 Continuous Carbon Monoxide and Dispersed Opacity.

4.4 CARbon Monoxide And Particulate Matter

CHAPTER 5: CONCLUSIONS AND RECOMMENDATIONS....................... 74

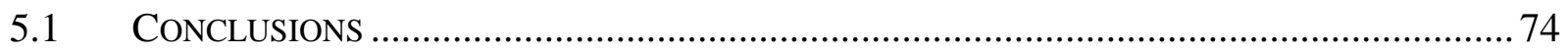

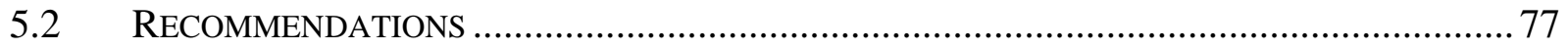

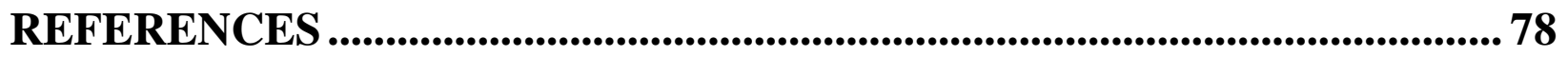

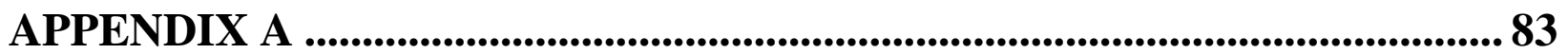

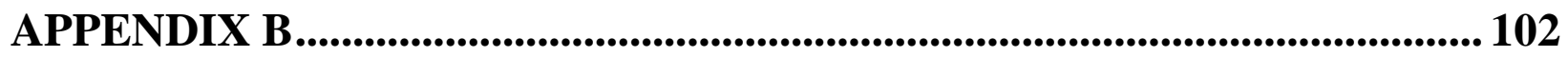

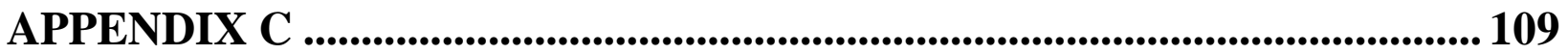




\section{LIST OF FIGURES}

Figure 3-1. The Wager 650CP opacity meter sensor head assembly.......................................... 16

Figure 3-2. Particle scattering effects diagram......................................................................... 19

Figure 4-1. Comparison of Bosch and Wager Peak Opacity Values........................................... 31

Figure 4-2. Wager Peak Opacity as a Function of Bosch Peak Opacity....................................... 31

Figure 4-3. Peak CO Concentrations as a Function of Peak Bosch and Wager Opacity Values. 33

Figure 4-4. Original and Corrected Continuous Wager Opacity Data......................................... 37

Figure 4-5. Continuous Wager Opacity Data From Fogged Lenses............................................... 37

Figure 4-6. PM as a Function of Opacity Data From Snap-Acceleration.Tests............................ 41

Figure 4-7. PM as a Function of Opacity For Loaded and Non-Loaded Tests.............................42

Figure 4-8. PM as a Function of Opacity From a Vehicle Exercised Through Different Cycles.43

Figure 4-9. PM as a Function of Opacity From a Vehicle Exercised At Different Loads........... 45

Figure 4-10. PM as a Function of Opacity from Six Buses Exercised Through CBD Tests....... 46

Figure 4-11. PM as a Function Opacity From All Tests Evaluated For This Research............... 47

Figure 4-12. Continuous Opacity Data.From a Series of Test Runs.............................................49

Figure 4-13. Continuous Opacity Data and Continuous CO From a Series of Test Runs............51

Figure 4-14. Peak CO as a Function of Peak Opacity From a Series of Test Runs.....................55

Figure 4-15. Peak CO as a Function of Peak Opacity From All Tests ........................................54

Figure 4-16. Original Levenspiel Dispersion Model Fit to $\mathrm{CO}_{2}$ Data. ........................................58

Figure 4-17. Modified Levenspiel Dispersion Model.Fit to $\mathrm{CO}_{2}$ Data.........................................59

Figure 4-18. Original and Dispersed Continuous Opacity Data. ………………….................... 62

Figure 4-19. Continuous CO Dispersed Continuous Opacity Data. ..............................................64

Figure 4-20. Continuous CO as a Function of Dispersed Continuous Opacity............................64 
Figure 4-21. CO/PM Ratio for Different Vehicles Tested Through Different Cycles at

Different Test Sites

Figure 4-22. Average PM as a Function of Average CO From a Bus Exercised

Through Five Different Test Cycles 70

Figure 4-23. Average PM as a Function of Average CO From a Truck Exercised

Through The Save Test Cycle and Test Weight at Different Test Sites. .73

Figure C-1. Speed-Time Plot of the Central Business District (CBD) Cycle. 110

Figure C-2. Speed-Time Plot of the West Virginia University Five Peak

(WVU 5-Peak) Cycle.

Figure C-3. Speed-Time Example From a Vehicle Exercised Through the

West Virginia University Five Mile (WVU 5-Mile) Route.

Figure C-4. Speed-Time Plot of the EPA Urban Dynamometer Driving

Schedule for Heavy Duty Vehicles (Test D). 113

Figure C-5. Speed-Time Plot of the New York City Bus (NYCB) Cycle. 114

Figure C-6. $\mathrm{CO}_{2}$ Data From Pulse Injections From Dispersion Test 1.................................. 115

Figure C-7. $\mathrm{CO}_{2}$ Data From Pulse Injections From Dispersion Test 2.................................... 116

Figure C-8. $\mathrm{CO}_{2}$ Data From Pulse Injections From Dispersion Test 3.................................... 117

Figure C-9. Continuous CO and Dispersed Opacity From a Snap-Acceleration Test............... 118

Figure C-10. Continuous CO as a Function of Continuous Dispersed Opacity

From a Snap-Acceleration Test. 119

Figure C-11. Continuous CO and Dispersed Opacity From a CBD Test. 120

Figure C-12. Continuous CO as a Function of Continuous Dispersed Opacity

From a CBD Test. 
Figure C-13. Continuous CO and Dispersed Opacity From a WVU 5-Mile Route Test.

Figure C-14. Continuous CO as a Function of Continuous Dispersed Opacity

From a WVU 5-Mile Route Test............................................................... 123

Figure C-15. Continuous CO and Dispersed Opacity From a NYCB Cycle Test................... 124

Figure C-16. Continuous CO as a Function of Continuous Dispersed Opacity

From a NYCB Cycle Test. ...................................................................... 125

Figure C-17. Continuous CO and Dispersed Opacity From a Test D Test........................... 126

Figure C-18. Continuous CO as a Function of Continuous Dispersed Opacity

From a Test D Test.

Figure C-19. Continuous CO and Dispersed Opacity From a Snap-Acceleration Test............ 128

Figure C-20. Continuous CO as a Function of Continuous Dispersed Opacity

From a Snap-Acceleration Test 


\section{LIST OF TABLES}

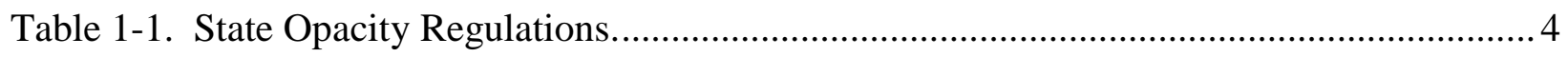

Table 3-1. Statistical Comparison Transient Driving Cycles............................................... 15

Table 4-1. Bosch and Wager Peak Opacity Data From Snap-Acceleration Tests..................... 30

Table 4-2. Average Emissions Results From A Series of Transient Test Runs........................48

Table 4-3. Original and Modified Levenspiel Dispersion Model Test Results. ....................... 61

Table 4-4. Statistical Results From Dispersed Opacity as a Function of CO Test Data.............65

Table 4-5. CO/PM Ratios From Four Buses Exercised Through Transient Driving Tests. ......... 69

Table 4-6. CO/PM Ratios From Eight Trucks Exercised Through the WVU 5-Mile Route.......71

Table 4-7. Emissions Results From a 1994 Navistar T-444E Engine....................................... 72 


\section{NOMENCLATURE}

\begin{tabular}{|c|c|}
\hline$a$ & Mean Particle Diameter \\
\hline $\mathrm{ADC}$ & Analog to Digital \\
\hline$a_{n}$ and $b_{n}$ & Scattering Coefficients \\
\hline$c$ & Distance Between Particles In a Particle Cloud or Phase Velocity \\
\hline$C_{a b s}$ & Absorption Cross Section \\
\hline$C_{e x t}$ & Extinction Cross Section \\
\hline$C_{s c a}$ & Scattering Cross Section \\
\hline $\mathrm{CBD}$ & Central Business District Transient Test Cycle \\
\hline $\mathrm{cfm}$ & Cubic Feet per Minute \\
\hline $\mathrm{cm}^{3}$ & Cubic Centimeters \\
\hline $\mathrm{CO}$ & Carbon Monoxide \\
\hline $\mathrm{CO}_{2}$ & Carbon Dioxide \\
\hline $\mathrm{CV} \%$ & Percent Coefficient of Variance \\
\hline Test D & EPA Urban Dynamometer Driving Schedule for Heavy-Duty Vehicles \\
\hline DDC & Detroit Diesel Corporation \\
\hline EPA & Environmental Protection Agency \\
\hline $\mathrm{ft}$. & Feet \\
\hline FTP & Federal Test Procedure \\
\hline GVW & Gross Vehicle Weight \\
\hline $\mathrm{HC}$ & Hydrocarbons \\
\hline HD & Heavy-Duty \\
\hline HFID & Heated Flame Ionization Detector \\
\hline
\end{tabular}




\begin{tabular}{|c|c|}
\hline $\mathrm{hp}$ & Horsepower \\
\hline in. & Inches \\
\hline in.-lb. & Inch-Pound \\
\hline $\mathrm{k}$ & Material's Absorptive Index (extinction coefficient) or Smoke Density \\
\hline$k_{v}$ & Critical Flow Venturi Calibration Constant \\
\hline $\mathrm{kg}$ & Kilogram \\
\hline $\mathrm{km}$ & Kilometers \\
\hline $\mathrm{kW}$ & Kilowatts \\
\hline lbm. & Pounds mass \\
\hline $\mathrm{m}$ & Meter \\
\hline$m$ & Complex Index of Refraction \\
\hline $\mathrm{mg}$ & Milligrams \\
\hline $\mathrm{mm}$ & Millimeters \\
\hline $\mathrm{ms}$ & Milliseconds \\
\hline $\mathrm{m}^{3} / \mathrm{s}$ & Cubic Meters per Second \\
\hline $\mathrm{n}$ & Material's Refractive Index \\
\hline NDIR & Non-Dispersive Infrared \\
\hline$n \mathrm{~m}$ & Nanometers \\
\hline $\mathrm{N} \cdot \mathrm{m}$ & Newton-meter \\
\hline $\mathrm{NO}_{\mathrm{X}}$ & Oxides of Nitrogen \\
\hline NYCB & New York City Bus Transient Test Cycle \\
\hline OP & Opacity \\
\hline $\mathrm{P}$ & Pressure \\
\hline
\end{tabular}




\begin{tabular}{ll} 
PC & Personal Computer \\
PM & Particulate Matter \\
PM $_{2.5}$ & Particulate Matter Smaller Than Two and One Half Microns \\
PM $_{10}$ & Particulate Matter Smaller Than Ten Microns \\
ppm & Parts per Million \\
psi & Pounds per Square Inch \\
Q & Flow Rate \\
$Q_{a b s}$ & Absorption Efficiency Factor \\
$Q_{s c a}$ & Scattering Efficiency Factor \\
$Q_{e x t}$ & Extinction Efficiency Factor \\
$r_{c / w}$ & Clearance-to-Wavelength Ratio \\
$\mathrm{R}^{2}$ & Coefficient of Determination \\
rpm & Revolutions per Minute \\
SAE & Society of Automotive Engineers \\
SGD & Span Gas Divider \\
t & Time \\
T & Temperature \\
TEOM & Tapered Element Osculating Microbalance \\
THDVETL & Transportable Heavy-Duty Vehicle Emission Testing Laboratory \\
VDN & Vessel Dispersion Number \\
VOC & Volatile Organic Compounds \\
\hline & West Virginia University \\
\hline
\end{tabular}


$\in$

$\sigma$

$\sigma_{\mathrm{e}}$

$\lambda$

$\mu \mathrm{g}$

$\mu \mathrm{m}$
Electrical Permittivity

Dispersion Model Variance

Electrical Conductivity

Electromagnetic Wavelength

Micrograms

Micrometers (Microns) 


\section{CHAPTER 1: INTRODUCTION}

In comparison to spark ignited gasoline engines, diesel engines yield relatively low levels of hydrocarbons (HC), volatile organic compounds (VOC), and carbon monoxide (CO) [1]. As global warming concerns increase, diesel engines have an added advantage with carbon dioxide production $10 \%$ to $25 \%$ less than gasoline engines [1]. However, diesel engines are relatively high emitters of oxides of nitrogen $\left(\mathrm{NO}_{\mathrm{x}}\right)$ and particulate matter $(\mathrm{PM})$ when compared to spark ignited engines. Highway and non-road heavy-duty (HD) engines (primarily diesel engines) have been reported to account for approximately $40 \%$ of inhalable ambient particulate $\left(\mathrm{PM}_{10}\right)$, and $60 \%$ to $80 \%$ of fine particulate $\left(\mathrm{PM}_{2.5}\right)$ inventory [1,2], although claims of their fractional inventory contribution vary widely. The Northern Front Range Air Quality Study [3] has shown diesel PM contribution to be in question and has highlighted differences between ambient and inventory data. Further comment is available in Cass's 1997 [4] report on ambient carbonaceous PM. A 1997 Standard and Poor's report prepared for the American Trucking Association argues that U.S. freight volume will increase by $21.5 \%$ by 2006 , so that concerns over heavy-duty truck emissions are likely to escalate.

In recent years, diesel engine manufacturers have reduced PM emissions for HD applications through engine, injection, and control system design improvements. The European Auto/Oil Program supports this approach with its finding that engine design dominated the formation of PM emissions [5], although diesel engines for light HD applications now often employ catalytic converters. Increased fuel injection system pressure, late injection timing, improved injector design, improved fuel/air mixing, and low sulfur fuels have resulted in average particulate size reduction and improved oxidation of the carbon particles in the combustion chamber. However, some medical research is suggesting that total particle count and size, not 
simply mass, poses a greater health concern [6]. Moore [7] has argued that motor vehicle emissions are a major contributor to poor visibility in urban areas, so that diesel engines will also be impacted by Environmental Protection Agency (EPA) haze regulations. One concern is that modern engine technologies, while reducing total PM mass, may be increasing the total particle count and reducing the average particle size to the more potentially damaging low sub-micron size range.

It is well established that inhalation of diesel PM can pose health risks. Health risks include increased respiratory symptoms and diseases, reduction of lung function, mutation of lung tissue and structure, reduction of respiratory tract immune defenses, and premature death (especially for the elderly and people with cardiopulmonary diseases) [1,2,5,8-10]. Epidemiological studies show a consistent correlation between the rate of cardiopulmonary diseases and societal industrialization [2,11]. Emerging research is suggesting $\mathrm{PM}_{2.5}$ to be of greater concern than $\mathrm{PM}_{10}$. The smaller particles stay airborne longer and penetrate further into the alveoli of the lung. Dockery et al. [12] found a strong relation between indoor and ambient $\mathrm{PM}_{2.5}$ levels, and found ambient $\mathrm{PM}_{2.5}$ levels to remain relatively constant while ambient levels of $\mathrm{PM}_{10}$ had dropped. Stronger associations of mortality and morbidity have been observed with $\mathrm{PM}_{2.5}$ than $\mathrm{PM}_{10}$, and it has been hypothesized that hydrogen ions, which are associated with $\mathrm{PM}_{2.5}$, may have a stronger detrimental effect on infants and toddlers due to the lower levels of ammonium ions in their conductive airways [13].

To date, filter sampling of PM over the duration of a test is the only accepted means of PM measurement for emission standards certification. However, this provides no means for the researcher to ascribe PM production to any specific portion of a transient test, or to correlate PM production with engine load, speed, and change of speed. The tapered element oscillating 
microbalance (TEOM) shows the most promise in determining real-time continuous PM. Yet observations of TEOM data suggest moisture from combustion corrupts TEOM data through deposition and evaporation of water on the TEOM filter. In addition, PM analysis by filter capture and the TEOM unit are limited to laboratory environments and do not lend themselves to use for roadside inspection and/or shop maintenance.

Optical analysis of PM emissions by continuous opacity monitoring appears promising in that opacity meters are easily transportable, relatively inexpensive, installation requires little to no modifications to the vehicle, and operation is simple and requires little technical knowledge. Opacity meter smoke testing is attractive to states that want to check and regulate vehicles in the field since present mass/power based emissions regulations can only be enforced at the manufacturing stage of an engine. A snap-acceleration test is commonly used for roadside opacity inspection. In general, the test is a series of rapid engine accelerations from idle to governed speed while the transmission is in neutral [14]. This test simulates transient operation associated with PM production, but does not provide engine loading, which also contributes to PM production. In an effort to provide state-to-state consistency, the EPA has established recommended peak opacity limits for HD vehicles tested using the snap-acceleration test as specified by the Society of Automotive Engineers (SAE) special publication J1667 [15]. The guidelines recommend 55\% peak opacity for 1990 model years and earlier, and 40\% for 1991 model years and newer. These values represent opacity data which have been corrected for ambient conditions and altitude. Detailed correction methods are found in the SAE J1667 publication. States that have established in-use testing based on opacity are shown in Table 1-1 along with an overview of the basic criteria and fines for non-compliance where applicable. 


\begin{tabular}{|c|c|c|}
\hline State & Criteria & Fines \\
\hline Arizona & $\begin{array}{l}\text { Based on SAE J1667. No roadside enforcement. Fleets } \\
\text { can self-certify. Maximum opacity of } 20 \% \text { at } 2,000 \mathrm{ft} \text {., and } \\
\text { up to } 40 \% \text { based on altitude. }\end{array}$ & \\
\hline California & $\begin{array}{l}\text { Based on SAE J1667. Fleets can self-certify. Roadside } \\
\text { enforcem ent. }\end{array}$ & $\begin{array}{r}\$ 8001^{\text {st }} \text { Ticket } \\
\$ 1,8002^{\text {na }} \text { Ticket }\end{array}$ \\
\hline Colorado & $\begin{array}{l}\text { Yearly inspection under Regulation \# } 12.35 \% \text { and } 30 \% \\
\text { limits for naturally asperated and turbocharged engines. } \\
\text { Corrections for altitude. Possible switch to SAE J1667. }\end{array}$ & \\
\hline Connecticut & $\begin{array}{l}\text { Presently instituting pilot study through random checks } \\
\text { at rest areas and weigh stations. }\end{array}$ & \\
\hline Illinois & $\begin{array}{l}\text { HD study completed by task force. HD emissions } \\
\text { program to start July } 1,2000 \text {. Inspection at state safety } \\
\text { inspection station and fleets may self-certify. }\end{array}$ & \\
\hline Indiana & $\begin{array}{l}\text { HD Pilot Study at point of entry (weigh stations) during } \\
\text { summer of } 1999 .\end{array}$ & \\
\hline Maryland & Program started January 1, 2000 based on SAE J1667. & \\
\hline Massachusetts & $\begin{array}{l}\text { Emission checkup program as of spring } 1999 . \\
\text { Information posted at http://www.state.ma.us/dep/ }\end{array}$ & \\
\hline Nevada & Based on SAE J1667. Random roadside testing. & $\begin{array}{r}\$ 8001^{\text {st }} \text { Ticket } \\
\$ 1,5002^{\text {nd }} \text { Ticket }\end{array}$ \\
\hline New Hampshire & $\begin{array}{l}\text { Based on SAE J1667. Effective January } 1999 . \\
\text { Six months "education" period with warnings only. }\end{array}$ & \\
\hline New Jersey & $\begin{array}{l}\text { Yearly inspections based on SAE J1667. } \\
\text { Fleets > } 25 \text { may self-certify. } \\
\text { Information at http://www.state.nj.us/dep/aqm }\end{array}$ & $\begin{array}{r}\$ 7001^{\text {st }} \text { Ticket } \\
\$ 1,5002^{\text {nd }} \text { Ticket }\end{array}$ \\
\hline New York & $\begin{array}{l}\text { Program started June 1, } 1999 \text { in "non-attainment" areas. } \\
\text { No definitive information on test standard, probably } \\
\text { SAE J1667. }\end{array}$ & $\begin{array}{r}\$ 7001^{\text {st }} \text { Ticket } \\
\$ 1,3002^{\text {nd }} \text { Ticket }\end{array}$ \\
\hline Ohio & Regulations are being drafted covering buses only. & \\
\hline Utah & $\begin{array}{l}\text { Pilot study for port of entry and roadside enforcement in } \\
\text { progress. Currently only certain counties in Salt Lake } \\
\text { City area are testing HD vehicles. }\end{array}$ & \\
\hline Vermont & $\begin{array}{l}\text { Pilot study with legislation for enactment pending. } \\
\text { SAE J1667 based with enforcement through spot checks. }\end{array}$ & \\
\hline Washington & $\begin{array}{l}\text { SAE J1667 based. Fleets may self-certify. } \\
\text { Decentralized stations. }\end{array}$ & \\
\hline
\end{tabular}

Table 1-1. States, criteria, and fines based on opacity testing [16]. All states shown have adopted EPA recommended peak opacity limits of 55\% for 1990 model year and earlier and $\mathbf{4 0 \%}$ for 1991 model year and newer unless indicated different. 
Opacity data obtained during a snap-acceleration test can arguably provide a good indication of increased PM production, but the concern is whether the data can be used as a quantitative indication of PM. There is also concern of an opacity meter's ability to "see" the particulate matter since much of the PM mean diameter is smaller than the wavelength of the light source used. If there is little correlation between continuous opacity data and total PM, then it could be argued that opacity data obtained from snap-acceleration tests should be limited to use as an indicator for maintenance and/or further testing and not for regulation enforcement.

Despite the fact that PM emissions from diesel powered vehicles merit attention, present inventory prediction is not thorough. Emissions levels are based on the Federal transient heavy-duty engine certification test [17] and are translated to emissions factors using fuel consumption data. West Virginia University (WVU), through its Transportable Heavy Duty Vehicle Emissions Testing Laboratories (THDVETL) [18], has assembled a bank of data from field chassis testing of trucks and buses across the nation. Whereas gaseous emissions data are available continuously over the duration of a test cycle, PM is quantified only for the whole cycle by weighing the mass of PM collected on a filter. At present, the WVU THDVETLs have collected data from over 2,000 heavy-duty diesel vehicles exercised through transient chassis dynamometer tests that might yield continuous PM if a post processing technique could be developed. In order to derive a general modal or neural network-based [19] relationship for PM emissions from a specific vehicle, the PM must be apportioned continuously over the duration of the test cycle. In this way PM can then be related to operating parameters such as vehicle speed, acceleration or load. Although some continuous mass measuring devices are in the marketplace, they have not yet been accepted as a substitute for gravimetric analysis of PM captured on a filter over the duration of an emissions test. Response time of these instruments is also of concern for 
instantaneous measurement. It would be attractive to proportion the total PM in terms of continuous emissions of a regulated gas: for diesel engines there is strong argument that $\mathrm{CO}$ and PM are related, since they both can be argued to arise from rich combustion zones. Kittelson and Johnson [20] have recognized this relationship using "Round Robin" test data, although they showed considerable data scatter on the CO versus PM plots. In these plots, the CO and PM values represent total test emissions averaged in reference to total engine work and expressed in mass of emissions measured per unit work produced (g/bhp-hr). The author has also observed from field testing that $\mathrm{CO}$ and PM were strongly related, with both rising near full power operation of a diesel vehicle. This research evaluates the correlation between opacity and PM, PM and $\mathrm{CO}$, and $\mathrm{CO}$ and opacity to better understand the relation between the three emission measurements. 


\section{CHAPTER 2: OBJECTIVE}

The primary objective of this research was to evaluate opacity data obtained from snap-acceleration tests. This is imperative given the common belief that there is a weak correlation between opacity and PM, and that more and more states are using opacity data obtained from snap-acceleration tests as a means for emissions regulation. The two opacity meters which are commonly used are the Wager 650CP and the Bosch RT 100. Both are described in detail in Sections 3.3.1 and 3.3.2 respectively. The primary objective consisted of two parts. The first was to evaluate opacity data collected with both meters simultaneously from the same snap-acceleration tests. The second was to evaluate the effects of engine loading on the opacity/PM relation. This was done by collecting opacity and PM data from the same vehicles exercised through the snap-acceleration test (no load) and chassis dynamometer tests (with load). In addition, opacity and PM data were collected from the same vehicle exercised through the same chassis driving cycle at various loads.

The second objective of this research was to evaluate the triangulated relation between opacity, PM, and CO. The relation between opacity and PM was evaluated by integrating continuous opacity over the time of the test to compare with total PM obtained by filter capture. The relation between opacity and $\mathrm{CO}$ is inferred since both $\mathrm{PM}$ and $\mathrm{CO}$ are attributed to rich combustion and opacity is a partial function of PM. Since opacity data was available continuously it was possible to compare it with continuous $\mathrm{CO}$. The ratio between $\mathrm{CO}$ and PM was also of interest. This relation was explored as a function of different variables such as different engines, different electronic fuel injection controllers on the same engine, engine load, driving cycle, and testing environment. In pursuing a relationship between $\mathrm{CO}$ and PM, the author infers that the sulfate and lubricant contribution to the total PM mass is small. Sulfur in 
diesel fuel is now typically at the level of 350 parts per million (ppm) in the United States, and this content is likely to drop further in the future. Schaberg et al. [21] have shown the sulfate content of PM to be less than $1 \%$ for emissions from a modern diesel engine burning low-sulfur diesel fuel. Schaberg et al. and Ariga et al. [21, 22] have both shown lubrication oil products to account for approximately $20 \%$ of the total PM mass from HD diesel engines. While sulfate and lubricant contributions could not be neglected for certification purposes, the author believes that they were a minor contribution to over-all PM and were neglected in this study. This assumption may introduce more error in the future as emissions from fuel combustion are reduced further while the lubricating oil contribution to PM stays approximately the same as present.

An additional hypothesis was that the total PM might be proportioned over the cycle with respect to continuous opacity, measured with an instantaneous light extinction detector at the vehicle exhaust. Several studies have attempted to correlate diesel particulate emissions with measurements using opacity or smoke meters [23-26], but they have attempted to predict PM a priori from opacity, rather than use opacity for proportioning the total PM mass over a single test from a specific vehicle. In addition, the role of hydrocarbons in relating carbon particulate, total PM mass, and opacity has been considered previously [25]. Many of these studies have shown good correlation with empirical equations, but these have been based on steady state operating conditions and are engine specific. Transient driving conditions have a wide range of dynamic factors which determine not only the particulate mass, but its optical light extinction effect as well. 


\section{CHAPTER 3: DATA COLLECTION}

The primary objective of this research was to collect continuous opacity data using two different opacity meters during the course of transient chassis tests of HD diesel trucks and buses while continuous gaseous emission data and gravimetric PM data were collected. This would allow continuous and integrated opacity data from both opacity meters to be compared, as well as evaluating the correlation between opacity data and gaseous emission data on a continuous and integrated basis. All chassis dynamometer emissions data were collected using the WVU THDVETLs. The THDVETLs were established to conduct emission tests for HD diesel and alternative fueled vehicles and are described in Section 3.1 and elsewhere [18].

\subsection{Transportable Heavy Duty Vehicle Emission Testing Laboratory}

The THDVETLs consist of a mobile chassis test bed, emission analyzer trailer, and tool trailer. The laboratory is operated by a team of engineers and technicians possessing a combined knowledge of combustion, fluid flow, electrical and computer engineering, and HD diesel engine repair, maintenance and operation.

\subsubsection{Chassis Dynamometer}

The chassis dynamometer test bed is built into a $9.14 \mathrm{~m} \mathrm{(30} \mathrm{ft.)} \mathrm{flat-bed} \mathrm{trailer} \mathrm{which} \mathrm{is}$ transported by a tractor truck. Four hydraulic legs built into the test bed lift the bed off of the tractor and rear tandem dolly and lower the test bed to the ground for testing. Once it is leveled, the dynamometer rollers are approximately $0.33 \mathrm{~m}$ (13 in.) above the ground. The test vehicle is driven onto the test bed via ramps, leveled with pedestals under the front wheels, and chained 
down to the test bed for testing. Four pairs of steel idle rollers with a $0.3175 \mathrm{~m}$ (12.5 in.) diameter are mounted in the test bed and allow for stationary driving of the test vehicle. Vehicle inertial and road load losses are simulated by a right and left set of flywheel weights and power absorbers. Power is taken from the vehicle by means of removing each of the outer tandem wheels (one from each side) and bolting hub adapters in place on each side of the vehicle drive axle. Each hub adapter is attached to a drive axle which delivers the vehicle axle torque and rotation to a right and left set of flywheel inertial weights and power absorbers. Flywheel weights can be combined in varying combinations to simulate vehicle inertia from approximately $9072 \mathrm{~kg}(20,000 \mathrm{lbm}$.$) to approximately 22,680 \mathrm{kg}(48,000 \mathrm{lbm}$.$) in approximately 113 \mathrm{~kg}$ (250 lbm.) increments (depending on tire size). Road load (wind and rolling resistance) is simulated by two Mustang air-cooled eddy current power absorbers each rated at $224 \mathrm{~kW}$ (300 hp) continuous load, and $745 \mathrm{~kW}$ (1000 hp) peak load. The power absorber load is controlled by the amount of electric current through the power absorber coils which in turn is controlled by a Dyn-loc IV power absorber controller. Axle torque is measured with two Eaton torque transducers (one for each axle) with a 22,600 Nm (200,000 in.-lb.) rating.

\subsubsection{Dilution Tunnel}

During chassis testing, vehicle exhaust was ducted through a $0.127 \mathrm{~m}$ (5 in.) diameter insolated exhaust transfer pipe into a full flow dilution tunnel which was $0.457 \mathrm{~m}$ (18 in.) in

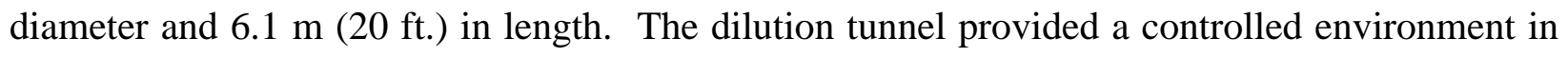
which vehicle exhaust was thoroughly mixed with ambient air prior to probe sampling for gaseous and PM analysis. Exhaust mixing with ambient air in the dilution tunnel was necessary to simulate real-world conditions where vehicle exhaust is mixed with ambient air. Exhaust gas 
mixing with ambient air provided rapid cooling of the exhaust gases which promoted PM formation. The dilution tunnel also reduced the dew point temperature of the exhaust gases. Condensation of exhaust moisture in the exhaust sampling system would have detrimental effects on emission testing in terms of partial capture of exhaust gases and PM, as well as interference with analyzer performance such as the non-dispersive infrared analyzers. The high flow rate through the dilution tunnel provided near plug flow conditions. A true plug flow is a highly turbulent flow characterized by extensive mixing and a uniform velocity profile [27]. The results were complete mixing of ambient air with exhaust gases which allowed for consistent sampling for analyzer probes at any radial position. Dilution tunnel turbulence was aided by a restrictor plate located $0.9 \mathrm{~m}$ (3 ft.) into the tunnel with a $0.305 \mathrm{~m}$ (12 in.) diameter center hole. Tunnel flow was generated by a two-stage blower and flow rate was controlled by a critical flow venturi. The critical flow venturi was located between the blower and tunnel and limits the maximum volumetric flow by means of sonic flow conditions within the venturi throat. Approximate flow rates of $0.47,0.71,1.0$, or $1.2 \mathrm{~m}^{3} / \mathrm{s}(1000,1500,2000$, or 2500 cubic feet per minute [cfm]) were selected by varying the venturi cross-sectional area using different diameter center-line inserts. Absolute pressure and temperature were measured continuously just up-stream from the venturi to calculate actual flow rate, $Q$, in cubic feet per minute (cfm) using the equation,

$$
Q=k_{v} \frac{P}{\sqrt{T}}
$$

where,

$k_{v}$ is the calibration constant and is dependent on the size insert used.

$P$ is absolute pressure measured in pounds per square inch (psia).

$T$ is temperature measured in Fahrenheit $\left({ }^{\mathrm{O}} \mathrm{F}\right)$. 


\subsubsection{Emissions Gas Collection and Measurement}

Regulated exhaust gases $\left(\mathrm{CO}, \mathrm{NO}_{\mathrm{X}}, \mathrm{HC}\right)$ and $\mathrm{CO}_{2}$, were collected from the full scale dilution tunnel using four stainless steel probes $4.57 \mathrm{~m}$ (15 ft.) downstream in the dilution tunnel. This distance was determined by a factor of ten times the dilution tunnel diameter which is to assure proper mixing of ambient air and exhaust gases before sampling [18]. Probes are located at a radial position of $0.076 \mathrm{~m}$ ( 3 in.) from the tunnel axis. Heated lines carry the mixed exhaust sample to the five analyzers (two for $\mathrm{CO}$ and one for each of the other gases).

Two analyzers were used for $\mathrm{CO}$ due to the broad concentration range during a transient test. Low CO was measured with a Rosemont Model 880A non-dispersive infrared (NDIR) analyzer. High $\mathrm{CO}$ and $\mathrm{CO}_{2}$ were measured with two Rosemont Model 868 NDIR analyzers. $\mathrm{NOx}\left(\mathrm{NO}\right.$ and $\mathrm{NO}_{2}$ ) were measured using a Rosemont Model 955 Chemiluminescent analyzer. HC was measured using a Rosemont Model 402 heated flame ionization detector (HFID).

All analyzers were calibrated before emission testing using calibration gases of known concentration. Since all but the NOx analyzer are non-linear, calibration gases were routed through a SGD-710C span-gas divider from $0 \%$ to $100 \%$ in $10 \%$ increments and analyzer reading were taken at each point. The eleven points were used to generate a third order polynomial which was applied to analyzer data during data reduction.

During the course of each test, dilute exhaust samples and background samples were collected separately in $\operatorname{Tedlar}^{\circledR}$ bags. These samples were pumped through the gas analyzer bench after the test to measure average and background concentrations for the respective gases. Background concentrations were subtracted from average and continuous gas concentration data which yielded average and continuous gaseous emissions from the test vehicle. Continuous 
results were integrated and averaged on a distance basis and compared with bag concentrations also averaged on a distance basis. This provided a quality control check.

\subsubsection{Particulate Matter Collection and Measurement}

Particulate matter from the test vehicle's diluted emissions were collect by filtration capture and measured gravimetrically. A sample probe for PM collection was located in the same region of the dilution tunnel as the other gas sample probes. The sample line from the probe was routed to a secondary dilution tunnel prior to filtration. The secondary dilution tunnel was $76 \mathrm{~mm}$ (3 in.) in diameter and $0.76 \mathrm{~m}$ (30 in.) in length and was designed to provide additional mixing with ambient air for exhaust gas sample cooling (if necessary) so that the sample gas temperature does not exceed $125^{\circ} \mathrm{F}\left(50^{\circ} \mathrm{C}\right)$.

Total flow through the secondary dilution tunnel and secondary dilution air flow were generated by two Gast Model 1023 rotary vane pumps with flow rates controlled by two Sierra Model 740 mass flow controllers. Secondary dilution tunnel flow rates ranged from 1.4 to $2.8 \mathrm{~L} / \mathrm{s}$ (3 to $6 \mathrm{cfm}$ ) and secondary dilution air flow rates ranged from 0 to $1.4 \mathrm{~L} / \mathrm{s}$ (0 to $3 \mathrm{cfm}$ ). Diluted sample gases were then routed through two $70 \mathrm{~mm}$ (2.75 in.) Pallflex fluorocarbon coated fiberglass filters (primary and secondary) for PM capture.

The Pallflex filters (Type T60A20) have a 98\% capture efficiency for particles greater than 0.1 micron $(\mu \mathrm{m})$. All filters were conditioned for at least 12 hours before use in an Envirotronics SH8 environmental chamber with a Chromalox 2030 environmental test chamber controller. After sampling, filters were stored in the environmental chamber for at least 24 hours before weighing. Filters were housed in unsealed glass petri dishes when being stored in the environmental chamber. The glass petri dishes do not allow static electricity buildup, provide 
dust protection to the filters, and allow for moisture exchange for reconditioning before weighing. Before and after mass readings were taken using a Cahn C-32 microbalance scale. The mass measuring range used on the C-32 was $0.000 \mathrm{mg}$ to $1350 \mathrm{mg}$. In this range, the unit had a sensitivity of $10 \mu \mathrm{g}$ and a repeatability of $10 \mu \mathrm{g}$. The microbalance was also housed in the environmental chamber.

\subsection{Driving Cycles and Routes}

Driving cycles and routes provide a testing standard for emission comparison and evaluation and, in the case of driving cycles, provide the test vehicle driver a speed map to follow during a chassis dynamometer emission test. By definition, a cycle is a speed-time schedule and a route is a speed-distance schedule and is note dependent on time. A route allows the vehicle full accelerate which is arguable more representative to real-life driving conditions. There is a need for different driving cycles and routes since a vehicle's emission signature will vary depending on driving conditions, such as highway or inner city.

The driving cycles used for this research were the Central Business District (CBD) cycle, the WVU 5-Peak Truck cycle, the WVU 5-Mile route, the EPA Urban Dynamometer Driving Schedule for Heavy-Duty Vehicles (Test D), and the New York City Bus (NYCB) cycle. The WVU 5-Mile route is basically the WVU 5-Peak cycle (which also covers a distance of five miles), but with full acceleration. The vehicle is accelerated at full power to the same cruise speeds as in the WVU 5-Peak $(20,25,30,35$, and $40 \mathrm{mph})$, and the test is concluded when the vehicle has traveled five miles. There is no recommended speed-time trace for the WVU 5-Mile route so an example speed-time plot from a test is shown. Plots of the four driving cycles and the route example are shown in Appendix $\mathrm{C}$ as Figures $\mathrm{C}-1$ through $\mathrm{C}-5$. Table 3-1 below shows 
a statistical comparison of the four driving cycles based on test duration, maximum and average speed, maximum and average acceleration, and distance covered in the test. Average speed is based on the entire test time, where as average acceleration is based on positive acceleration averaged over the respective time period.

\begin{tabular}{|c|c|c|c|c|c|c|}
\hline Test Cycle & Duration & Max. Speed & Aver. Speed & Max. Accel. & Aver. Accel. & Distance \\
\hline & $s$ (min) & kph (mph) & kph (mph) & $\mathrm{m} / \mathrm{s}^{2}(\mathrm{mi} / \mathrm{hr}-\mathrm{s})$ & $\mathrm{m} / \mathrm{s}^{2}$ (mi/hr-s) & km (mi) \\
\hline CBD & "574 (9.57) & $32.19(20)$ & $20.24(12.58)$ & $1.07(1.07)$ & $0.89(0.88)$ & $3.23(2.00)$ \\
\hline Test D & $1060(17.67)$ & $93.34(58)$ & $30.35(18.86)$ & $1.97(1.96)$ & $0.49(0.49)$ & $8.94(5.55)$ \\
\hline NYCGT & $585(9.75)$ & $32.19(20)$ & $3.75(2.33)$ & $1.34(1.33)$ & $0.52(.052)$ & $0.61(0.38)$ \\
\hline NYCB & $600(10.00)$ & $49.57(30.8)$ & $5.94(3.69)$ & $2.77(2.76)$ & $1.17(1.16)$ & $0.99(0.61)$ \\
\hline WVU 5-Peak & $900(15.00)$ & $64.21(39.9)$ & $32.22(20.02)$ & $0.40(0.40)$ & $0.32(0.32)$ & $8.05(5.00)$ \\
\hline
\end{tabular}

Table 3-1. Statistical comparison of the four transient chassis dynamometer driving cycles used for data collection for this research.

\subsection{Opacity Meters}

\subsubsection{Wager 650CP Opacity Meter}

The Wager 650CP opacity meter is a full flow exhaust opacity meter, meaning that the optical measurement path of the meter "looks" through the entire exhaust plum of the vehicle at the end of the exhaust stack. It is non-invasive to the exhaust flow. The Wager opacity meter uses a light emitting diode (LED) green gallium phosphide light source $(570 \mathrm{~nm})$ and a Si photo diode with an infrared filter. It has a 0 to 1 volt analog output with a linearity of $1 \%$ from 0 to $100 \%$ opacity, and a response time of 0.45 seconds from 0 to $95 \%$ opacity. A pressurized air supply routed through a moisture/oil paper-filter was directed across the Wager light source and sensor lenses to avoid fogging and PM accumulation. All data were collected through an ADC signal conditioner at $10 \mathrm{~Hz}$ and averaged to one-second intervals for processing and evaluation. 
To incorporate the Wager opacity meter with the existing emission testing configuration, the unit was installed in a configuration different than designed by the manufacturer. The manufacturer's intended installation was at the end of the truck's exhaust stack, with the optical path "looking" through the exhaust plum just as it exits the exhaust pipe. This was not possible during emission testing since an exhaust transfer pipe was fastened to the end of the vehicle exhaust pipe and ducted into the dilution tunnel. To solve this problem, a $0.305 \mathrm{~m}$ (12 in.) section of $0.127 \mathrm{~m}$ (5 in.) diameter exhaust transfer pipe was modified to incorporate the Wager and Bosch opacity meters. For the Wager, two $25.4 \mathrm{~mm}$ ( 1 in.) diameter pieces of pipe were welded onto the five-inch diameter pipe such that they were opposite each other and their shared axis was perpendicular to and crossed through the axis of the five-inch pipe (see Figure 3-1).

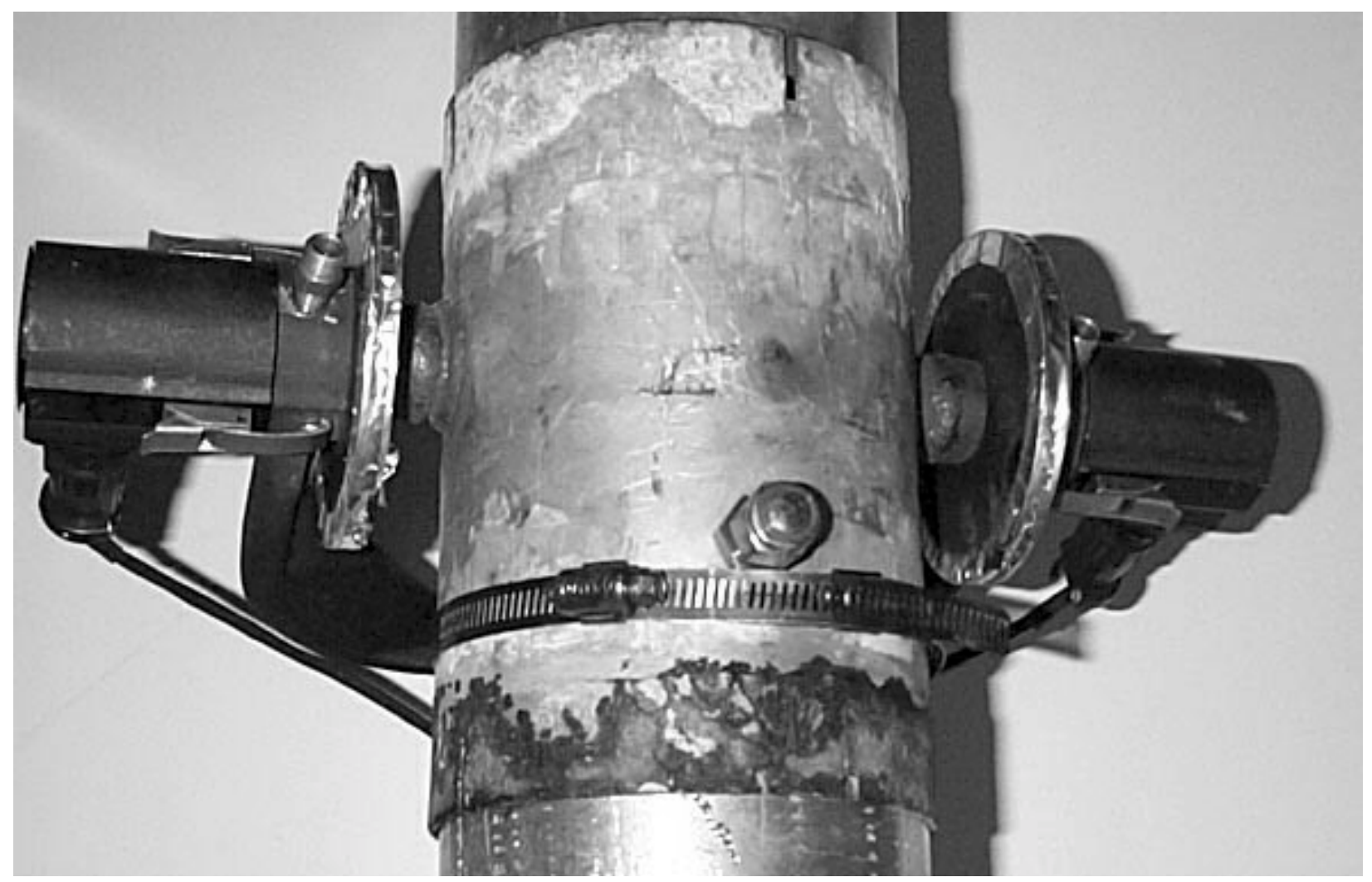

Figure 3-1. The Wager 650CP opacity meter sensor head assembly mounted on the modified exhaust pipe section. The capped nipple for the Bosch sample hose attachment can be seen in the foreground. 
When mounted onto this section of pipe, the opposing faces of the Wager would fit snuggly to the two surfaces of the one-inch pipes. This would minimize any exhaust leaking while allowing the Wager to "look" through the exhaust transfer pipe and through the vehicle exhaust plume. A centerline sample probe was also fitted into the 12-inch section of exhaust transfer pipe down-stream from the Wager optical path (to avoid exhaust flow disturbance to the Wager optical path). The probe was directed to an exterior nipple to which the Bosch sample hose was attached. This configuration allowed for Bosch and Wager opacity data collection during the course of a transient test without interference to emission gas and PM collection and measurement. This allowed for opacity data comparison with other emission data, as well as with engine and or axle data and comparison between the two opacity data.

At the start of each testing period, the Wager opacity meter was turned on for warm-up and self-calibration. This was done with the optical sensor headset in place and the engine not running. After the unit had zeroed itself, the ADC channel output was zeroed. Then the optical sensor headset was moved such that the optical path was obscured (100\% opacity). The ADC output was then adjusted to 2000 and the system was ready for data acquisition.

\subsubsection{Bosch RTT 100 Opacimeter}

The Bosch RTT 100 opacimeter is a partial flow opacity meter, meaning that a portion of the exhaust plume is sampled by a probe inserted in the exhaust pipe. At the start of initial operation, The RTT 100 went through a warm-up phase (about 6 to 9 minutes). During this time the quartz lens heating elements heated up to their operating temperature of $680^{\circ} \mathrm{C}\left(1256^{\mathrm{O}} \mathrm{F}\right)$. The heating elements operated continuously throughout the test period which provided a constant exhaust sample temperature in the measurement chamber and burned off any soot deposit which 
could have accumulate on the optical lenses. The unit performed a self-test for calibration and to establish the reference of zero opacity. Exhaust samples were drawn at a $1.2 \mathrm{~L} / \mathrm{s}(2.54 \mathrm{cfm})$ flow rate through a $9.53 \mathrm{~mm}$ ( $3 / 8 \mathrm{in}$.) silicone hose $5.18 \mathrm{~m}$ (17 ft.) in length which was attached to the metal probe nipple on the modified section of the exhaust transfer pipe shown in Figure 3-1. The sample then entered a $102 \mathrm{~mm}$ (4 in.) enclosed chamber for optical analysis (opacity for this research). The unit uses a green LED with a spectral peak of $550 \mathrm{~nm}$ to $570 \mathrm{~nm}$ for its light source.

The RTT 100 is capable of measuring exhaust smoke in terms of opacity, absorption coefficient (or smoke density), and mass concentration. Opacity is measured in a percent range of 0 to $100 \%$ with a resolution of $0.1 \%$ and represents the fraction of a known light source which is blocked by the exhaust sample. Opacity is the preferred form of smoke measurement in the United States.

Absorption coefficient ( $\mathrm{k}$ ) is a quantification of the light absorbing abilities of the exhaust plum when measured across a one-meter optical path, has units of $\left(\mathrm{m}^{-1}\right)$, and is the preferred form of smoke measurement in Europe. The RTT 100 measures the absorption coefficient in a range of 0 to $30.0 \mathrm{~m}^{-1}$ with a resolution of $0.01 \mathrm{~m}^{-1}$.

Mass concentration is calculated by the RTT 100 from the absorption coefficient and is presented in milligrams of PM per cubic meter $\left(\mathrm{mg} / \mathrm{m}^{3}\right)$. The range is 10 to $1966 \mathrm{mg} / \mathrm{m}^{3}$ with a resolution of $1 \mathrm{mg} / \mathrm{m}^{3}$. The RTT 100 manual states that this calculation is only accurate under steady state conditions. Given that opacity is the preferred smoke measurement in the U.S. and that mass concentration output is only accurate during steady state vehicle operation, only opacity data were considered for this study. 


\subsection{Particulate Radiative Properties}

To fully understand the opacity data obtained, the interaction between electromagnetic waves, particles, and particle clouds must be understood. When an electromagnetic wave comes in contact with a field of particles (or particle cloud) the wave intensity can be diminished by either absorption and/or scattering. Scattering is caused by diffraction, reflection, and/or refraction as shown in Figure 3-2. Diffraction is when an electromagnetic wave does not actually come in contact with a particle but passes close enough such that the particle's presence alters the wave's direction. Reflection occurs when a wave bounces off a particle and refraction occurs when a wave travels through a particle and reemerges in a different direction [28].

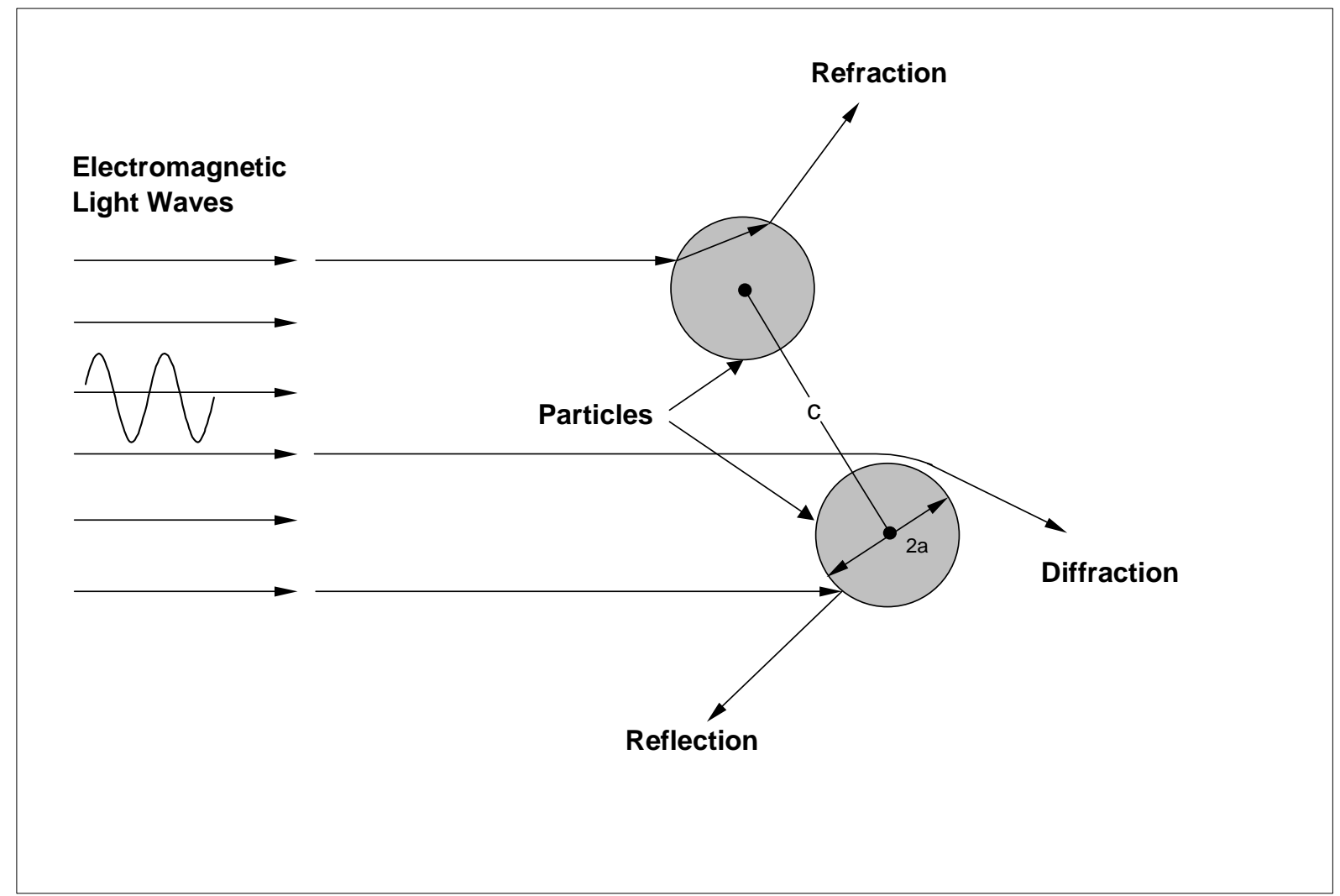

Figure 3-2. Diagram of the scattering effects of a particle on electromagnetic waves. 


\subsubsection{Optical Parameters}

Absorption and scattering are usually quantified in terms of absorption cross section $\left(C_{a b s}\right)$ and scattering cross section $\left(C_{s c a}\right)$, both having units of area. These are often combined into one term called the extinction cross section $\left(C_{e x t}\right)$ by the relation,

$$
C_{e x t}=C_{a b s}+C_{s c a}
$$

Equation 3-2

Dividing these terms by the particle's projected cross section area yields a nondimensionalized efficiency factor $(Q)$ where,

absorption efficiency factor: $Q_{a b s}=\frac{C_{a b s}}{\pi \cdot a^{2}}$

Equation 3-3

scattering efficiency factor: $\quad Q_{s c a}=\frac{C_{s c a}}{\pi \cdot a^{2}}$

Equation 3-4

extinction efficiency factor: $\quad Q_{e x t}=\frac{C_{e x t}}{\pi \cdot a^{2}}$

Equation 3-5

and,

$Q_{\text {ext }}=Q_{a b s}+Q_{s c a}$

Equation 3-6

where $a$ is the particle's effective radius.

This approach assumes that the particles are spherical. It is well established that diesel particulate are conglomerate chains of carbon and hydrocarbons which are far from being spherical. However, the error introduced when modeling a single diesel particle as a sphere goes towards zero when integrated over an entire cloud of particles [28]. 
The effective radius can be determined by either a volume (or mass) average or a number average. It is also noted that particle size is referred to in both radius and diameter by different researchers. The reader should be careful to note which dimension is being used.

The absorption and scattering effects are a function of; (i) particle size and/or size distribution, (ii) the clearance between particles (clearance/wavelength ratio $\left[r_{c / w}\right]$ ), (iii) material composition of the particles (complex index of refraction $[m]$ ), and (iv) relative size of the particles to the electromagnetic wave length (size parameter $[x]$ ). The first of these four parameters, particle size, is accounted for by the size parameter. Clearance-to-wavelength ratio, complex index of refraction, and size parameter are nondimensional and are independent when $\mathrm{r}_{\mathrm{c} / \mathrm{w}}$ is sufficiently large [28].

\subsubsection{Clearance-To-Wavelength Ratio}

The clearance-to-wavelength ratio $\left(r_{c / w}\right)$ is a ratio of the distance between neighboring particles and the electromagnetic wavelength and is shown by the relation,

$$
r_{c / w}=\frac{c}{\lambda}
$$

where,

$c$ is the center to center distance between neighboring particles.

$\lambda$ is the electromagnetic wavelength.

If the distance between two particles is smaller than the electromagnetic wavelength (i.e.

$r_{c / w}$ less than 1) than the electromagnetic wave cannot pass between the two particles without interacting with both. Similarly, if $r_{c / w}$ is greater than 1 then the interaction between the 
electromagnetic wave and a given particle will not be affected by neighboring particles. Modest [28] states that if $r_{c / w} \gg 1.0$ then scattering effects are independent, meaning that $Q_{a b s}$ and $Q_{s c a}$ are functions only of $x$ and $m$, and that the optical effects of a particle cloud are additive. In their evaluation of diesel exhaust size distribution and particle count, Rickeard et al. [29] reported maximum particle number concentrations of $220,000 / \mathrm{cm}^{3}$. Assuming an even distribution, the average distance between particles from this report is $165.7 \mu \mathrm{m}$, which results in a clearance-towavelength ratio of 290 . Thus, it is safe to assume that opacity data obtained from diesel exhaust are a function of $x, m$ and particle number count and are independent of the clearance-towavelength ratio.

\subsubsection{Complex Index Of Refraction}

The complex index of refraction $(m)$ is primarily a material property which indicates how the material surface will absorb or scatter an electromagnetic wave. However, it is also a partial function of the electromagnetic wavelength. The complex index of refraction is represented by the relation,

$m=n-i k$

where,

$n$ is the refractive index of the particle material.

$k$ is absorptive index (extinction coefficient) of the particle material. 
The variables $n$ and $k$ are defined by the relations,

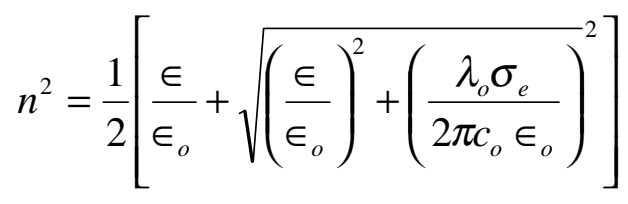

$$
\begin{aligned}
& k^{2}=\frac{1}{2}\left[-\frac{\epsilon}{\epsilon_{o}}+{\sqrt{\left(\frac{\epsilon}{\epsilon_{o}}\right)^{2}+\left(\frac{\lambda_{o} \sigma_{e}}{2 \pi c_{o} \epsilon_{o}}\right)}}^{2}\right]
\end{aligned}
$$

where,

$\in$ and $\sigma_{\mathrm{e}}$ are electrical permittivity and electrical conductivity which are phenomenological coefficients and are dependant on the wavelength.

$c$ is the phase velocity of the electromagnetic wave (not to be confused with the speed of light), and the subscript 'o' designates property values in a vacuum.

Due to shape and composition variations, experimental determination of $n$ and $k$ for diesel particulate is more desirable. Modest [28] showed values of $n$ and $k$ to be 2.20 and 1.12 respectively for carbon. Dalzell and Sarofim [30] reported values of $n$ and $k$ for propane soot to be 1.57 and 0.56 respectively for a wavelength of $570 \mathrm{~nm}$. However, Hunt et al. [31] reported very poor results when using the values determined by Dalzell. Hunt et al. reported values of 1.33 and 0.00 for $n$ and $k$ respectively under no-load operating conditions (mean particle diameter of $36 \mathrm{~nm}$ ), and 1.34 and 0.19 respectively under full-load conditions (mean particle diameter of $120 \mathrm{~nm}$ ). His results suggest that the light absorption of diesel particulate is zero (or near zero) for very small particles and only scatter effects are present. Modest also reported $n$ to 
vary little for different types of pulverized coals (i.e. carbon particles), but $k$ to vary considerably from 0.008 to 0.020 . This agrees with the results reported by Hunt et al.

\subsubsection{Size Parameter}

The size parameter $(x)$ is a unitless comparison between a particle's size and the electromagnetic wavelength, which for this research is the opacity meter light beam at a wavelength of $570 \mathrm{~nm}$ or $0.57 \mu \mathrm{m}$. The size parameter is defined by the relation, $x=\frac{2 \pi a}{\lambda}$

Equation 3-11

Rickeard et al. [29] reported particle effective diameters to range from approximately 16 to $400 \mathrm{~nm}$, with peak size concentration at $100 \mathrm{~nm}$. Hunt et al. [31] found particle diameters to range from 2 to $500 \mathrm{~nm}$ under no-load operating conditions and 10 to $1000 \mathrm{~nm}$ under full-load operating conditions. Particle size range will vary from study to study, and will also vary due to fuel properties, engine design, operating and loading conditions, and after-treatment devices. For the particle size ranges reported by these two studies, the size parameter, $x$, ranges from 0.011 to 5.51 .

\subsubsection{Light Extinction Equations}

The interaction between a sphere and an electromagnetic wave is generally described by the Mie scattering theory. However, this is a complicated theory and more simple approaches can be used in some cases. The Rayleigh scattering theory may be used when the size parameter, $x$, is very small (i.e. gas molecules and very small particles). Van de Hulst [32] gives $x<<1$ as a 
criteria for evaluating light extinction using Rayleigh scattering regimes. Modest suggests that $x=0.1$ is sufficiently small. The other extreme is when the particle is much larger than the electromagnetic wavelength. In this case geometric optics can be used when the criteria of $x \gg>1$ and $x k \gg>1$ is satisfied. Geometric optics is not applicable for this research and thus will not be presented. A brief overview of Mie and Rayleigh scattering regimes will be discussed in Sections 3.4.2.1. and 3.4.2.2 respectively.

\subsubsection{Mie Scattering Theory}

The Mie scattering theory is named after its developer German physicist, Gustav Mie (1868-1957). His theory of electromagnetic wave interaction with particles is far beyond the scope of this thesis, however his basic equations will be shown below. Mie developed the following equations for determining the scattering and extinction efficiency factors;

$$
\begin{aligned}
& Q_{s c a}=\frac{2}{x^{2}} \sum_{n=1}^{\infty}(2 n+1)\left(\left|a_{n}\right|^{2}+\left|b_{n}\right|^{2}\right) \\
& Q_{e x t}=\frac{2}{x^{2}} \sum_{n=1}^{\infty}(2 n+1) \Re\left(a_{n}+b_{n}\right)
\end{aligned}
$$

where $\mathfrak{R}$ is the real part of the complex number and $a_{n}$ and $b_{n}$ are scattering coefficients and are defined as,

$$
\begin{aligned}
& a_{n}=\frac{\psi_{n}^{\prime}(y) \psi_{n}(x)-m \psi_{n}(y) \psi_{n}^{\prime}(x)}{\psi_{n}^{\prime}(y) \zeta_{n}(x)-m \psi_{n}(y) \zeta_{n}^{\prime}(x)} \\
& b_{n}=\frac{m \psi_{n}^{\prime}(y) \psi_{n}(x)-\psi_{n}(y) \psi_{n}^{\prime}(x)}{m \psi_{n}^{\prime}(y) \zeta_{n}(x)-\psi_{n}(y) \zeta_{n}^{\prime}(x)}
\end{aligned}
$$


where $y=m x$ and $m$ and $x$ are the complex index of refraction and size parameter respectively. The functions $\Psi$ and $\zeta$ are Riccati-Bessel functions, which are related to the Bessel function $(J)$ and Hankel function $(H)$ by the relations,

$$
\begin{aligned}
& \psi_{n}(z)=\left(\frac{\pi z}{2}\right)^{1 / 2} J_{n+1 / 2}(z) \\
& \zeta_{n}(z)=\left(\frac{\pi z}{2}\right)^{1 / 2} H_{n+1 / 2}(z)
\end{aligned}
$$

where, $z$ is generic for either $x$ or $y$ and $n$ is a integer ranging from 1 to infinity.

Details of the Bessel and Hankel functions can be found in the National Bureau of Standards "Handbook of Mathematics" [33].

For practical application, Modest states that $n$ can be truncated at approximately $n_{\max }=2 x$. Wiscombe [34] evaluated computer solutions to Mie's scattering equations and found $Q_{e x t}$ as a function of $x$ to have primary and secondary oscillations for values of $x>1$. These oscillations dampened out as $x$ increased with $Q_{e x t} \rightarrow 2$ as $x \rightarrow \infty$ (which in relative terms is $x>30)$.

\subsubsection{Rayleigh Scattering Theory}

Evaluating Mie equations as $x \rightarrow 0$ (i.e. very small particles) yields equations similar to ones first developed by Lord Rayleigh and referred to as the Rayleigh scattering theory. These equations are much simpler to solve and are shown in Equations 3-18 and 3-19.

$$
Q_{s c a}=\frac{8}{3}\left|\frac{m^{2}-1}{m^{2}+2}\right|^{2} x^{4}
$$


and

$Q_{e x t}=-4 \mathfrak{I}\left\{\frac{m^{2}-1}{m^{2}+2}\right\} x \approx Q_{a b s}$

Equation 3-19

where $\mathfrak{I}$ is the imaginary part of the complex numbers. When evaluating Equation 3-18 in terms of $x<<1$ (i.e. the wavelength is much larger than the particle), it can be seen that the scattering effects become negligible and absorption effects are dominant. Although Modest and Van de Hulst do not specifically state which scattering theories should be used in terms of specific values of $x$, it is the author's interpretation that the Raleigh scattering theory should be used when $x<0.1$, geometric optic properties for $x>30$, and the Mie scattering theory should be used when $x$ is approximately 0.1 to 30 .

Two observations can be drawn here. First is that the scattering effects of a particle cloud will vary widely when the particles are of similar size magnitude as the electromagnetic wavelength (as is true with diesel particles and opacity light waves). This is evident by the size parameter, $x$, in Equation 3-18 being raised to the forth power. Second, for a given particle size range, reduction in wavelength size such that $x$ is greater than approximately 30 would result in a consistent and predictable extinction of an electromagnetic wave due to PM. In application terms, a better correlation between PM mass and light extinction would exist for a known particle size range.

In the effort to increase fuel efficiency and power, and to reduce PM mass emissions, manufacturers have increased fuel injection pressure and developed injectors that deliver better fuel atomization. This has resulted in reducing the mean particulate diameter, such that many of the particles are smaller than the wavelength of most opacity meters. For the optical affect of diesel PM to be predictable (i.e. $x>30$ resulting in $Q_{e x t}=2$ ), and if a mean particle diameter of $40 \mathrm{~nm}$ is assumed, an electromagnetic wavelength of approximately $8.0 \mathrm{~nm}$ would be required. 
This wavelength is bordering between ultraviolet light and X-rays. However, X-rays are known to penetrate many materials and it is not known what their interaction with diesel particulate would be. 


\section{CHAPTER 4: DATA EVALUATION}

\subsection{Comparison of Opacity Meters}

Despite claims by the Bosch operating manual and extensive efforts from Richard Atkinson (electrical engineer with the WVU Engine Testing Laboratory), the Bosch opacimeter could not be configured to interface with a PC to down-load continuous opacity data over the course of a transient test. This limited comparison of Bosch and Wager opacity data to that of peak opacity values obtained from snap-acceleration tests. Continuous opacity data were gathered from the Wager opacity meter, but only peak values from the continuous data were used when compared with Bosch data. PM mass was also collected during each test but cannot be attributed to any specific portion of the test. However, it can be assumed that most of the PM mass was generated during the transient portions of the snap-acceleration test. To isolate the PM mass due to the transient periods of the snap-acceleration tests, PM samples were collected during a five-minute idle test immediately after each snap-acceleration test to determine an average PM mass rate for idle operation. The relation shown in Equation 4-1 was used to determine PM mass due to transient operation as shown in Figure 4-1.

$$
P M_{\text {snaps }}=P M_{\text {test }}-P \dot{M}_{\text {idle }} * t_{\text {test }}
$$

Equation 4-1

where,

$P M_{\text {snaps }}$ is the PM mass due solely to the transient operation during a snap-acceleration test (g).

$P M_{\text {test }}$ is the total PM mass from a snap-acceleration test $(\mathrm{g})$.

$P \dot{M}_{\text {idle }}$ is the PM mass rate determined from an idle test $(\mathrm{g} / \mathrm{s})$.

$t_{\text {test }}$ is the time length of a snap-acceleration test (s). 
The average PM mass per snap was determined simply by dividing $P M_{\text {snaps }}$ by the total number of full-throttle accelerations (or snaps) in the snap-acceleration test, which was ten for each of the three tests. Average opacity per snap was determined by summing the peak opacity data and dividing by the total number of snaps. Peak opacity data from both meters are shown in Table 4-1 below, along with statistical results, PM mass due to transient operation $\left(P M_{\text {snaps }}\right)$, and the ratio of average peak opacity values to $\mathrm{PM}_{\text {snaps }}($ Aver. OP/PM).

Peak Opacity Values From Snap-Acceleration Tests

\begin{tabular}{|c|c|c|c|c|c|c|}
\hline & \multicolumn{3}{|c|}{ Bosch Peak Opacity Values (\%) } & \multicolumn{3}{|c|}{ Wager Peak Opacity Values (\%) } \\
\hline & 0918 & 0919 & 0927 & 0918 & 0919 & 0927 \\
\hline Snap 1 & 10.7 & 7.8 & 111.6 & 4.32 & 3.53 & $\overline{4.81}$ \\
\hline Snap 2 & 8.8 & 6.9 & 10.8 & 4.66 & 1.43 & 5.73 \\
\hline Snap 3 & 10.0 & 7.1 & 10.8 & 3.64 & 2.71 & 4.25 \\
\hline Snap 4 & 8.9 & 7.9 & 10.8 & 4.97 & 3.09 & 5.08 \\
\hline Snap 5 & 8.6 & 7.4 & 11.0 & 4.10 & 2.97 & 5.18 \\
\hline Snap 6 & 8.8 & 7.1 & 11.1 & 5.15 & 1.89 & 5.32 \\
\hline Snap 7 & 8.6 & 7.1 & 12.5 & 3.89 & 1.76 & 5.69 \\
\hline Snap 8 & 9.1 & 7.9 & 10.7 & 3.84 & 3.52 & 5.55 \\
\hline Snap 9 & 8.3 & 7.9 & 11.0 & 3.30 & 2.49 & 4.28 \\
\hline Snap 10 & 7.9 & 7.1 & 10.7 & 5.02 & 3.13 & 5.47 \\
\hline Average & 8.97 & 7.42 & 11.1 & 4.29 & 2.65 & 5.14 \\
\hline Std. Dev. & 0.817 & 0.410 & 0.560 & 0.639 & 0.740 & 0.538 \\
\hline CV\% & 9.10 & 5.53 & 5.04 & 14.9 & 27.9 & 10.5 \\
\hline $\mathrm{PM}_{\text {snaps }}$ & 0.342 & 0.196 & 0.211 & 0.342 & 0.196 & 0.211 \\
\hline Aver. OP/PM & 262.4 & 379.3 & 527.3 & 125.4 & 135.6 & 244.0 \\
\hline
\end{tabular}

Table 4-1. Peak opacity data from a Bosch RTT 100 opacimeter and a Wager 650CP opacity meter. Data were collected from three snap-acceleration tests conducted on three transit buses powered by similar 1996 DDC Series 50 engines. Each snap-acceleration test consisted of ten open-throttle no load accelerations from idle to maximum governed engine speed followed by rapid deceleration back to idle as prescribed by SAE J1667.

The peak opacity values from the Bosch and Wager opacity meters are plotted in bar graph form for magnitude comparison in Figure 4-1. The Bosch readings were consistently higher than the Wager by a factor of almost two. This relation is quantified by the slope of the linear best fit between the data when Wager values are plotted as a function of Bosch values as shown in Figure 4-2. 


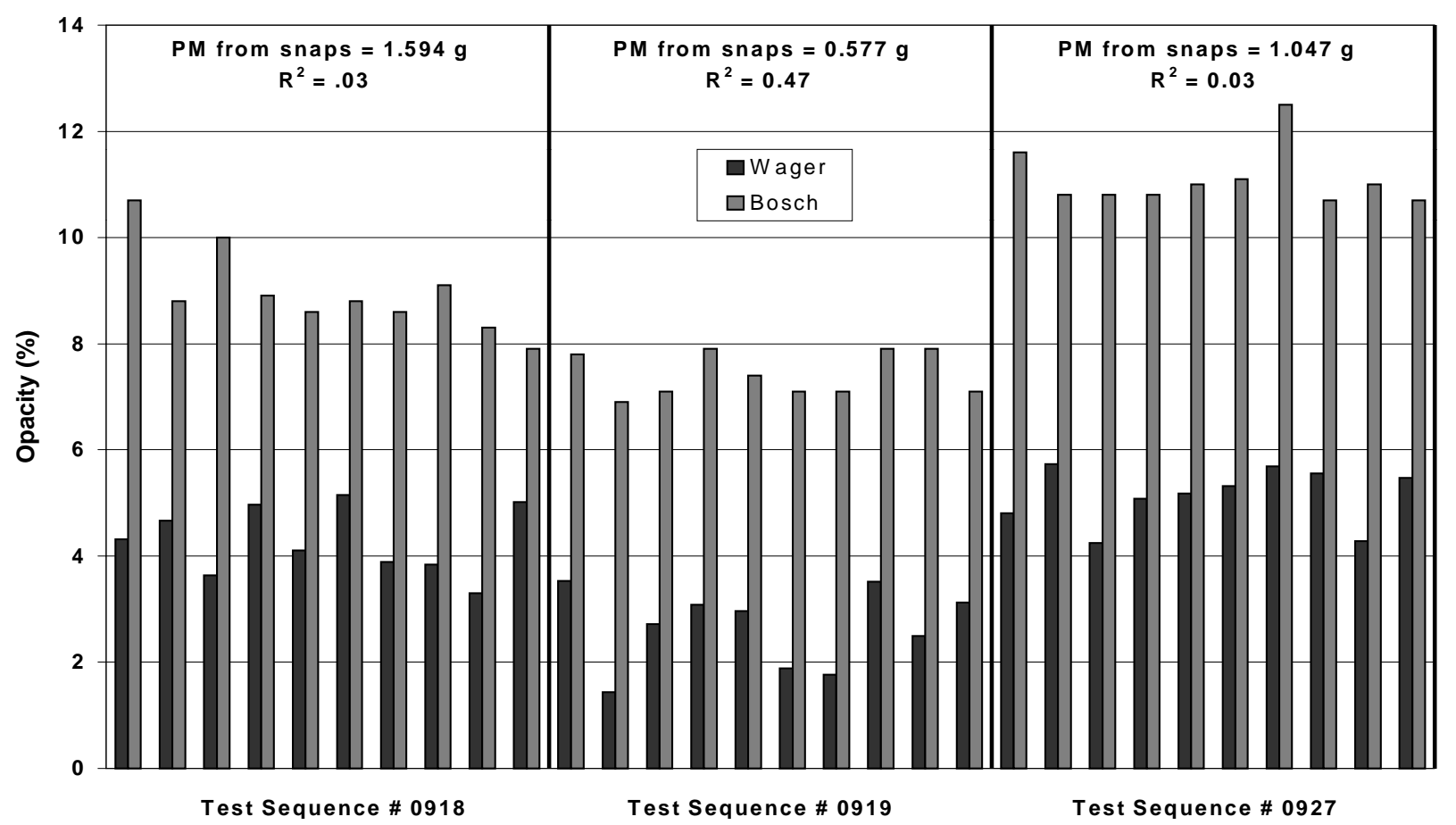

Figure 4-1. Bosch and Wager peak opacity values obtained from three transit buses powered by similar 1996 DDC Series 50 engines exercised through snap-acceleration tests. The $\mathbf{R}^{2}$ values are from plotting Wager data as a function of Bosch data for each test. Data are shown in Table 4-1.

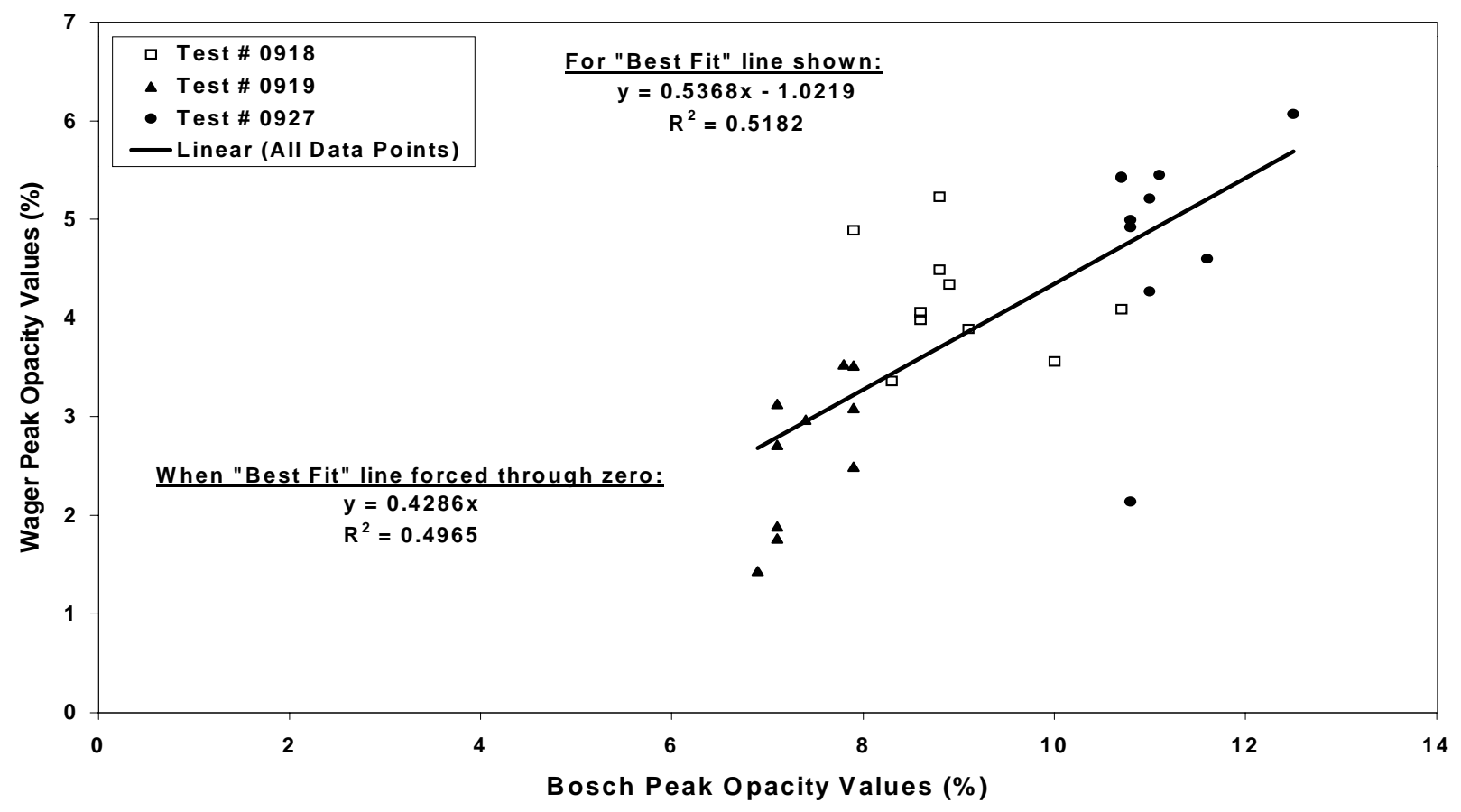

Figure 4-2. Wager peak opacity plotted as a function of Bosch peak opacity. Data are shown in Table 4-1 and plotted in Figure 4-1. The $R^{2}$ values are for a linear best fit to data from all three tests. 
The peak opacity readings from the Wager seem to have a higher inconsistency than the Bosch when evaluated in terms of the percent coefficient of variance (CV\%) shown in Table 4-1, but this observation cannot be assumed true without knowledge of the PM production during each snap. Although the PM mass for each snap was not known, it is known that CO and PM are both products of rich combustion or combustion zones within a cylinder. The correlation between $\mathrm{CO}$ and PM is discussed further in Section 4.5. Thus, peak $\mathrm{CO}$ concentrations were compared with peak opacity values for each snap in an attempt to determine which opacity meter was providing a better indication of PM. Figure 4-3 shows a plot of the peak CO concentration as a function of peak opacity values from both meters for all three snap-acceleration tests. It is noted that the peak $\mathrm{CO}$ concentrations measured at the analyzer were less than if they had been measured directly after the engine. This is due in part to exhaust dilution and also to axial dispersion in the exhaust sampling system. The dispersion effects of the exhaust gas transport system will be discussed in detail in Section 4.4.2. Results from Section 4.4.2 show that it is safe to assume the axial dispersive effects are similar throughout each of the three snap-acceleration tests. With this assumption and knowing that a correlation between $\mathrm{CO}$ and PM exists, it is inferred that the peak $\mathrm{CO}$ concentration values measured at the analyzer provide some indication of PM production. Thus a better correlation between peak opacity values and peak CO concentrations for the Bosch opacimeter suggests it was better identifying PM.

It is noted that some may question the validity is showing coefficient of determination $\left(\mathrm{R}^{2}\right)$ values of less than 0.6 or 0.7 due to lack of correlation. However, the author has chosen to show all values of $\mathrm{R}^{2}$ when plotting one set of data as a function of another to provide a quantification of a lack of correlation. 


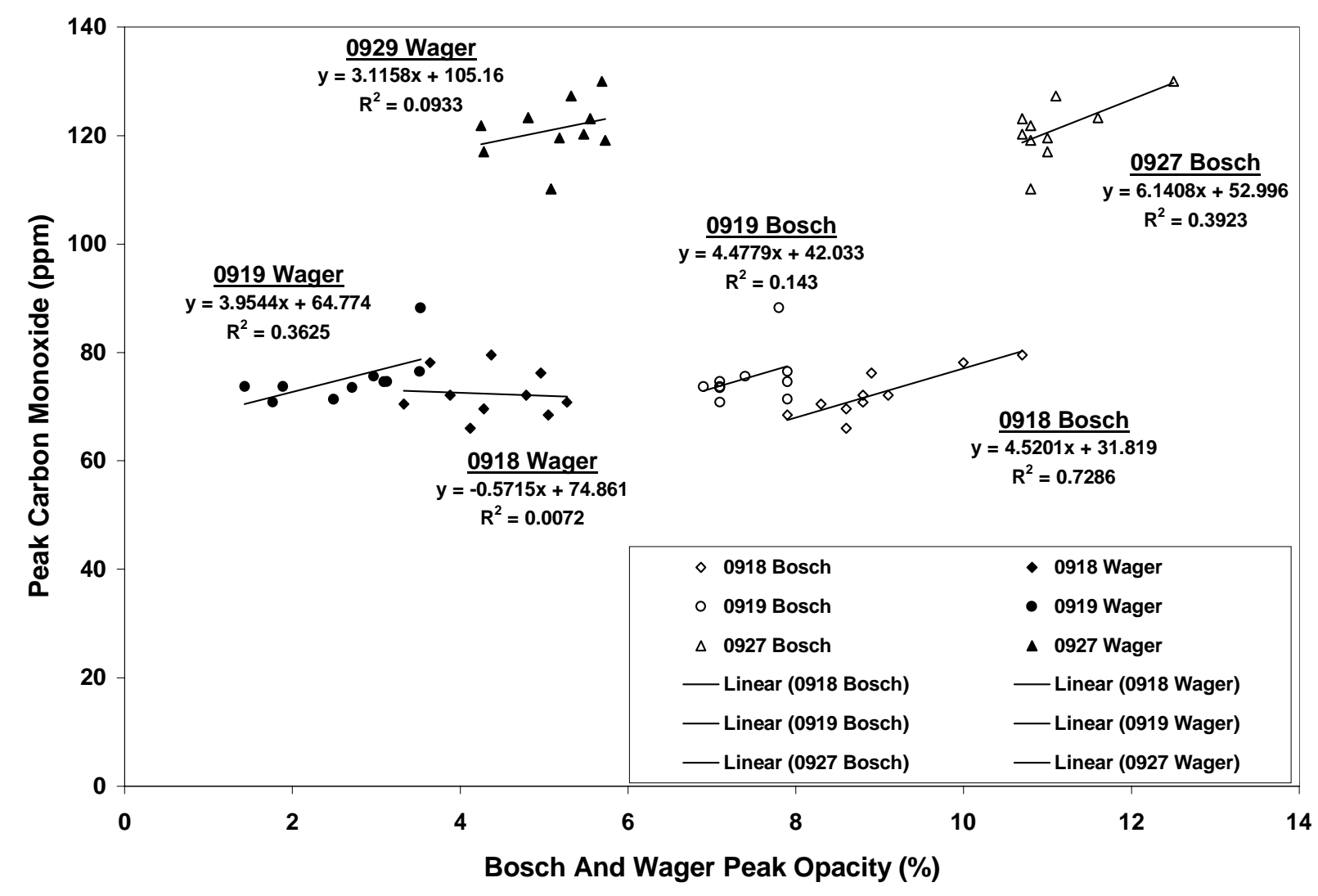

Figure 4-3. Peak CO concentrations plotted as a function of peak Bosch and Wager opacity values. Data are from three transit buses powered by similar 1996 DDC Series 50 engines which were exercised through snapacceleration tests.

The results show little correlation between peak $\mathrm{CO}$ concentrations and peak opacity values for these tests, with the Bosch data showing a better correlation than the Wager data. This agrees with the CV\% shown in Table 4-1, suggesting that the Wager readings were more scattered than the Bosch readings. The average OP/PM ratios shown in Table 4-1 have a wide range of values when compared for each meter. The values are slightly less scattered for the Bosch than for the Wager (CV\% 34.1 and 39.0 respectively), again indicating that the Bosch opacity data correlate slightly better with PM than the Wager data. However, both meters show poor correlation when evaluated in terms of gravimetric PM and peak CO concentrations, 
suggesting that neither meter provides a good means for quantifying PM mass from a diesel engine in transient operation.

Without the reference of readings from other opacity meters, it is difficult to determine which meter is more accurate. The large difference between opacity raises some concern. Both meters use a light source of similar wavelength (approximately $570 \mathrm{~nm}$ ), so it would first appear that the size parameter, $x$, would not be the source of difference. However, particle size may be a factor due to differences in sampling methods between the two meters.

The Wager opacity meter was mounted at the end of the exhaust transfer pipe just prior to the dilution tunnel. The exhaust transfer pipe was insolated to minimize exhaust gas cooling and thus minimizing condensation of exhaust moisture in the pipe's inner wall. PM formation is a partial function of exhaust gas cooling, which is one of the primary purposes of the dilution tunnel. Thus, the Wager opacity meter was "looking" at the PM before exhaust gas cooling and thus before complete particulate formation. In contrast, the Bosch opacity meter exhaust sample travels through a $5.2 \mathrm{~m}$ (17 ft.) silicone line before opacity is measured. Based on the silicone sample line dimensions and the flow rate given in Section 3.2.2, the travel time of the exhaust sample in the silicone hose was approximately 0.31 seconds. Although this is a rather brief time period, there would be some cooling of the exhaust gas while traveling through the Bosch sample line and more time allowed for particle nucleation, adsorption, and conglomeration. AbdulKhalek et al. [35] evaluated particle size distribution and concentration from a diesel engine and found that the particle count increased by a factor of more than ten between residence times of $40 \mathrm{~ms}$ and $400 \mathrm{~ms}$ in the diluted sample. Another cause of the difference in opacity magnitude may be differences in data sampling rates. The Bosch RTT 100 sampled at a frequency of 100 $\mathrm{Hz}$, where as the Wager $650 \mathrm{CP}$ put out a continuous voltage signal which was sampled at a 10 
$\mathrm{Hz}$ frequency through the laboratory's ADC data acquisition board. Jones et al. [36] reported a $16 \%$ increase in smoke density $(\mathrm{k})(12 \%$ when converted to opacity) when the data acquisition frequency was raised from $10 \mathrm{~Hz}$ to $20 \mathrm{~Hz}$. Thus, data acquisition of the Wager opacity meter signal may have missed peak opacity values that the Bosch RT 100 was able to capture. It is noted that the Bosch opacimeter also "looks" at the PM before adequate exhaust gas cooling occurs.

The lack of correlation between gravimetric PM and opacity data from both meters was probably due to geometric differences, improper sample conditioning at the point of optical analysis, and optical effects such as the size parameter and complex index of refraction. The geometric difference is based on the fact that opacity is a partial function of a particle's crosssectional area where as PM mass is a partial function of a particle's volume. If it is assumed for the moment that PM is spherical then the cross-sectional area is $\pi r^{2}$ and the volume is $4 / 3 \pi r^{3}$. Assuming no change in density as the particulate conglomerates, it is evident that the ratio of opacity to PM is a partial function of radius. The opacity data were obtained just prior to the dilution tunnel. PM formation in diesel exhaust is strongly affected by the rapid cooling associated with mixing of ambient air. It is apparent that PM would not be fully formed at the point of optical analysis and thus the exhaust particulate would have a lower opacity signature prior to dilution. The absorption and scattering effects of the particle cloud are dependent on the particle's complex index of refraction (which is a function of shape and composition) and size parameter between each particle and the opacity meter light wavelength. Since PM size, shape, and composition vary throughout different operating conditions, the optical effects of the particle cloud will vary as well. 
It can be seen that the Bosch peak opacity values correlate better with peak $\mathrm{CO}$ concentrations than the Wager peak opacity values. These results complement the observation from Table 4-1 that the Wager data were more scattered. Both results suggest that the Bosch opacimeter data correlate with PM slightly better than the Wager data. However, both meters showed poor correlation when compared with PM mass.

\subsection{Wager Opacity Meter Modifications}

Despite the use of a continuous dry airflow across the Wager opacity meter lenses, there were some initial problems in terms of PM buildup on the lenses during continuous operation. Byrd [37] noted this same problem in his thesis. PM buildup is evident by the nature of the continuous opacity curve labeled "original opacity" shown in Figure 4-4. The continuous opacity data stay relatively constant during the idle periods of the test and show a steady increase during loaded operation. Lens fogging results in a more gradual and continuous increase in the opacity data as shown in Figure 4-5. The opacity data shown in this figure were collected when the dry air source was not turned on.

It was theorized that the PM accumulation on the optical lenses was due to a positive pressure gradient from the exhaust transfer pipe to the lens surface. This was solved by utilizing the dry air supply to the opacity meter and by sealing the outer rim of the meter's sensor plates. This allowed the dry air supply to reverse the pressure gradient and eliminated any further PM deposition on the opacity meter lenses. Subsequent test data showed no signs of PM accumulation. Concerns of the compressed air supply introducing foreign hydrocarbons (from the air compressor lubricating oil) and polluting hydrocarbon test analysis were alleviated by the use of an oil/moisture filter in the air supply line. 


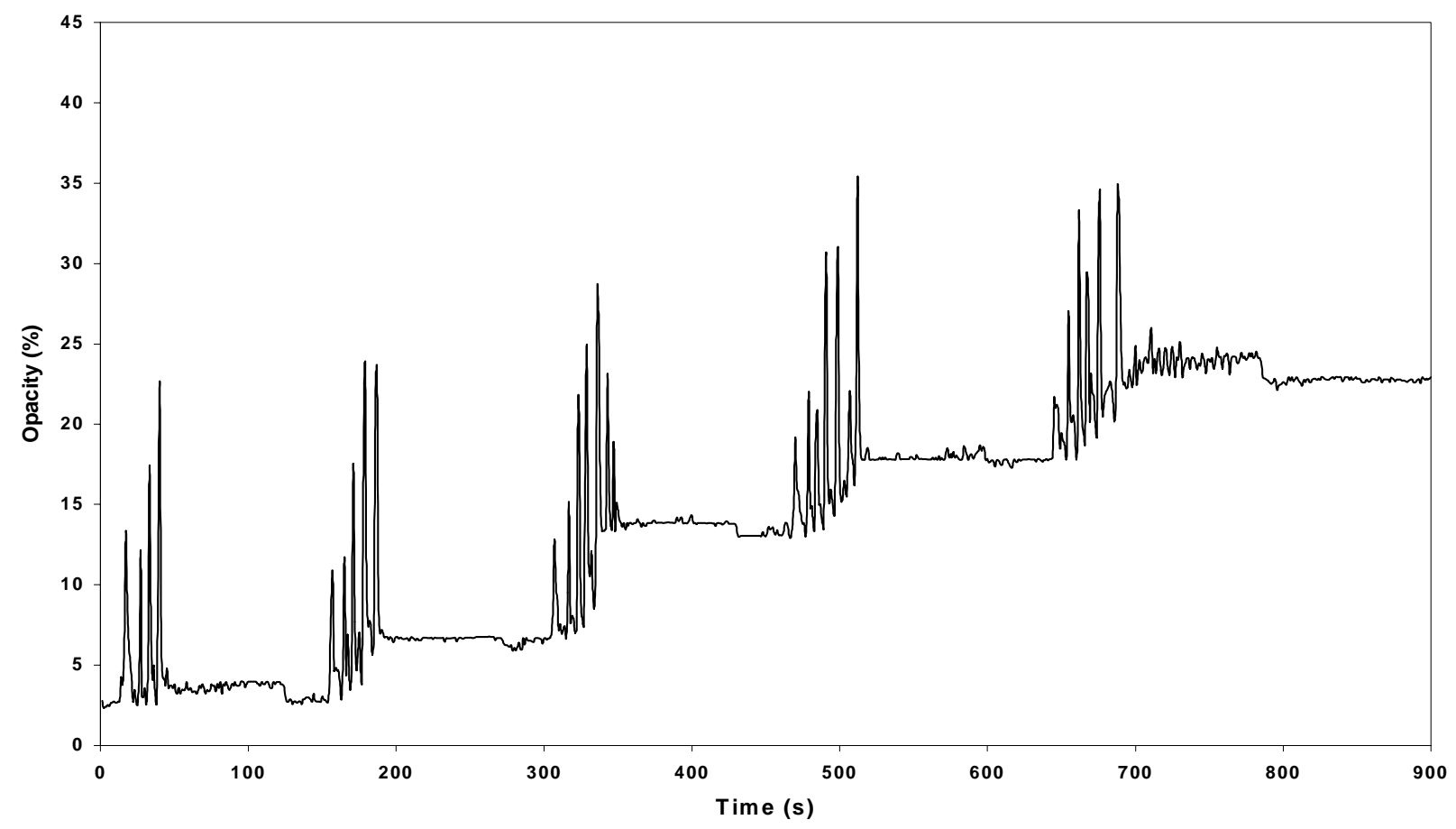

Figure 4-4. Wager continuous opacity data from a line-haul tractor powered by a 1982350 Cummins engine exercised through the WVU 5-Peak test cycle. The opacity data reveal PM buildup on the opacity meter optical lenses, despite the use of pressurized dry air flow across the lenses.

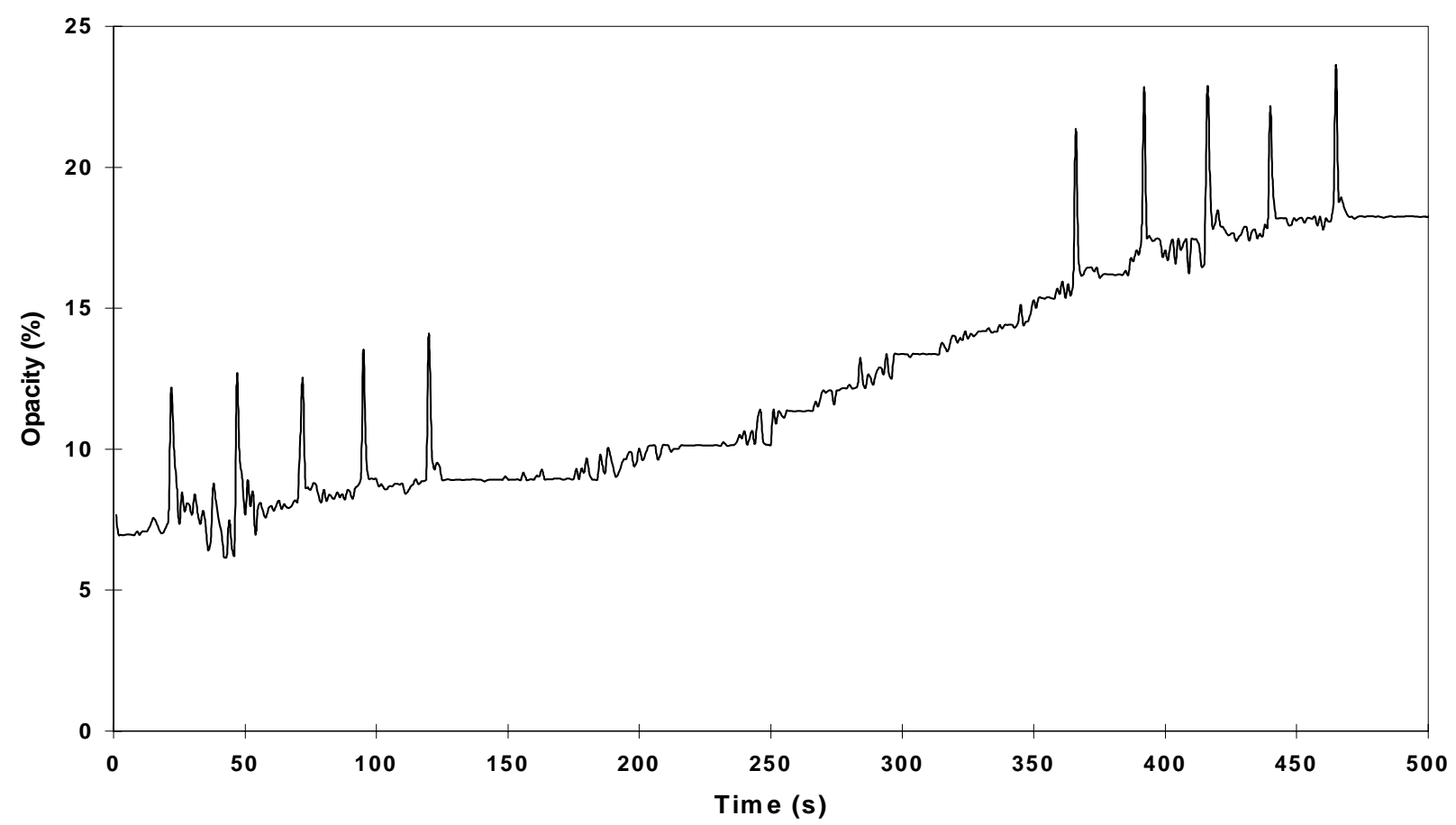

Figure 4-5. Wager continuous opacity data where lens fogging occurred. The data were obtained from a 1996 transit bus powered by a 1996 DDC S-50 engine which was exercised through a snap-acceleration test. 


\subsection{Opacity and Particulate Matter}

The PM mass collected during a transient test cycle is a function of the total exhaust volume sampled, the number concentration of particles, the particle size distribution, and the particle density. It is acknowledged that the mass of PM collected on a filter is influenced by the filter face velocity, filter medium, and sampling temperature. However, attempts were made to

keep the last three variables constant throughout all tests to minimize their effect on PM sampling. Opacity is a function of the number concentration of the particles, the projected area of the particle, and the light extinction (absorption and scattering) properties of the particles. Thus, the ratio between PM and opacity is a function of particle size, as well as the light extinction effects of the particles. Even with the assumption that the particles are spherical, monodispersed, and of the same bulk density, it is evident that particle size and nature will affect the relationship between opacity and PM mass. However, it should be noted that these assumptions could create considerable error. The particle density is a partial a function of the amount of hydrocarbons deposited on the particle. Hydrocarbon deposition and particle effective radius are a function of fuel, engine design and type, nature of the exhaust gas dilution, and possibly speed and load within the same engine family. Furthermore, the light extinction effects of a particle are a function of the particle's complex index of refraction $(m)$ and the size parameter $(\lambda)$. Given that most diesel particles are in the sub-micron range, the particle diameter is of the same size order as the wavelength of the opacity meter light source. This results in Mie scattering for the larger particles and Rayleigh scattering for the smaller particles. Most diesel particles fall into the Rayleigh scattering classification which is a function of $x^{4}$ [28]. Thus, a small change in particle size has a much larger effect on light extinction. As a result, prediction 
of instantaneous and total PM with present forms of optical exhaust measurement (light extinction) is elusive at best.

The relationship between opacity and PM was evaluated from three perspectives. The first compares integrated PM and integrated opacity from twelve different vehicles (three different engine types) which were exercised through snap-acceleration tests. The second perspective compares integrated opacity and integrated PM data from three different vehicles exercised through loaded (CBD cycle) and non-loaded (snap-acceleration) tests. The third perspective evaluates integrated PM plotted as a function of integrated opacity for one engine exercised through different simulated driving patterns, the same engine type exercised through the same transient test cycle, and different engine types exercised through different simulated driving patterns.

\subsubsection{Snap-acceleration Tests}

The first perspective was determined in part because the snap-acceleration test is intended to identify PM production and because most of the filter-captured PM can be attributed to the transient periods of a snap-acceleration test. The PM mass due to transient operation during snap-acceleration testing was isolated as shown in Equation 4-1. Opacity data from the transient test periods were isolated in a similar method and shown in Equation 4-2. The average integrated opacity per snap was determined by the relation,

$O P_{\text {aver } / \text { snap }}=\frac{\sum O P-O P_{\text {aver }, \text { idle }} \cdot t_{\text {test }}}{n_{\text {snap }}}$

Equation 4-2 
where,

$\Sigma O P$ is the integrated opacity for the entire test $(\% \mathrm{~s})$.

$O P_{\text {aver, } \text { idle }}$ is the average opacity during idle $(\%)$.

The results of this analysis applied to three different engine types are shown in Figure 4-6. Best-fit linear curves are displayed for two of the three sets of data, the third being omitted due to only two data points (lower left corner of Figure 4-6). A best-fit linear curve was also applied to all twelve of the data points. All three curves show a weak positive correlation between opacity and PM and also indicate that integrated opacity data cannot accurately predict the total integrated PM emitted by a HD diesel vehicle operated in a snap-acceleration test. From this one may also conclude that integrated opacity cannot predict total integrated PM for other transient driving conditions, and that instantaneous opacity cannot predict instantaneous PM in a general fashion. The positive ordinate intercept of all three best-fit linear equations also suggests the existence of PM when instantaneous opacity is zero. In other words, PM may exist in the exhaust while eluding optical detection and/or additional PM formation had occurred in the dilution tunnel after optical analysis. Discussion in Section 3.4 would suggest that both cases are true. 


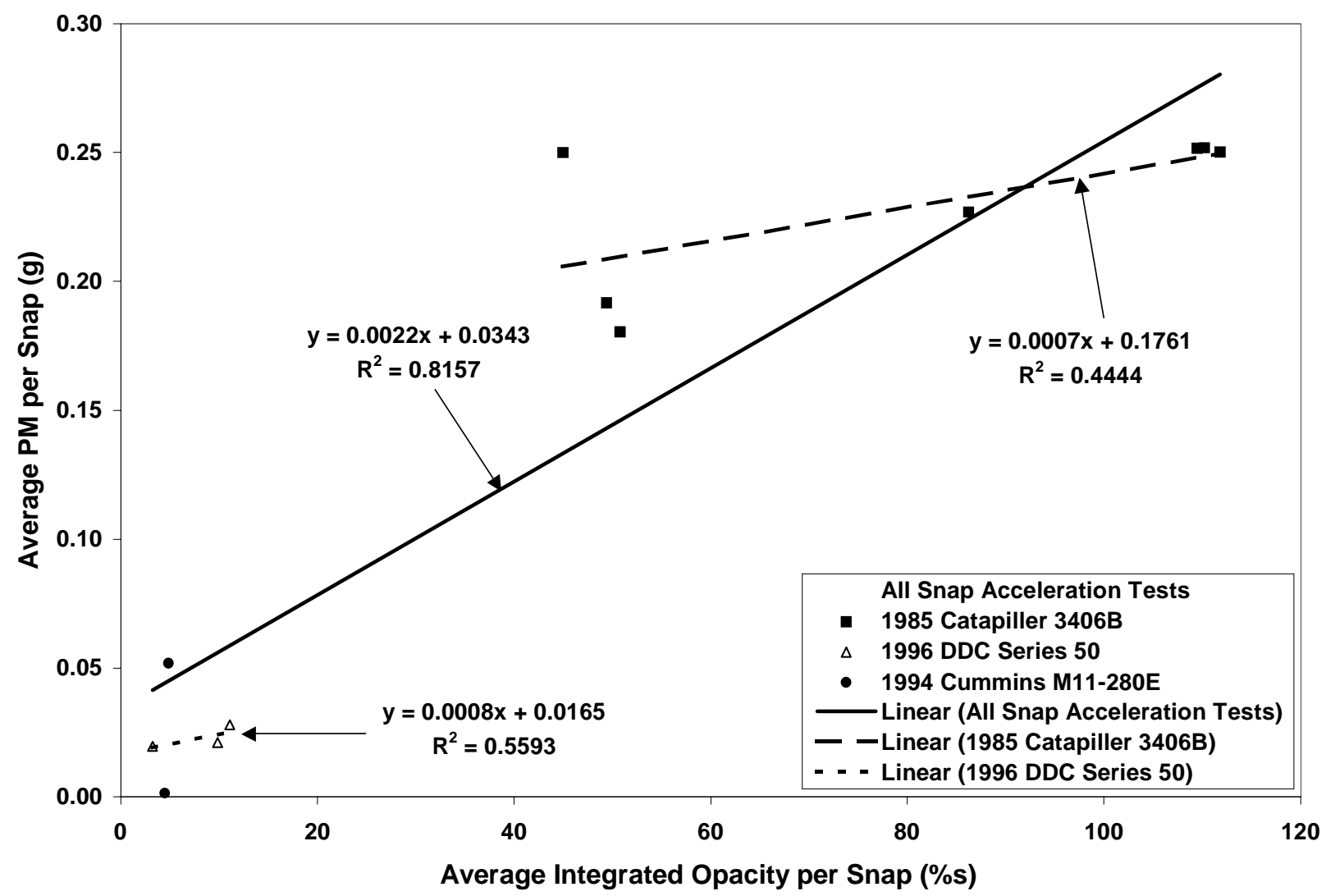

Figure 4-6. Average PM data as a function of average opacity data from three different vehicles exercised through snap-acceleration tests. Both PM and opacity were averaged on a "per snap" basis.

\subsubsection{Engine Loading Effects}

The next approach is to evaluate integrated PM and integrated opacity data from an engine exercised through a loaded transient test and a snap-acceleration test. The loaded transient test in this analysis was the CBD cycle. Since integrated PM cannot be attributed to any specific portions of the test, values used for this analysis are integrated PM and integrated opacity over the course of both tests. Results from two transit buses powered by different engines of the same model are shown in Figure 4-7. These plots further supports the argument that the snap-acceleration tests fail to identify PM due to engine loading. The PM output from 
the CBD cycle for the same integrated opacity value is much higher than that of the snapacceleration test for both engines. This is due to the difference in engine loading between the two tests. Furthermore, the $\mathrm{R}^{2}$ values for the linear best fits from the CBD tests show little to no correlation between the integrated opacity and integrated PM. It is noted that the scaling of the figure to include data points from the snap-acceleration tests cause the CBD data points to appear closer in proximity to the best fit line than they actually are. It is also noted that the ordinate intercept suggests PM production at zero opacity as observed in Figure 4-5.

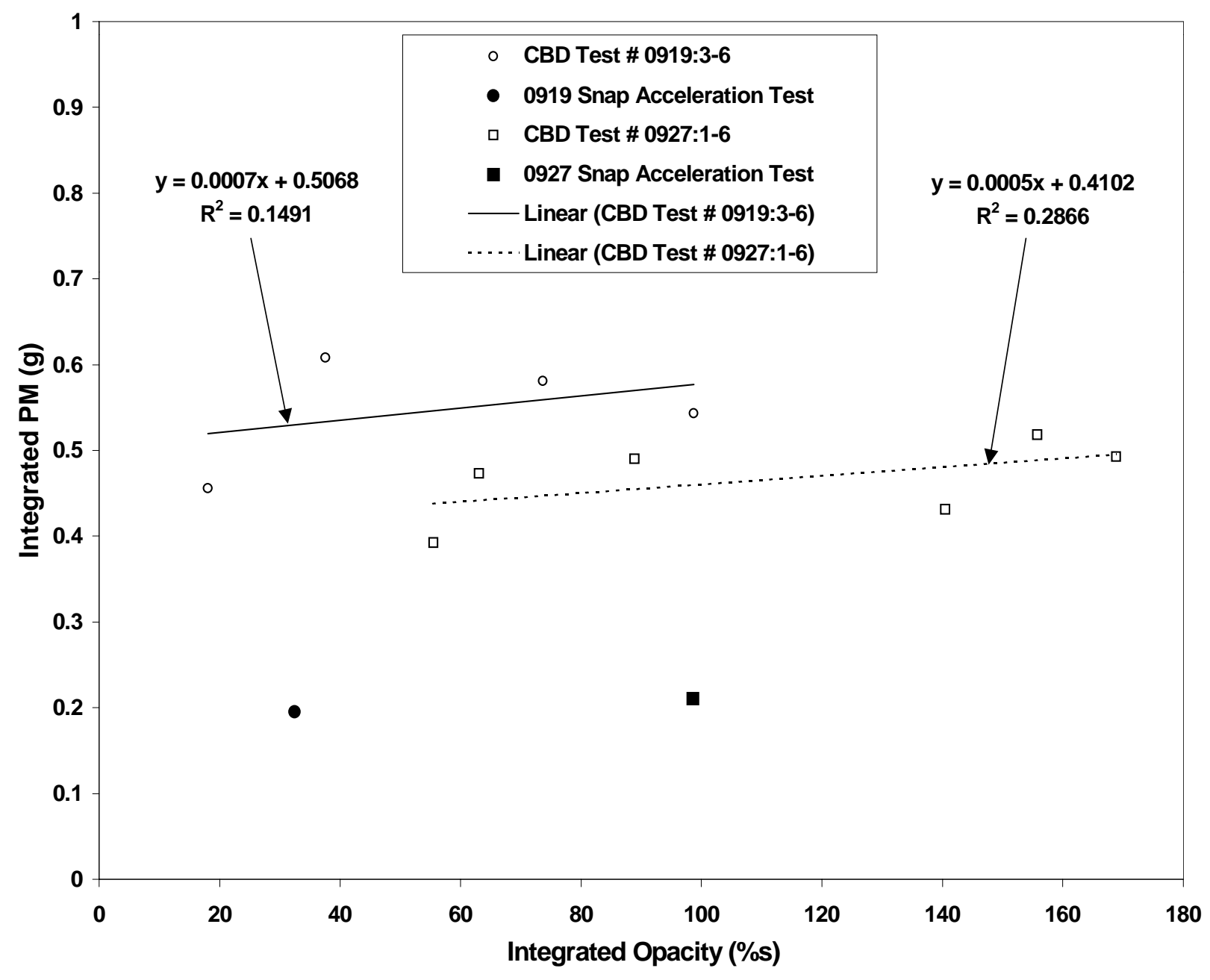

Figure 4-7. Comparison of integrated PM a as a function of integrated opacity from two 1996 transit buses powered by similar DDC Series 50 engines exercised through loaded and non-loading transient tests (CBD cycle and snap-acceleration). These plots show higher integrated PM for loaded operating conditions than for non-loaded operation for respective integrated opacity values. 


\subsubsection{Driving Cycle Effects}

Since it is known that transient operation and loading affect PM production, then it would be logical that different driving conditions would affect PM production. For this evaluation PM and opacity data were collected from a single engine exercised through different driving cycles. Figure 4-8 shows integrated PM plotted as a function of integrated opacity on a per mile basis from a 1996 transit bus powered by a 1996 DDC Series 50 engine exercised through four different transient tests; 5-Mile route, NYCB cycle, Test D, and the CDB cycle.

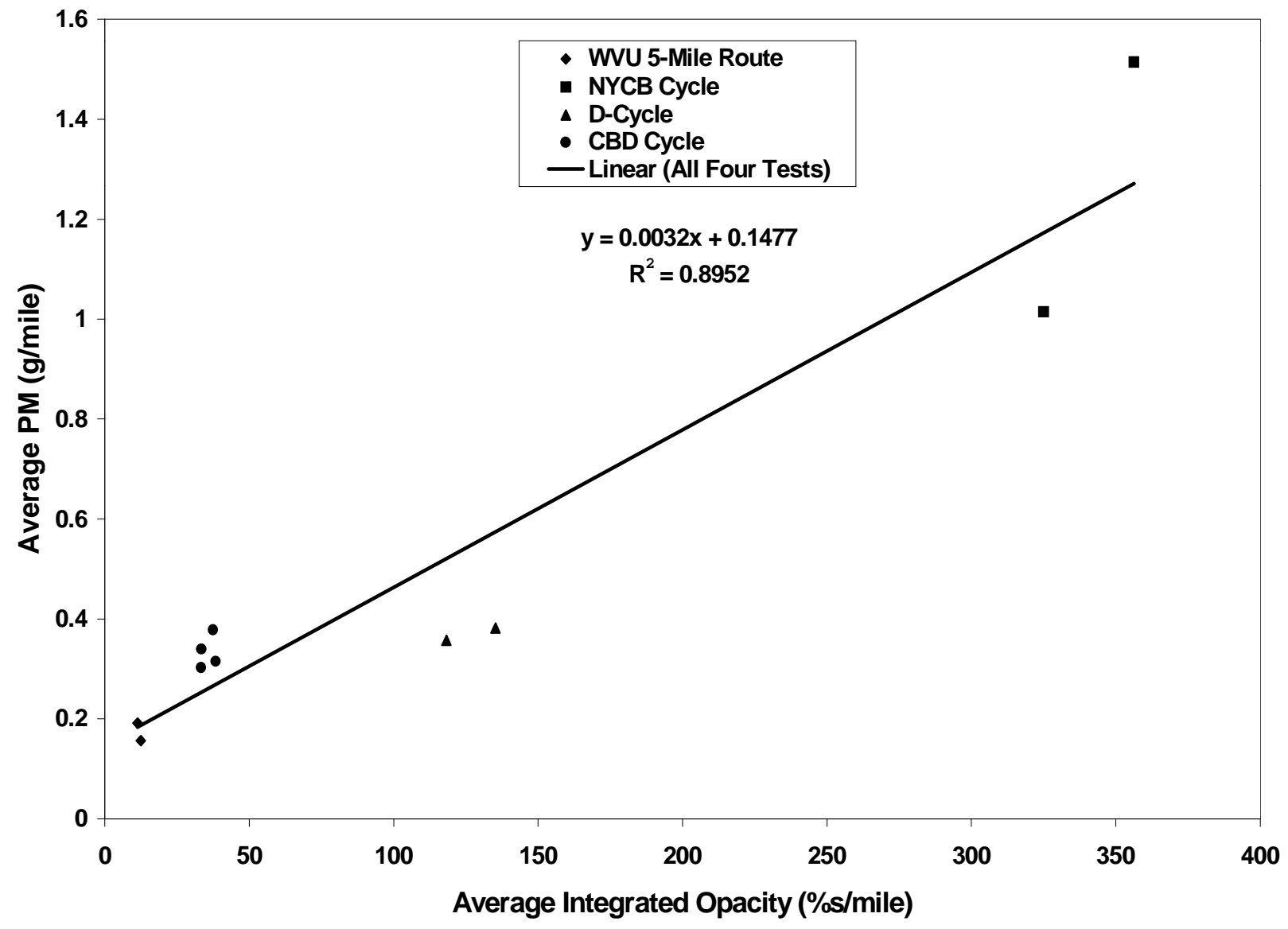

Figure 4-8. Integrated particulate matter as a function of integrated opacity from a DDC Series 50 engine exercised through four different transient tests. This plot shows the strongest correlation between integrated PM and integrated opacity which may suggest some correlation between PM and opacity for a specific engine. 
This plot shows the highest linear correlation between PM and opacity within this research, suggesting that the PM/opacity relation may be engine specific. This would be supported by the fact that particle size, the ratio between soluble organic fraction and elemental carbon, and lubrication oil contribution to PM are all engine specific.

In addition to exercising the same vehicle through different driving cycles, a series of tests was done where the same vehicle was exercised through the same driving cycle (CBD) for three different simulated inertial weights. Test 0920 was tested at $85 \%$ of the gross vehicle weight $(\mathrm{GVW})$, or $14,897 \mathrm{~kg}(32,843 \mathrm{lb}$.); test 0921 was tested at the vehicle curb weight plus $113 \mathrm{~kg}$ (250 lb.); and test 0922 was tested at $100 \%$ of GVW 17,269 kg (38,072 lb.). Average PM plotted as a function of average integrated opacity from these tests is shown in Figure 4-9. The results show no correlation between PM and opacity when vehicle loading is varied. These results agree with results shown in Figure 4-7. 


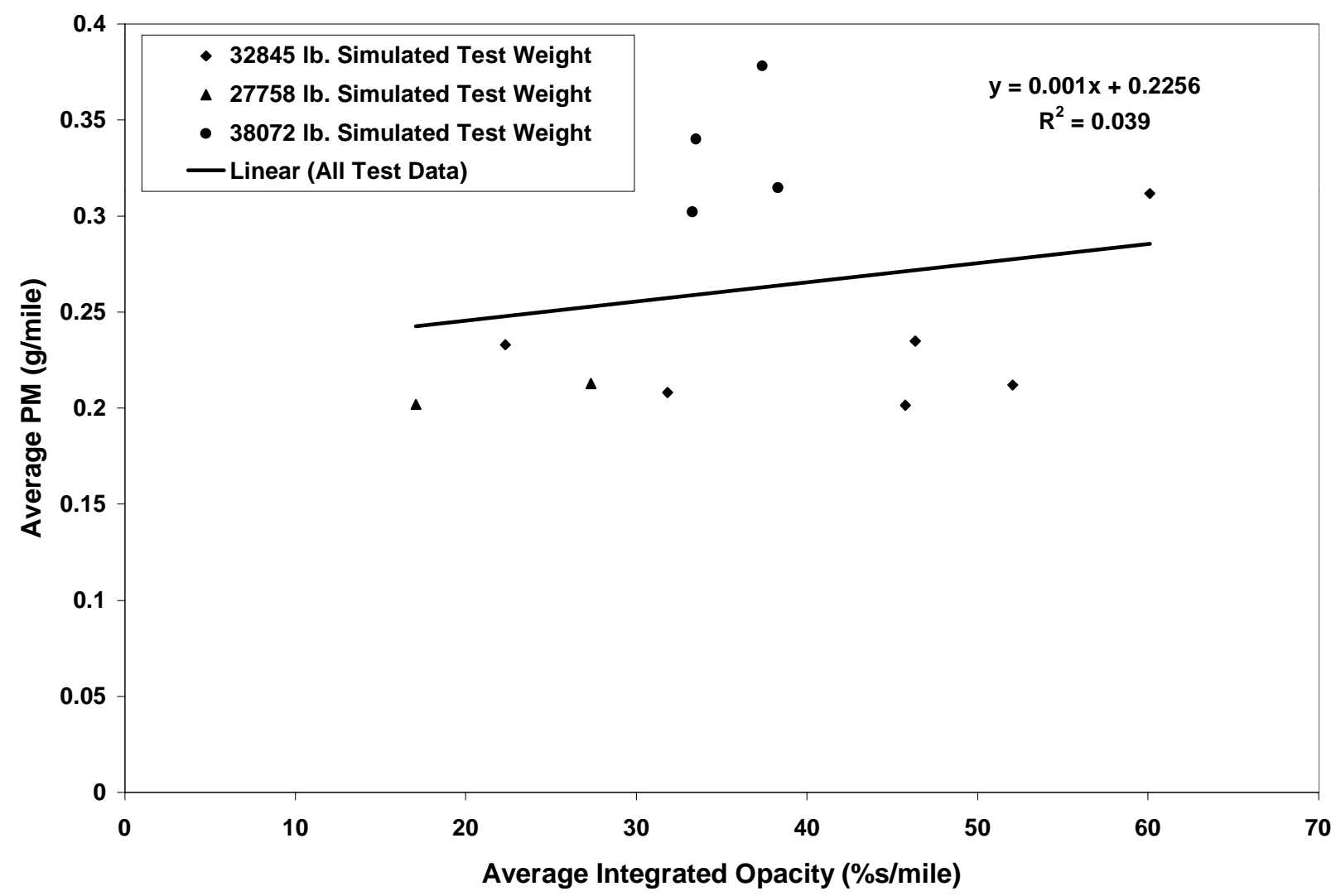

Figure 4-9. Average PM plotted as a function of average integrated opacity from a single vehicle exercised through similar driving conditions for three different simulated inertial weights. The vehicle was a 1996 transit bus powered by a 1996 DDC Series 50 engine exercised through a CBD cycle.

Figure 4-10 plots average PM as a function of average integrated opacity for all Flint, MI CBD tests with the same simulated inertial weight. This plot shows considerable scatter in the data, suggesting little to no correlation between average PM and average integrated opacity for the same engine type (i.e. different engines of the same model) exercised through similar driving and loading conditions. This could be due to several reasons but not limited to engine wear, maintenance history, fuel quality, driving habits, and ambient weather conditions. However, for the tests represented in Figure 4-10, vehicle odometer readings ranged from 43,000 to 66,000 km (27,000 to 41,000 miles), so engine wear and maintenance were probably not a factor. All buses 
were driven on the same fuel, driven by the same driver, and weather conditions varied little. Also noted is the positive ordinate intercept of the linear fit.

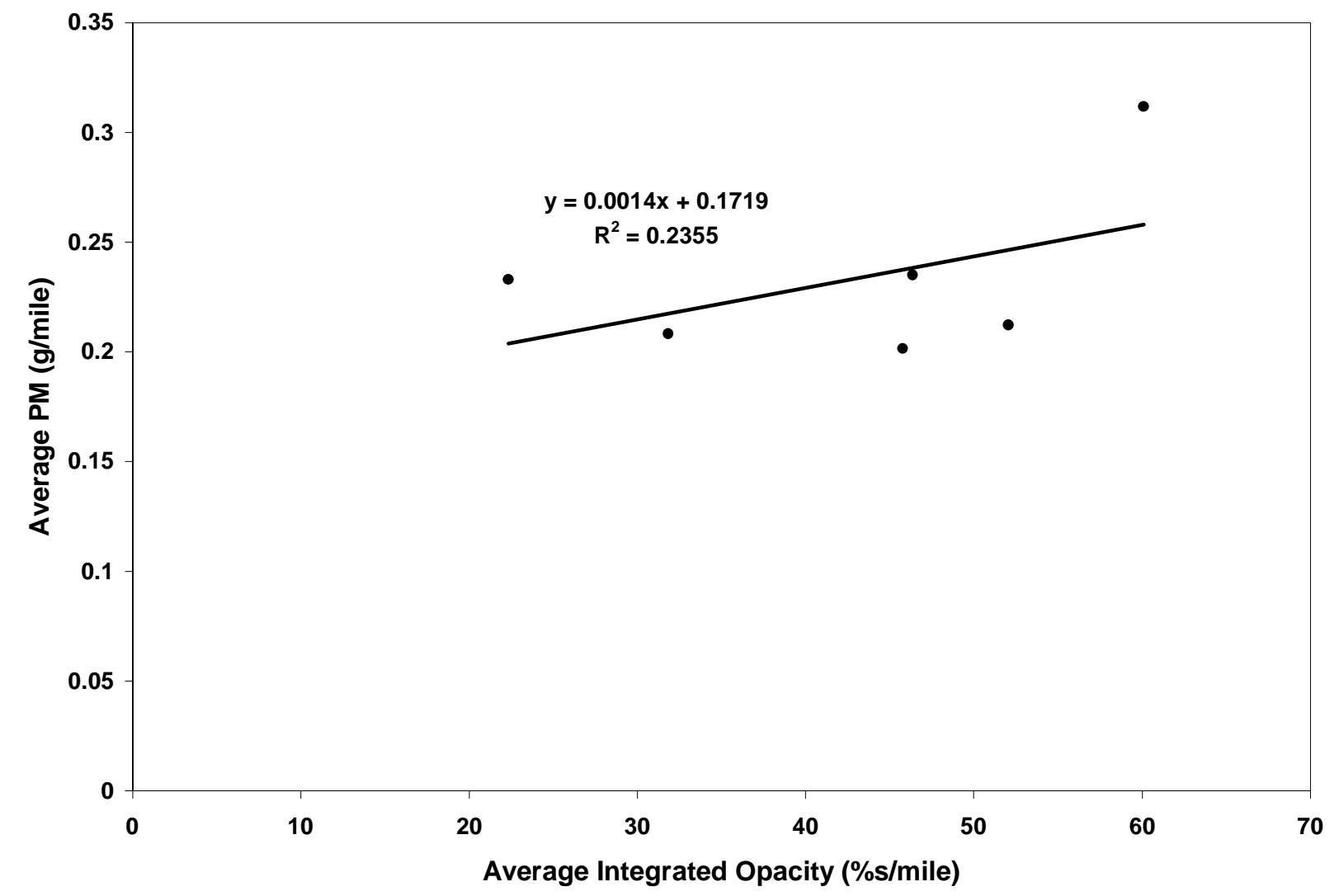

Figure 4-10. Integrated PM as a function of integrated opacity from six different 1996 transit buses powered by similar 1996 DDC Series 50 engines exercised through a total of twenty-three CBD transient tests.

If there were a final statement to the lack of universal relation between PM and opacity, Figure 4-11 would be that statement. All transient chassis tests with valid PM and opacity data taken for this research are shown in Figure 4-11. The data in this plot represent twenty-one vehicles powered by five different engine types which were exercised through six different transient emission tests for a total of sixty-three data points. The plot shows a very weak correlation between PM and opacity, as well as the positive ordinate intercept as in all the other plots of PM as a function of opacity. 


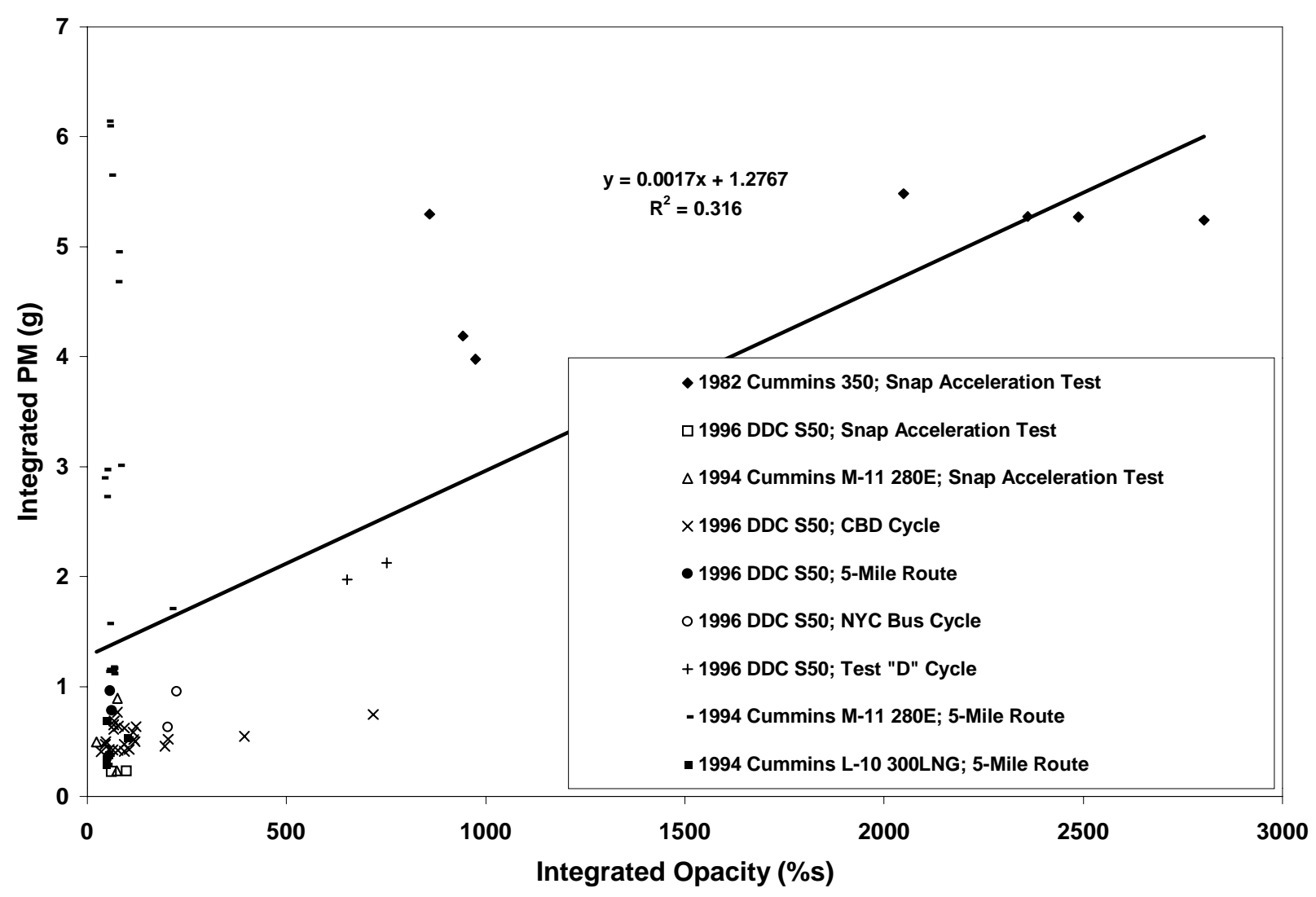

Figure 4-11. Integrated PM as a function of integrated opacity for all transient emissions tests evaluated in this report.

A possible contribution to the considerable scatter in Figures 4-6 through 4-11 is human and/or instrumentation error. Human error could have been introduced through driving variations, filter handling and measurement, and/or instrument calibration. However, the cause is more than likely due to opacity data. Figure 4-12 shows continuous opacity data from a transit bus powered by a 1996 DDC Series 50 engine exercised through four CBD tests which were executed sequentially (tests 0919-3 through 0919-6). The average gaseous and PM emissions results from the same tests are shown in Table 4-2, along with averaged integrated opacity and the PM/opacity ratio. The percent coefficient of variance (CV\%) for distance-averaged gaseous and PM emissions ranges from 1.55 to 11.42 , where as the CV\% for time-averaged and distance-averaged integrated opacity and the PM/opacity ratio is 37.88 and 32.57 respectively. 
Although the CV\% values for NOx and PM are a little high (five percent is the preferred maximum), the over-all range of $\mathrm{CV} \%$ for the gaseous and PM emissions suggest an acceptable repeatability of the test execution. The high $\mathrm{CV} \%$ values for integrated opacity quantify the inconsistencies which are visibly evident when comparing respective peak magnitudes and time widths of the continuous opacity response from test to test. The high CV\% values for averaged opacity must be due to either inconsistencies within the Wager opacity meter operation, or inconsistencies within the interaction between the opacity meter light beam and the PM in the exhaust. It is the author's belief that it is due to the latter. Clearly the low correlation between PM and opacity observed in Figures 4-6 through 4-11 are due to inconsistencies in the opacity data.

1996 Detroit Diesel DDC Series 50 Engine: 8.5L 275 hp @ 2110 rpm

\begin{tabular}{|c|c|c|c|c|c|c|c|}
\hline & $\mathrm{HC}$ & $\mathrm{CO}$ & $\mathrm{CO2}$ & Nox & PM & Opacity & PM/Opacity \\
\hline Test \# - Run \# & (g/mile) & (g/mile) & (g/mile) & (g/mile) & (g/mile) & (\%/mile) & $(g / \%)$ \\
\hline 0919-3 & 0.137 & 4.24 & 2608 & 27.56 & 0.3116 & 0.0980 & 3.182 \\
\hline 0919-4 & 0.124 & 4.41 & 2690 & 30.79 & 0.2936 & 0.1214 & 2.418 \\
\hline 0919-5 & 0.136 & 4.14 & 2654 & 34.65 & 0.2468 & 0.0483 & 5.110 \\
\hline 0919-6 & 0.135 & 4.37 & 2698 & 30.56 & 0.3229 & 0.0699 & 4.617 \\
\hline Average & 0.133 & 4.29 & 2662 & 30.89 & 0.2937 & 0.0844 & 3.831 \\
\hline Std. Dev. & 0.006 & 0.1228 & 41.23 & 2.910 & 0.0335 & 0.0320 & 1.248 \\
\hline CV\% & 4.54 & 2.862 & 1.548 & 9.421 & 11.41 & 37.88 & 32.57 \\
\hline
\end{tabular}

Table 4-2. Emission results from the same tests shown in Figures 4-12 through 4-14. The high percent coefficient of variance (CV\%) value for opacity in relation to the gaseous and PM emissions suggests a higher level of inconsistency in opacity measurement. 

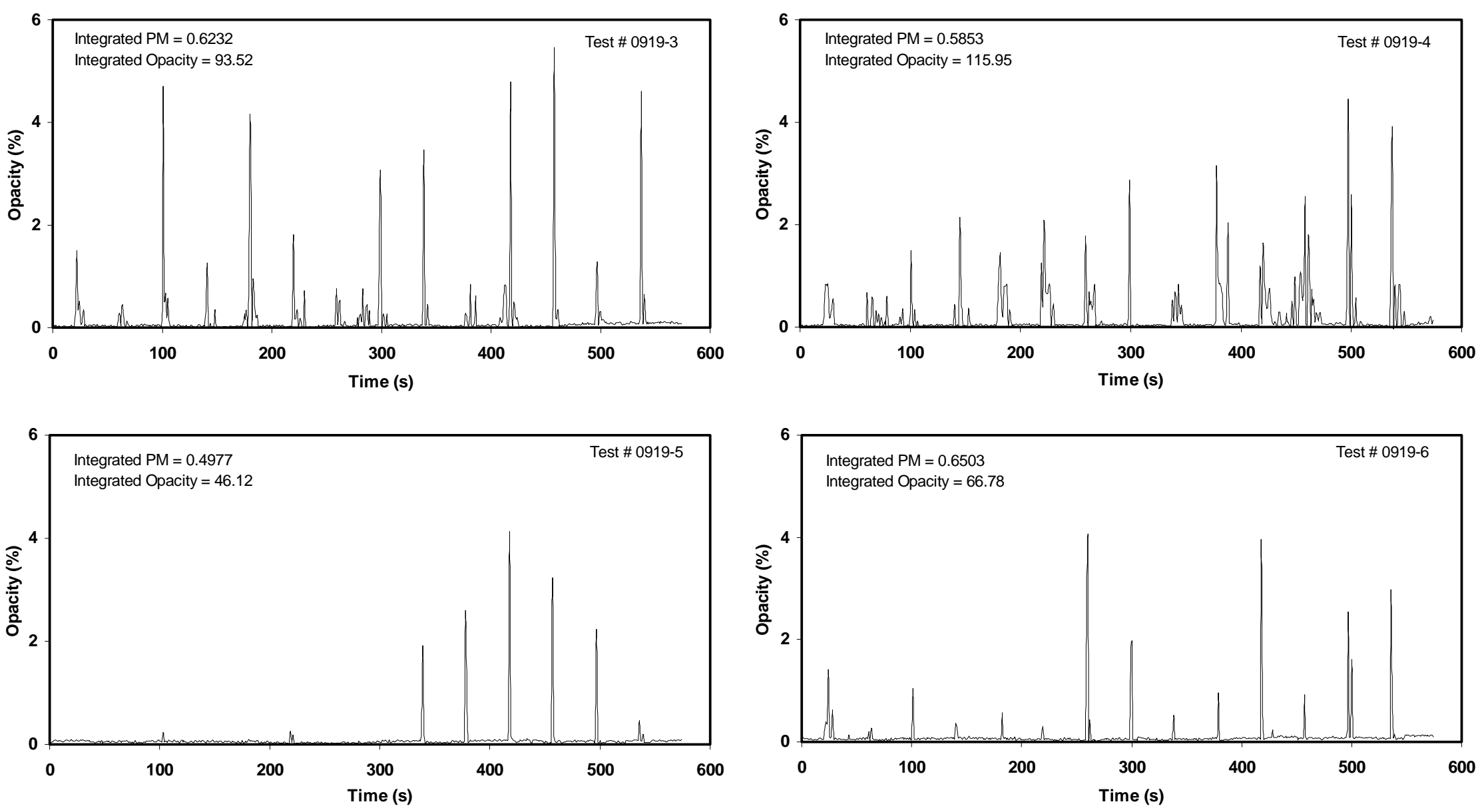

Figure 4-12. Continuous opacity data measured by the Wager full-flow opacity meter. The data were obtained from a 1996 transit bus powered by a 1996 DDC Series 50 engine exercised through four CBD transient test cycles sequentially. Values of integrated continuous opacity data and total PM obtained through filter capture are shown as well. The charts show extensive variation between the respective opacity data in terms of peak magnitudes, time duration of the response, and integrated values. The integrated emissions for the same tests show little variation from test to test. 


\subsection{Carbon Monoxide and Opacity}

There is an excellent opportunity to explore the relationship between $\mathrm{CO}$ and opacity because both are available as continuous functions throughout an emissions test and because both can be attributed to regions of rich combustion within the combustion chamber. Figure 4-13 shows plots of continuous $\mathrm{CO}$ and continuous opacity from the same tests shown in Figure 4-12 (tests 0919-3 through 0919-6), which are from a transit bus powered by a 1996 DDC Series 50 engine exercised through a CBD cycle. These plots suggest a relation between the relative magnitudes of the $\mathrm{CO}$ and opacity values for each acceleration ramp of the cycle.

\subsubsection{Evaluation of Peak Carbon Monoxide and Peak Opacity Values}

To evaluate the correlation of $\mathrm{CO}$ and opacity further, the maximum values of $\mathrm{CO}$ concentration (or peak values) were plotted as a function of peak opacity values from each acceleration ramp and are shown in Figure 4-14. It is acknowledged that peak $\mathrm{CO}$ values measured at the analyzer bench are less than peak values at the exhaust manifold due to axial dispersion of the exhaust gases. However, tests have shown the dispersive effects of the exhaust gas transport system to be consistent ranges of pulse input and to vary little for different engine speeds. Thus peak $\mathrm{CO}$ values at the analyzer bench will be reflective of peak $\mathrm{CO}$ values at the exhaust manifold. The dispersive effects of the exhaust transport system will be discussed further in Section 4.4.2. 

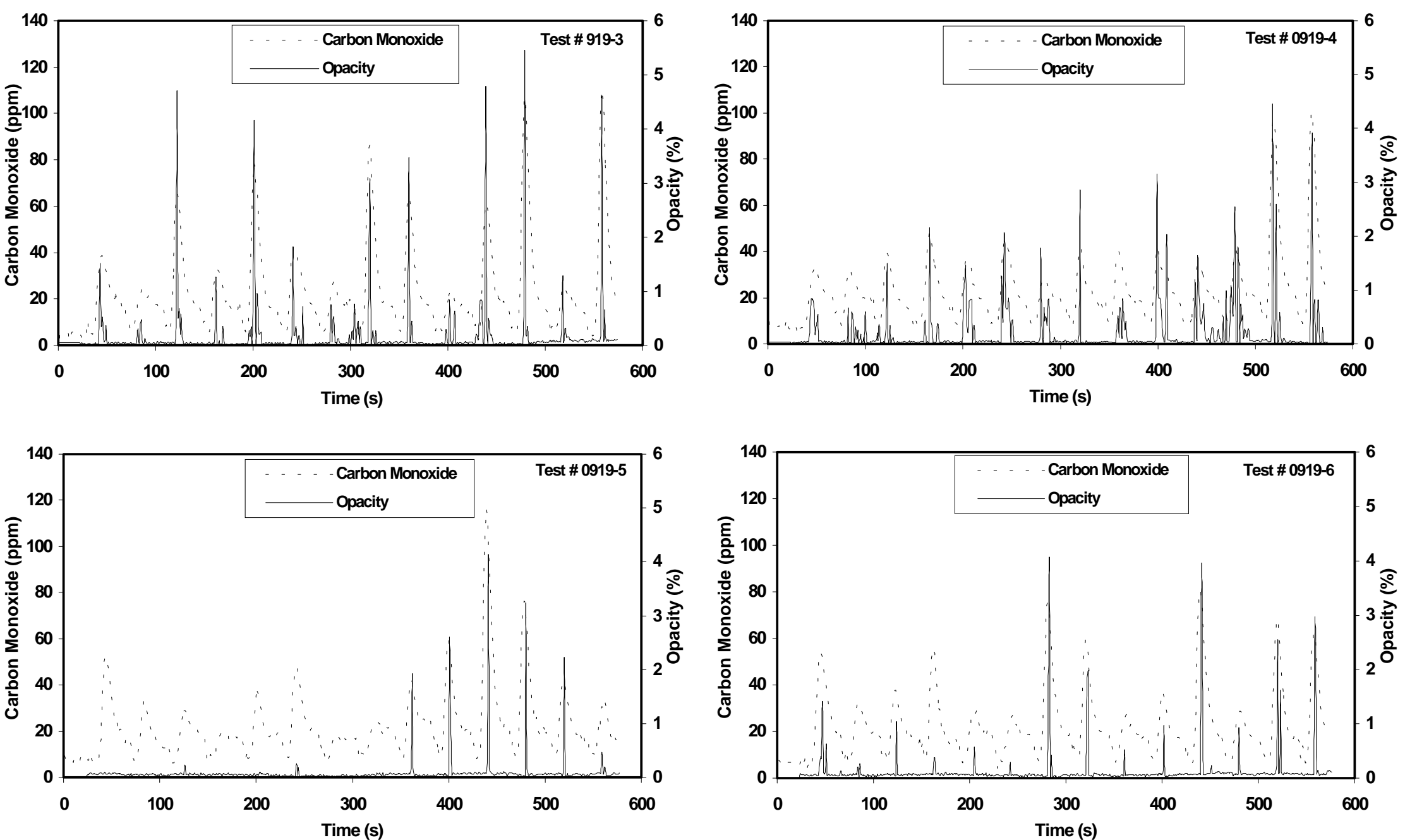

Figure 4-13. Continuous opacity data and continuous carbon monoxide data from a 1996 transit bus powered by a 1996 DDC Series 50 engine exercised through four CBD cycles (the same tests as shown in Figure 4-12). These plots show an apparent relation between the peak magnitude values of opacity and $\mathrm{CO}$. These plots also suggest that the variations in peak opacity magnitudes observed in Figure 4-12 may be reflective of engine operation since the $\mathrm{CO}$ magnitudes seem to follow a similar trend. 

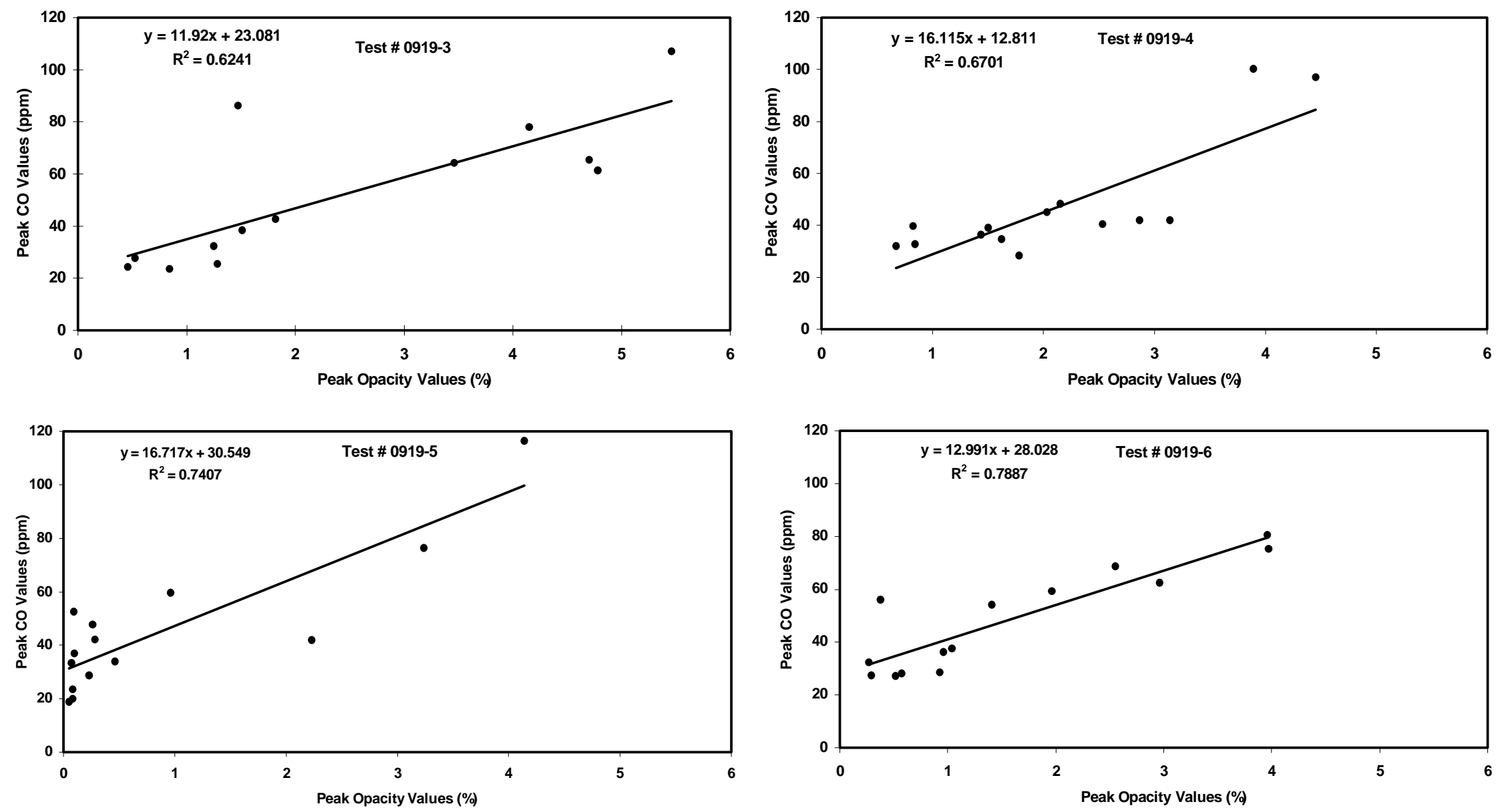

Figure 4-14. Peak CO values plotted as a function of peak opacity values from a 1996 transit bus powered by a 1996 DDC Series 50 engine exercised through four CBD cycles. These data points were obtained from the same tests shown in Figures 4-11 and 4-12. These four plots suggest existence of a mild, linear relation between peak magnitude values of opacity and $\mathrm{CO}$. 
These plots show some linear correlation between peak $\mathrm{CO}$ and peak opacity with the coefficient of determination $\left(\mathrm{R}^{2}\right)$ value ranging from 0.62 to 0.79 . It is also noted that $\mathrm{R}^{2}$ values increase with each consecutive test. However, this trend is not repeated for other test series and is thus considered coincidental. The relation of peak $\mathrm{CO}$ as a function of peak opacity was evaluated for all Flint, MI. tests which had valid CO and opacity data, resulting in a total of 33 tests evaluated. Of these 33 tests, 25 were CBD cycle, three were snap-acceleration tests, two were from the WVU 5-Mile route, two were from the NYCB cycle, and one was from the Test D. The 33 tests were obtained from 7 different transit buses, all of which were powered with 1996 DDC Series 50 engines. On a test-by-test evaluation, $\mathrm{R}^{2}$ ranged from 0.004 to 0.905 , with an average $\mathrm{R}^{2}$ of 0.545 . A plot of all peak $\mathrm{CO}$ values as a function of all peak opacity values is shown in Figure 4-15. This plot shows a some linear correlation with an $\mathrm{R}^{2}$ value of 0.6 , but also shows considerable data scatter. A cycle-specific evaluation of peak $\mathrm{CO}$ as a function of peak opacity found $\mathrm{R}^{2}($ Snap-Acceleration $)=0.002, \mathrm{R}^{2}(5$-Mile route $)=0.294, \mathrm{R}^{2}(\mathrm{NYC}-\mathrm{Bus}$ cycle $)=$ $0.008, \mathrm{R}^{2}($ Test $\mathrm{D})=0.046$, and $\mathrm{R}^{2}(\mathrm{CBD}$ cycle $)=0.468$. The lack of any correlation between peak $\mathrm{CO}$ and peak opacity for all but the CBD cycle may be due to an insufficient number of data for the given cycle. The number of data points for the snap-acceleration test, 5-Mile route, NYCB cycle, and Test D range from 10 to 28 , where as the number of data points for the CBD cycle is 358 . Note that the $\mathrm{R}^{2}$ value for the plot of all peak $\mathrm{CO}$ and peak opacity data is slightly higher than the $\mathrm{R}^{2}$ value for just the CBD tests which is based on a total of 438 data points. Thus, it is believed that a larger number of data points would be necessary to compare peak CO and peak opacity accurately on a transient cycle bases. Evaluation of continuous $\mathrm{CO}$ and continuous opacity provided a sufficient number of data points, but further adjustment to the 
continuous opacity data was necessary before comparing with continuous $\mathrm{CO}$. This was due to differences in data acquisition location and will be discussed in Section 4.4.2.

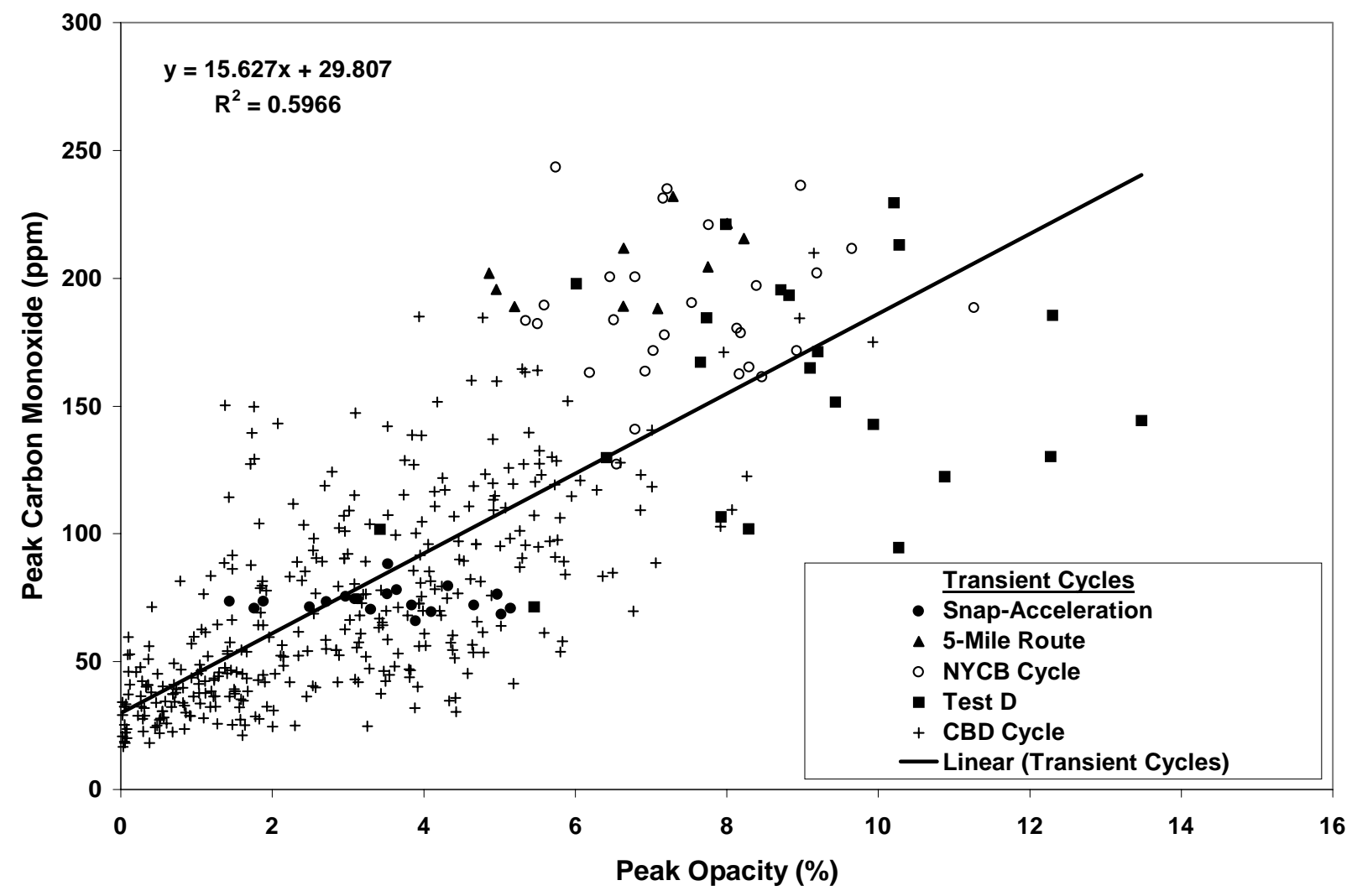

Figure 4-15. Peak CO values as a function of peak opacity values from all transient tests conducted in Flint, MI. All data in this plot are from 1996 transit buses powered by 1996 DDC Series 50 engines. The data represents seven different buses exercised through thirty-three tests spanning five different transient chassis tests (Snap-acceleration, 5-Mile Route, NYCB Cycle, Test D, and CBD Cycle).

\subsubsection{Axial Dispersion}

The Wager opacity meter was mounted at the end of the exhaust transfer pipe just before the dilution tunnel. In contrast, diluted exhaust samples for the $\mathrm{CO}$ analyzer were drawn from the end of the dilution tunnel through heated supply lines. By design, the dilution tunnel has a highly turbulent flow (Reynolds number of approx. 130,000) and can be approximated as a device having plug flow with back-mixing [27]. In addition to providing near uniform radial 
mixing, such flows create some axial dispersion in the flow field. This axial dispersion can easily be seen in the continuous CO plot in Figure 4-13 when compared to the continuous opacity plot which has pulse input characteristics. The spreading effect (or dispersion) of the exhaust transfer pipe, dilution tunnel, and analyzer supply lines on a pulse input can be modeled by a modified Gaussian curve. A theoretical dispersion model developed by Octave Levenspiel [27] for chemical reactors was chosen to analyze and model the dispersive effects of the exhaust transport and sampling system. This model is shown in Equation 4-3.

$C_{\theta}=\frac{1}{\left.2 \sqrt{\pi \theta_{i}(D / u L}\right)} \exp \left[-\frac{\left(1-\theta_{i}\right)^{2}}{4 \theta_{i}(D / u L)}\right]$

Equation 4-3

where,

$\theta_{i}=t_{i} / \tau$

$t_{i}$ is the time increment which ranges from $i$ to $i+n$. The value ' $i$ ' is the time-lag between the pulse injection the moment when the first traces of concentration are measured at the analyzer. The value of $n$ is determined by the time range of a dispersed concentration curve resulting from a one-second pulse input of the substance.

$\tau$ is the mean time value from the pulse input to the concentration centroid of the dispersed curve and is determined by the relation shown in Equation 4-4.

$C_{\theta}$ is the concentration predicted by the dispersion model at each interval of $t_{i}$.

$\mathrm{D} / u \mathrm{~L}$ is the dimensionless vessel dispersion number (VDN) and is a parameter which represents the extent of axial dispersion. 


$$
\tau=\frac{\sum_{i \rightarrow n} t_{i} \cdot C_{i}}{\sum_{i \rightarrow n} t_{i}}
$$

Equation 4-4

$C_{i}$ is the measured concentration by the analyzer of the pulse injection at time $t_{i}$ from the initial time of injection.

$\mathrm{CO}_{2}$ was chosen for dispersion analysis due to availability of pure $\mathrm{CO}_{2}(99.9 \%)$ at the laboratory. The author believes that the combined dispersive effects of the exhaust gas transfer system are similar for $\mathrm{CO}_{2}$ and $\mathrm{CO}$ since both use similar analyzers (the same analyzer type configured differently), and are in similar locations in the gas analyzer bench. It is also believed that the system's dispersive effects will be similar for NOx, HC, and opacity. Furthermore, the dispersive model can be applied to engine or chassis data such as torque and power for comparison with continuous data to any or all of the emission gases. The logic in this application would be to treat the engine or axle torque or power as if it traveled through the exhaust ducting along with the exhaust gases. This is justified since it would be difficult at best to develop a backward dispersion model.

To evaluate the system's dispersive effects on exhaust gases, pure $\mathrm{CO}_{2}$ gas $(99.9 \%)$ was injected into the exhaust transfer pipe at a location just after the end of the exhaust stack of the truck. The $\mathrm{CO}_{2}$ injections were of a pulse nature at pulse widths of one, two, and five seconds, and injected at thirty-second intervals. The time of the start of each injection was noted in reference to the test time displayed during the test. The dilution tunnel was operated at a flow rate of $0.708 \mathrm{~L} / \mathrm{s}(1500 \mathrm{cfm}) . \mathrm{CO}_{2}$ concentration data were collected from the analyzer during these tests at a $5 \mathrm{~Hz}$ frequency. Steady state engine speeds of idle and $1500 \mathrm{rpm}$ were chosen to evaluate the effects of increased exhaust flow rate on dispersion. Plots of the original data are shown in Figures C-6 through C-8 in Appendix C. Figures C-6 and C-7 show $\mathrm{CO}_{2}$ data from the 
two idle tests and Figure C-8 shows $\mathrm{CO}_{2}$ data from the $1500 \mathrm{rpm}$ test. The base-line $\mathrm{CO}_{2}$ values represent engine and background $\mathrm{CO}_{2}$ and were subtracted from the original data to yield injected $\mathrm{CO}_{2}$ only. Since the time range of the dispersed curve is a function of the VDN and the duration of the initial concentration input, only the curves resulting from one-second pulse injections were used for determining the VDN. Levenspiel also gave two relations for the variance $\sigma$. One is a function of measured concentrations of a dispersed input over time and the other is a function of the VDN. These relations are shown in Equations 4-5 and 4-6, which are, $\sigma_{\theta}^{2}=\left(\frac{\sum t_{i}^{2} C_{i} * \sum C_{i}}{\left(\sum t_{i} C_{i}\right)^{2}}\right)-1$ Equation 4-5 and, $\sigma_{\theta}^{2}=2 * V D N+8 * V D N^{2}$ Equation 4-6

Substituting the right hand term of Equations 4-5 into Equation 4-6 and using the quadratic equation to solve for VDN provided a means for determining VDN from measured data. Data from the eight, one-second pulse inputs were aligned using cross correlation, normalized and averaged into one curve. A VDN of 0.00933 was obtained from this normalized, average curve which is shown in Figure 4-16 along with a plot of the normalized dispersion curve generated using Equation 4-3 with the same VDN. 


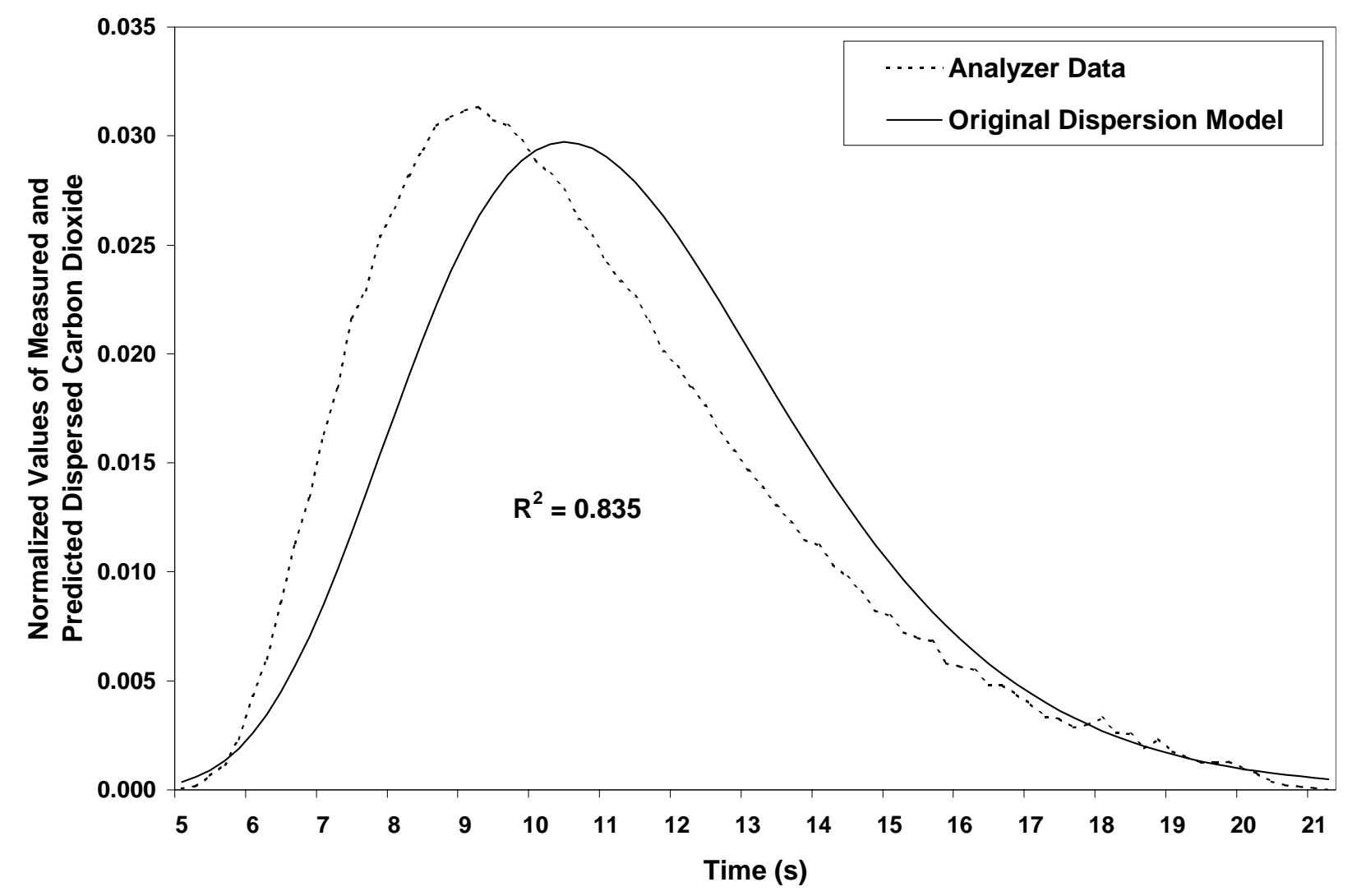

Figure 4-16. Normalized and averaged $\mathrm{CO}_{2}$ curve obtained from eight, one-second pulse injections of $\mathrm{CO}_{2}$ into the exhaust transfer pipe, and normalized concentration values obtained from the Levenspiel dispersion model.

Although the two plots appear to be out of phase, they both start and stop at the same point. The true cause of the misalignment is the dispersion model's slower rate at which it reaches its apex, which is when $\theta_{i}=1$. Using a value less than one would result in the model reaching its apex sooner. In addition to this modification, it was found that raising the $\theta_{i}$ term in the exponential denominator to a positive value greater than 1 had beneficial results in terms of reducing the error between the model and measured data. The result is a modified dispersion model shown in Equation 4-7, with the modifying variables designated as $a$ and $b$.

$$
C_{\theta}=\frac{1}{\left.2 \sqrt{\pi \theta_{i}(D / u L}\right)} \exp \left[-\frac{\left(a-\theta_{i}\right)^{2}}{4 \theta_{i}^{b}(D / u L)}\right]
$$


These variables were solved for through iteration using the Microsoft solver available in Microsoft Excel. The solver uses a generalized reduced gradient nonlinear optimization code. In this application, the solver varied $a$ and $b$ to minimize the error, which was the summation of the squares of the differences between the dispersed curve obtained through measurement and the dispersed curve of the modified Levenspiel dispersion model. The values determined for $a$ and $b$ were 0.8801 and 1.685 respectively. The results of these modifications to the dispersion model are shown in Figure 4-17 in relation to the normalized average curve of analyzer data from the one-second pulse injections. The coefficient of determination $\left(\mathrm{R}^{2}\right)$ between the data shown in Figures 4-16 and 4-17 is 0.884 and 0.998 respectively.

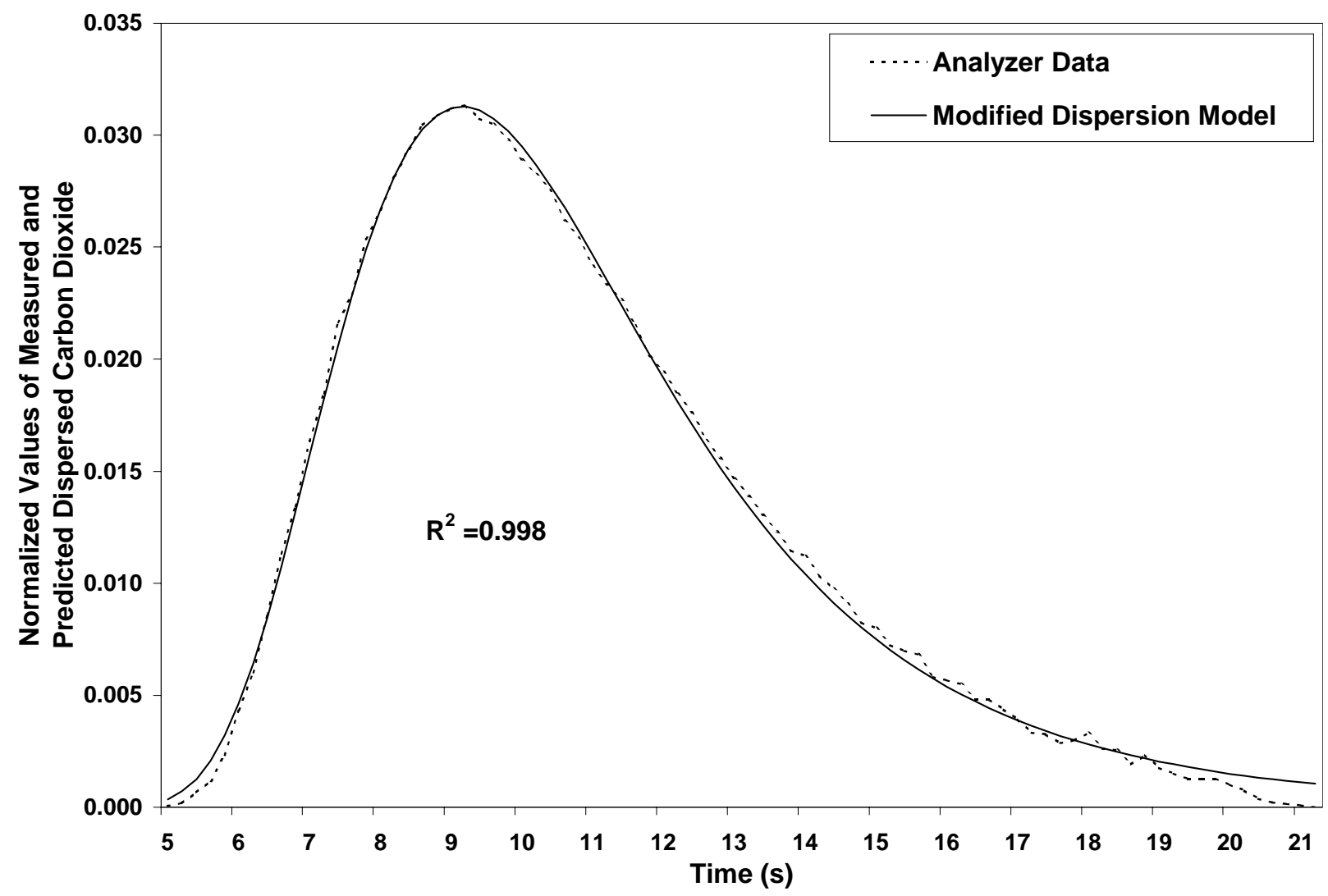

Figure 4-17. Normalized curve from the averaged $\mathrm{CO}_{2}$ data obtained from eight, one-second pulse injections and the modified Levenspiel dispersion model. 
To compare the modified dispersion model to $\mathrm{CO}_{2}$ data throughout the entire injection test, it was necessary to normalize the dispersion curve and apply it to a known input. Since the exact concentration of each pulse injection in the exhaust stream was not known, it was determined by integrating the area under each $\mathrm{CO}_{2}$ curve and dividing by the time length of the respective pulse injection. The normalized dispersion curve was applied to the pulse injections and compared with $\mathrm{CO}_{2}$ data from the analyzer. The techniques described above for determining the VDN and the dispersion model variables $a$ and $b$ were applied to all $\mathrm{CO}_{2}$ data obtained from one-second $\mathrm{CO}_{2}$ pulse injections, as well as to all data from all three injection tests. Table 4-3 shows the resulting values of the mean time delay from the pulse injection to the dispersed curve centroid $\left(\mathrm{t}_{\text {mean }}\right)$, the modified dispersion model variables $a$, and $b$, the VDN for the modified model $\left(\mathrm{VDN}_{\mathrm{mod}}\right)$, coefficient of determination when the modified dispersion model was used $\left(\mathrm{R}^{2}{ }_{\text {mod }}\right)$, and the $\mathrm{VDN}$ for the original dispersion model $\left(\mathrm{VDN}_{\text {orig }}\right)$ and corresponding coefficient of determination when the original dispersion model was used $\left(\mathrm{R}^{2}{ }_{\text {orig }}\right)$.

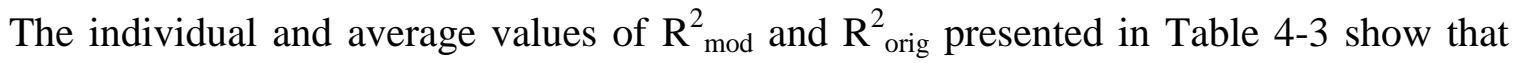
the modified dispersion model was more accurate in predicting the dispersed curve from a pulse injection. The respective values of the percent coefficient of variance reveal a higher level of consistency as well. The CV\% of all variables of the modified model were low, suggesting a high level of consistency. It is noted that the average values of $\mathrm{VDN}_{\text {mod }}$ and $\mathrm{VDN}_{\text {orig }}$ from Test 3 are slightly higher than the average values obtained from Tests 1 and 2. This suggests a slightly higher amount of dispersion, which would correspond with the fact that Test 3 was conducted with the engine operating at $1500 \mathrm{rpm}$ where as Tests 1 and 2 were conducted with the engine operating at idle. However, this same trend is not observed for VDN values obtained from the model being applied to the entire test. Thus, it is concluded that the VDN may vary with engine 
speed, as would be expected, but that the variance is small enough to justify using a constant value throughout a transient test. It is also noted that the $\mathrm{VDN}_{\text {mod }}$ values determined when the model was applied to the entire test were closer to the values determined when the model was

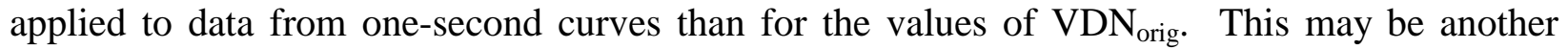
reflection of the improved accuracy of the modified dispersion model over the original dispersion model. Thus, for the rest of the report, any reference to dispersed data will imply data that has been dispersed by the modified Levenspiel dispersion model using a value of 0.9324 , 2.6624, and 0.0098 respectively for $a, b$, and VDN.

Dispersion Evaluation From $\mathrm{CO}_{2}$ Injection Tests

\begin{tabular}{|c|c|c|c|c|c|c|c|}
\hline & \multicolumn{3}{|c|}{ Original Dispersion Model } & \multicolumn{4}{|c|}{ Modified Dispersion Model } \\
\hline Test-Injection \# & $t_{\text {mean }}$ & VDN $_{\text {orig }}$ & $\mathbf{R}_{\text {org }}^{2}$ & $a$ & $b$ & VDN $_{\text {mod }}$ & $\mathbf{R}_{\text {mod }}^{2}$ \\
\hline Inj. 1-1 & 20.7 & 0.010 & 0.83 & 0.9351 & 2.701 & 0.0097 & 0.990 \\
\hline Inj. 1-2 & 20.0 & 0.011 & 0.80 & 0.9250 & 2.580 & 0.0110 & 0.988 \\
\hline Inj. 1-3 & 20.6 & 0.009 & 0.85 & 0.9380 & 2.569 & 0.0096 & 0.992 \\
\hline Inj. 1-4 & 20.3 & 0.009 & 0.86 & 0.9404 & 2.657 & 0.0089 & 0.993 \\
\hline Inj. 1-5 & 20.1 & 0.011 & 0.85 & 0.9394 & 2.732 & 0.0089 & 0.990 \\
\hline Test 1 Average & 20.4 & 0.010 & 0.84 & 0.9356 & 2.648 & 0.0096 & 0.990 \\
\hline Inj. 2-1 & 20.2 & $\overline{0.011}$ & 0.83 & 0.9344 & 2.636 & 0.0099 & 0.989 \\
\hline Inj. 2-2 & 20.9 & 0.009 & 0.85 & 0.9390 & 2.620 & 0.0094 & 0.992 \\
\hline Inj. 2-3 & 20.4 & 0.010 & 0.85 & 0.9371 & 2.663 & 0.0096 & 0.994 \\
\hline Test 2 Average & 20.5 & 0.010 & 0.84 & 0.9368 & 2.640 & 0.0096 & 0.992 \\
\hline Inj. 3-1 & 19.6 & $\overline{0.011}$ & 0.84 & 0.9374 & 2.740 & 0.0094 & 0.993 \\
\hline Inj. 3-2 & 20.0 & 0.010 & 0.84 & 0.9335 & 2.474 & 0.0108 & 0.991 \\
\hline Inj. 3-3 & 19.8 & 0.010 & 0.85 & 0.9374 & 2.532 & 0.0101 & 0.995 \\
\hline Test 3 Average & 19.8 & 0.010 & 0.84 & 0.9361 & 2.582 & 0.0101 & 0.993 \\
\hline Test 1 & $\overline{\mathrm{NA}}$ & 0.014 & 0.91 & 0.9193 & 2.800 & 0.0100 & 0.985 \\
\hline Test 2 & $\mathrm{NA}$ & 0.014 & 0.88 & 0.9142 & 2.696 & 0.0101 & 0.978 \\
\hline Test 3 & $\mathrm{NA}$ & 0.013 & 0.94 & 0.9229 & 2.873 & 0.0098 & 0.997 \\
\hline Tests Average & NA & 0.014 & 0.91 & 0.9188 & 2.790 & 0.0100 & 0.987 \\
\hline Over-All Average & 20.2 & 0.011 & 0.86 & 0.9324 & 2.662 & 0.0098 & 0.990 \\
\hline Standard Dev. & 0.379 & 0.002 & 0.033 & 0.008 & 0.103 & 0.001 & 0.004 \\
\hline CV\% & 1.87 & 14.827 & 3.86 & 0.87 & 3.857 & 5.97 & 0.450 \\
\hline
\end{tabular}

Table 4-3. Results from fitting the original and modified Levenspiel dispersion models to $\mathrm{CO}_{2}$ concentration data obtained from injecting one, two, and five second pulses of $99.9 \%$ pure $\mathrm{CO}_{2}$ into the exhaust transfer pipe. 


\subsubsection{Continuous Carbon Monoxide and Dispersed Opacity}

Now that an accurate dispersion model has been determined, the model can be applied to continuous opacity data to compare it with continuous $\mathrm{CO}$ data. A computer program was written to apply the dispersion model to the continuous opacity data. This program is shown in appendix B. The $C_{i}$ values obtained from the modified dispersion model were normalized and applied to each opacity data point as if it were a pulse input. The computer program summates each of these dispersed curves in a step-wise fashion which yields a dispersed opacity curve. This dispersed opacity curve is a prediction of the opacity as if it had been measured at the same location as the $\mathrm{CO}$ analyzer. This approach is a simpler alternative to attempting to perform a back-transform to yield instantaneous CO tail pipe emissions. Figure 4-18 shows plots of original and dispersed continuous opacity data.

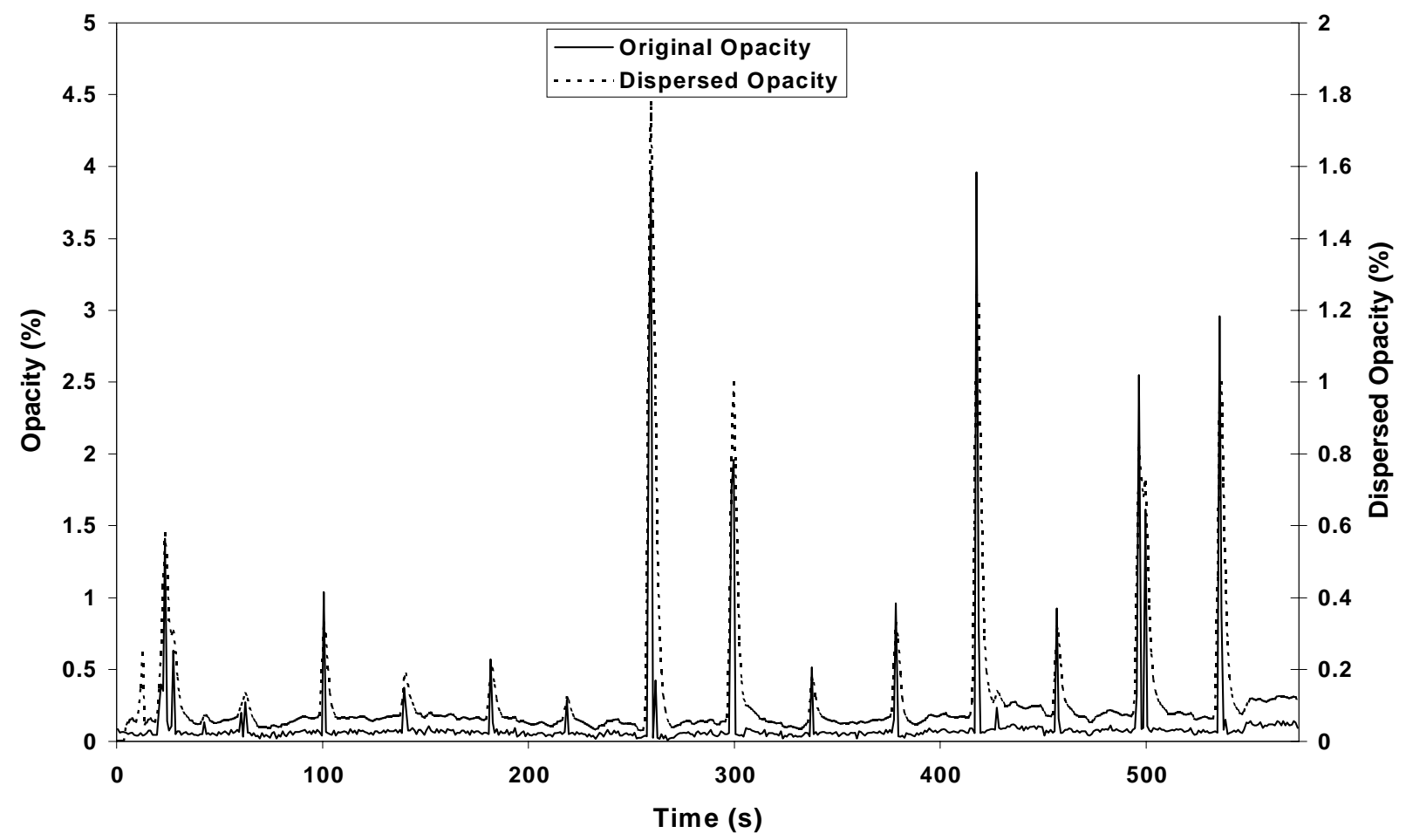

Figure 4-18. Original and dispersed opacity data from a 1996 transit bus powered by a 1996 DDC Series 50 engine exercised through a CBD transient test cycle. 
It is noted that the summation of dispersed opacity data is the same as the summation of original opacity data for each test. Thus, opacity is neither created nor destroyed by the dispersion process.

The modified dispersion model was applied to all Wager continuous opacity data using the average values of $a, b$, and $\mathrm{VDN}$ determined from the $\mathrm{CO}_{2}$ injection tests as shown in Table 4-3. Figures 4-19 and 4-20 below show plots of $\mathrm{CO}$ and dispersed opacity as a function of time and $\mathrm{CO}$ as a function of dispersed opacity respectively. These plots represent the best results (in terms of $\mathrm{R}^{2}$ ) of $\mathrm{CO}$ plotted as a function of dispersed opacity. The data are from a 1996 transit bus powered by a 1996 DDC Series 50 engine exercised through a NYCB cycle. Similar plots are shown in Appendix C, Figures C-9 through C-20, and represent tests with the best results from the five different test cycles and one with the worst results.

The correlation results from plotting $\mathrm{CO}$ as a function of dispersed opacity for all tests are shown in Table 4-4 in the column label "Modified Dispersion Model Correlation". In addition, the Excel solver was used to determine the best-fit values of $a, b$, and VDN, when opacity was dispersed to fit with CO data. The target of the solver was to minimize the sum of the square of the difference between each respective data point. This was done to evaluate the difference between $a, b$, and VDN values obtained from $\mathrm{CO}_{2}$ injection tests and values that worked best for dispersing opacity to $\mathrm{CO}$. The $\mathrm{R}^{2}$ values from best-fit variables are also shown in Table 4-4.

It may be argued that the measurement of raw $\mathrm{CO}$ with an infrared detection system in the region of the opacity meter would be preferable for purposes of correlation, but an objective of the author was to apply the method described above to the post-processing of existing data banks where $\mathrm{CO}$ has been measure in the diluted exhaust. 


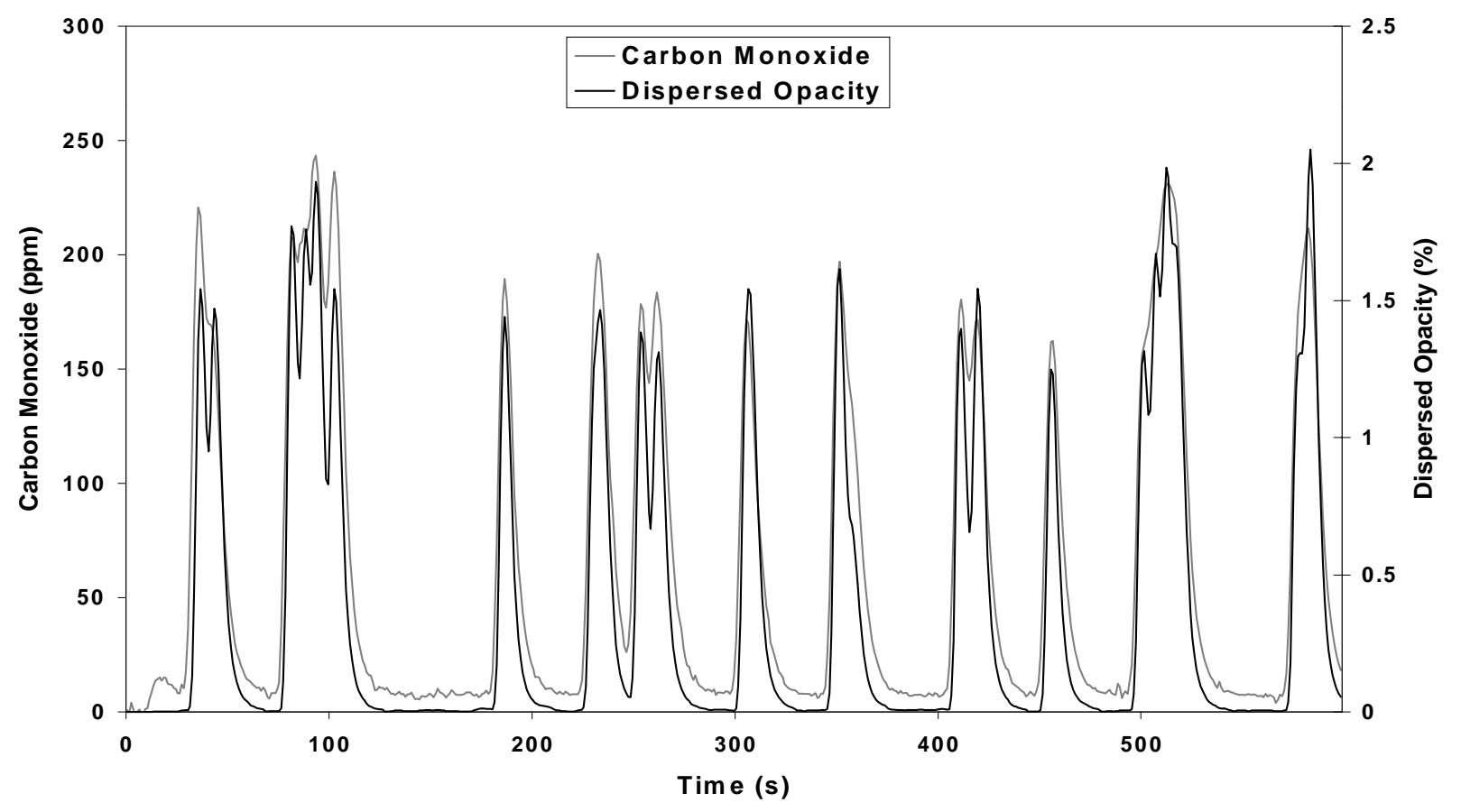

Figure 4-19. CO concentration and dispersed opacity from a 1996 transit bus powered by a 1996 DDC Series 50 engine exercised through a NYCB cycle.

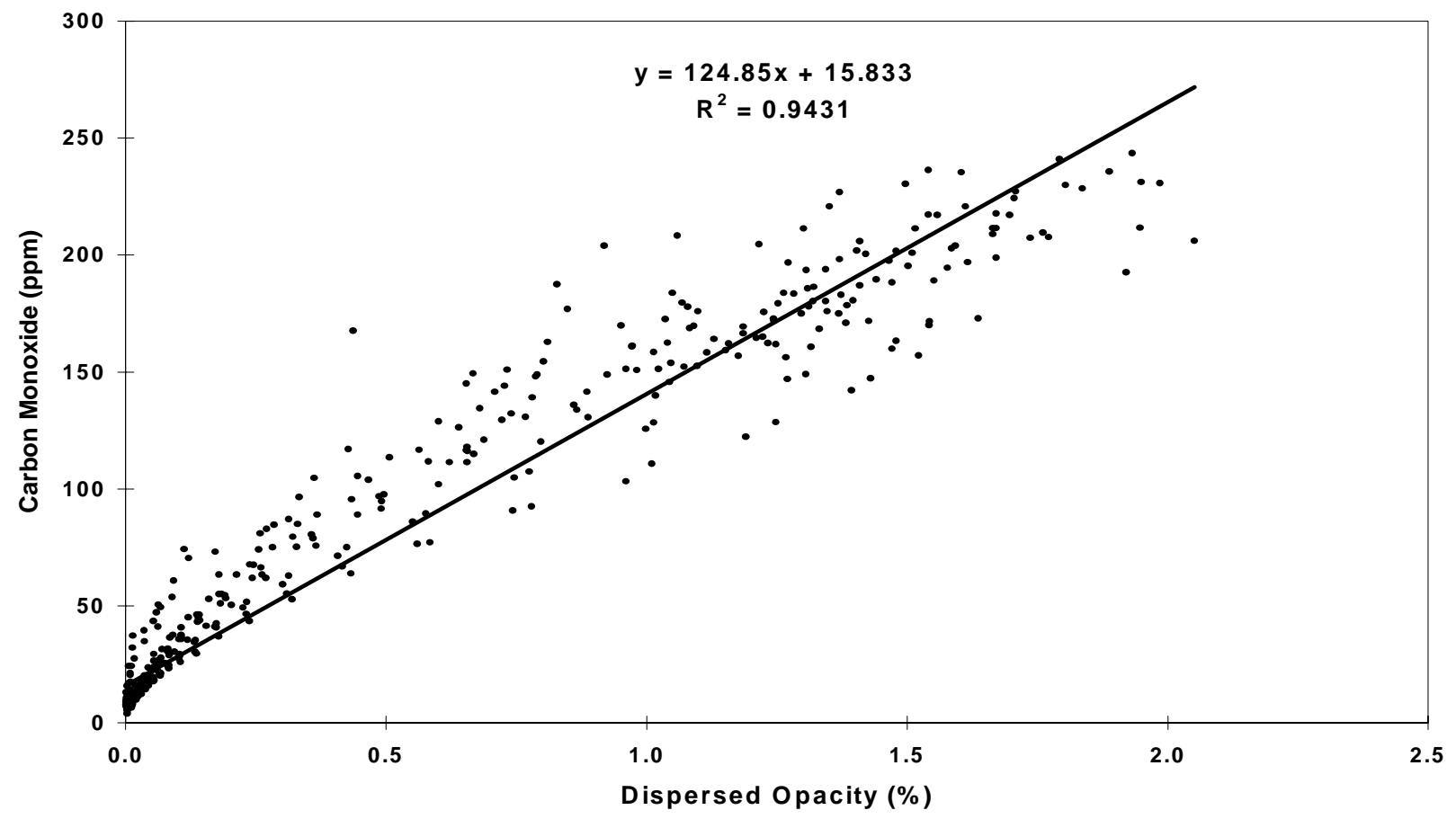

Figure 4-20. This is the same data as in Figure 4-19 but with $\mathrm{CO}$ concentrations plotted as a function of dispersed opacity. 
Aplication of Dispersed Opacity to CO Results

\begin{tabular}{|c|c|c|c|c|c|c|}
\hline & & \multicolumn{4}{|c|}{ Best Fit Values \& Correlation } & \multirow{2}{*}{$\frac{\text { Mod. Disp. Model Corr }}{\mathbf{R}^{2}}$} \\
\hline Test Number & Test Cycle/Route & $\mathbf{a}$ & $\bar{b}$ & VDN & $\mathbf{R}^{2}$ & \\
\hline 0919-3 & CBD & 0.890 & 3.01 & 0.017 & 0.811 & 0.766 \\
\hline 0919-4 & CBD & 0.932 & 2.66 & 0.010 & 0.614 & 0.619 \\
\hline $0919-5$ & CBD & 0.930 & 2.11 & 0.019 & 0.716 & 0.679 \\
\hline 0919-6 & CBD & 0.885 & 1.74 & 0.022 & 0.793 & 0.696 \\
\hline P0919-Snap & Snap-Acceleration & 0.918 & 1.10 & 0.025 & 0.930 & 0.804 \\
\hline $0920-1$ & CBD & 0.928 & 2.72 & 0.014 & 0.844 & 0.844 \\
\hline $0920-2$ & CBD & 0.927 & 2.61 & 0.014 & 0.926 & 0.912 \\
\hline $0920-3$ & CBD & 0.903 & 2.36 & 0.015 & 0.838 & 0.801 \\
\hline P0920-4 & CBD & 0.922 & 1.39 & 0.011 & 0.613 & 0.583 \\
\hline $0920-5$ & CBD & 0.975 & 3.06 & 0.014 & 0.829 & 0.751 \\
\hline $0920-6$ & CBD & 0.899 & 3.47 & 0.013 & 0.840 & 0.810 \\
\hline $0921-1$ & CBD & 0.919 & 3.12 & 0.014 & 0.856 & 0.835 \\
\hline $0921-2$ & CBD & 0.880 & 1.70 & 0.015 & 0.827 & 0.724 \\
\hline 0922-1 & CBD & 0.932 & 2.66 & 0.010 & 0.867 & 0.831 \\
\hline $0922-2$ & CBD & 0.943 & 1.96 & 0.017 & 0.873 & 0.841 \\
\hline $0922-4$ & CBD & 0.898 & 1.60 & 0.019 & 0.869 & 0.774 \\
\hline P0924-1 & WVU 5-Mile & 0.925 & 2.12 & 0.021 & 0.980 & 0.919 \\
\hline 0924-2 & WVU 5-Mile & 0.919 & 2.10 & 0.021 & 0.978 & 0.912 \\
\hline P0925-1 & NYCB & 0.924 & 2.09 & 0.017 & 0.968 & 0.943 \\
\hline $0925-2$ & NYCB & 0.894 & 1.50 & 0.018 & 0.973 & 0.890 \\
\hline 0926-1 & D-Cycle & 0.904 & 2.99 & 0.016 & 0.692 & 0.673 \\
\hline P0926-2 & D-Cycle & 0.992 & 1.52 & 0.014 & 0.764 & 0.740 \\
\hline $0927-1$ & CBD & 0.901 & 1.54 & 0.009 & 0.868 & 0.796 \\
\hline $0927-2$ & CBD & 0.898 & 0.09 & 0.005 & 0.769 & 0.619 \\
\hline $0927-3$ & CBD & 0.941 & 1.62 & 0.009 & 0.651 & 0.644 \\
\hline 0927-4 & CBD & 0.968 & 1.95 & 0.009 & 0.882 & 0.859 \\
\hline $0927-5$ & CBD & 0.953 & 0.98 & 0.005 & 0.832 & 0.793 \\
\hline $0927-6$ & CBD & 0.894 & 3.03 & 0.009 & 0.698 & 0.674 \\
\hline 0962-Snap* & Snap-Acceleration & 0.932 & 4.58 & 0.009 & 0.778 & 0.740 \\
\hline P0964-Snap* & Snap-Acceleration & 0.969 & 0.73 & 0.015 & 0.976 & 0.935 \\
\hline Average & & 0.923 & 2.14 & 0.014 & 0.828 & 0.780 \\
\hline Standard Dev. & & 0.028 & 0.916 & 0.005 & 0.105 & 0.101 \\
\hline CV\% & & 3.03 & 42.9 & 35.2 & 12.7 & 12.9 \\
\hline Cycle Average & Snap-Acceleration & 0.940 & 2.14 & 0.016 & 0.895 & 0.826 \\
\hline Cycle Average & CBD & 0.920 & 2.16 & 0.013 & 0.801 & 0.755 \\
\hline Cycle Average & WVU 5-Mile & 0.922 & 2.11 & 0.021 & 0.979 & 0.915 \\
\hline Cycle Average & NYCB & 0.909 & 1.80 & 0.018 & 0.970 & 0.917 \\
\hline Cycle Average & D-Cycle & 0.948 & 2.25 & 0.015 & 0.728 & 0.706 \\
\hline Average & & 0.928 & 2.09 & 0.016 & 0.875 & 0.824 \\
\hline Standard Dev. & & 0.016 & 0.174 & 0.003 & 0.109 & 0.094 \\
\hline CV\% & & 1.71 & 8.31 & 18.5 & 12.4 & 11.4 \\
\hline
\end{tabular}

Table 4-4. Results from two comparisons of continuous CO with dispersed opacity data. "Best-fit Values" were obtained by applying the Excel solver to continuous data from each test to determine optimized values for the variables in the modified Levenspiel dispersion model. $\mathbf{R}^{2}$ values under the heading "Modified Dispersion Model Correlation" reflect correlation results from applying the modified dispersion model while using average variable values ( $a, b$, and VDN) obtained from injection tests (shown in Table 4-2). All data were collected in Flint, MI accept where denoted with $(*)$. Tests with $\left(^{\mathrm{P}}\right)$ indicate test data are plotted in Appendix C. 
The $\mathrm{R}^{2}$ values between dispersed opacity and $\mathrm{CO}$ is shown in the far right column and shows a moderate to good correlation, with values from individual tests ranging from 0.594 to 0.940, and averaging at 0.781 . Results from adjusting the modified dispersion model variables for each test yielded an approximate seven percent improvement in $\mathrm{R}^{2}$, with values ranging from 0.613 to 0.980 , and averaging at 0.828 . While values of $a$ varied only slightly, values of $b$ and VDN varied considerably between each of the tests, with a CV\% of 46.05 and 35.86 respectively. However, the average values of the three variables were very similar to the values determined from the $\mathrm{CO}_{2}$ injection tests. The wide range of values for $b$ and VDN may be reflective of the fact that the variables of the modified dispersion model are being adjusted to "force" the opacity data to fit with the CO data. A larger VDN corresponds with more axial dispersion, which translates to a dispersion curve with lower peak magnitude and broader spreading in terms of time. It can be seen in several of the plots that there is little to no opacity response during some periods of increased $\mathrm{CO}$ production (see Figure 4-13). In-cylinder production of PM that can be "seen" by the opacity meter may drop off while production of $\mathrm{CO}$ continues, or in other words, the $\mathrm{CO}$ pulse width coming out of the engine may be wider than that of opacity. This would correspond with a larger VDN value needed to fit the pulse width of opacity to the dispersed curve of CO. Since the interest of this research was to evaluate the correlation between dispersed opacity and $\mathrm{CO}$, the average values of $a, b$, and VDN presented in Table 4-3 will be used as opposed to making dispersed opacity fit the CO data. 


\subsection{Carbon Monoxide and Particulate Matter}

Given that both $\mathrm{CO}$ and PM are attributed to either rich combustion or rich combustion zones in the cylinder, their relationship may be reveling. Various sets of average $\mathrm{CO}$ and average PM data were evaluated in an attempt to determine what trends, if any, existed in the $\mathrm{CO} / \mathrm{PM}$ relationship. Figure 4-21 presents average $\mathrm{CO}$ as a function of average PM obtained from transit buses (excepted where noted) powered by a range of different engine models exercised through the CBD cycle. These data were collected from seven different test sites and represents eleven different engine types, many operated under different loading conditions. It is apparent from Figure 4-21 that there is no universal relation between CO and PM. However, data point clustering for many of the engine types is noted and suggests that the CO/PM relation is unique for each engine type and perhaps for each engine. It is apparent that $\mathrm{CO}$ and PM are functions of (but not limited to) engine type, engine maintenance and condition, electronic injection controller, engine load, driving conditions, fuel quality, and environmental conditions. In general, the CO/PM ratio may be specific to a particular engine, loading and driving conditions. To further identify the CO/PM relation the ratio has been evaluated with respect to isolated variables. CO/PM ratios presented in Table 4-5 and 4-6 are from 1996 DDC Series 50 engines and 1994 Cummins M11-330E engines respectively. Table 4-7 shows test cell averaged emissions from a Navistar T-444E engine with fuel injection regulated by two different stock electronic engine controllers. 


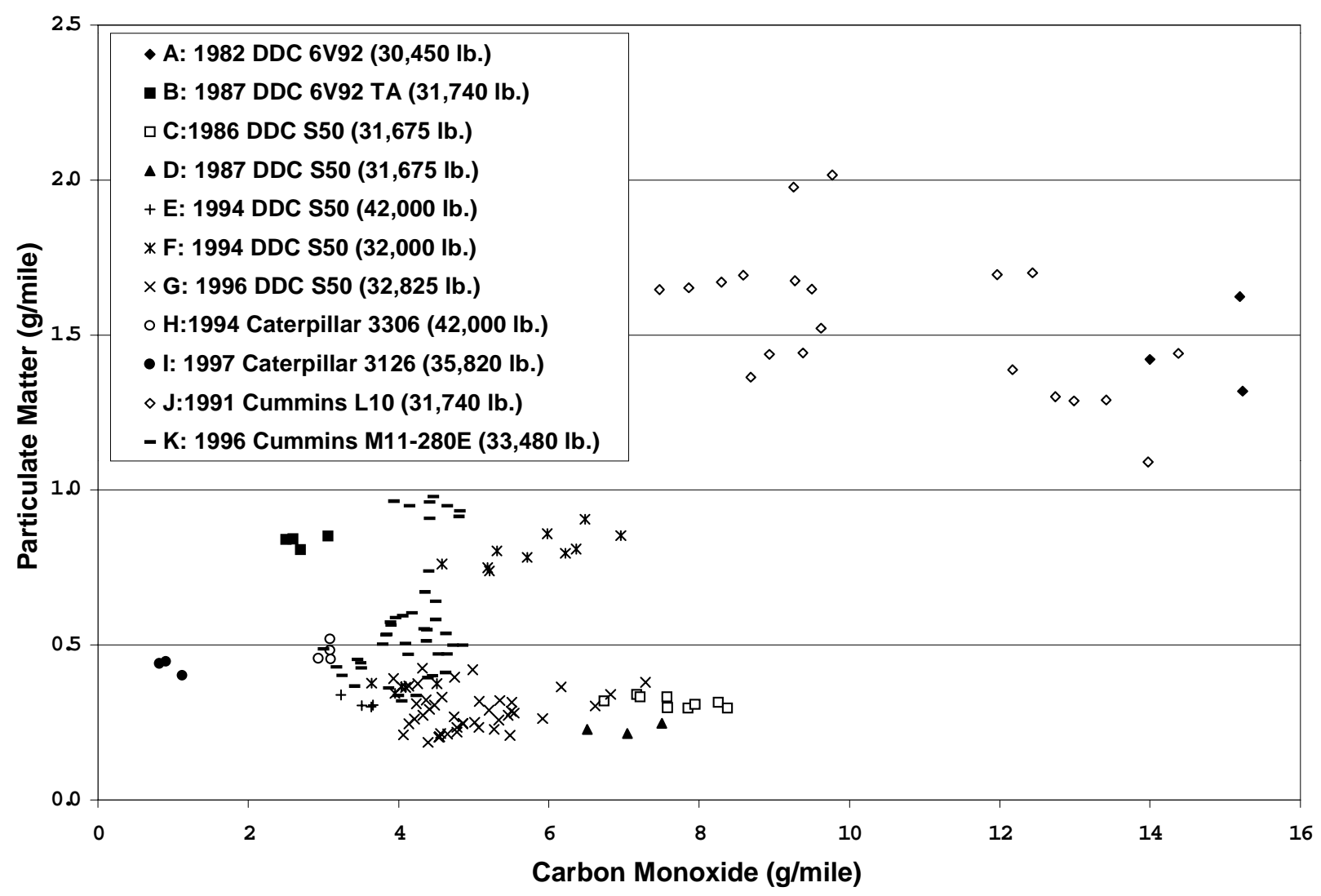

Figure 4-21. Cycle emissions of carbon monoxide and particulate matter from different transit buses (unless otherwise noted) driven through the CBD cycle. Parenthetical values in the legend are the simulated inertial loads applied to the vehicle from the test bed. The test site locations correspond to the following legend points: A - Idaho Falls, ID.; B - Tacoma, WA.; C - Idaho Falls, ID.; D - Idaho Falls, ID.; E - New York, NY. (refuse truck); F - Atlanta, GA.; G - Flint, MI.; H - New York, NY. (refuse truck); I - Long Island, NY. J - Tacoma, WA.; K - Cincinnati, OH.

Table 4-5 shows the CO/PM ratios from four 1996 transit buses powered by 1996 DDC Series 50 engines exercised through a range of transient driving tests and simulated inertial loads. The CO/PM ratios were obtained from integrated emission results averaged on mass per distance (g/mile) basis. Tests 0918, 0919, 0920, and 0927 represent the four different buses powered by similar engines (different engines but of the same model) exercised through the same transient test cycle and simulated inertial loads. The inertial load for these tests was $14,897 \mathrm{~kg}$ $(32,843 \mathrm{lb}$.), which is approximately $87 \%$ of gross vehicle weight (GVW). The CO/PM ratios for these four tests are $11.1,15.7,22.3$, and 20.5 respectively. Clearly the average CO/PM 
values from these tests vary considerably, suggesting that the ratio is engine specific for similar driving and loading conditions. Tests 0920, 0921, and 0922 represent the same vehicle exercised through the same transient test cycle at three different inertial loads; $87 \%$ GVW [14,897 $\mathrm{kg}$ $(32,843 \mathrm{lb})$.$] , curb weight plus 113 \mathrm{~kg}(250 \mathrm{lb}$.) which is $73 \% \mathrm{GVW}$ or [12,590 $\mathrm{kg}(27758 \mathrm{lb})$.$] ,$ and $100 \% \mathrm{GVW},[17,270 \mathrm{~kg}(38,072 \mathrm{lb}$.)]. Here the CO/PM ratio varies less with average values of $22.3,21.8$, and 20.3 respectively. This suggests that the CO/PM relation is less dependant (and maybe independent) of loading conditions. A statistical look at the ten ratios from the three different loading conditions yields an average CO/PM ratio of 21.6, with a CV\% of 9.37 (not shown in the Table 4-5). Tests 0920 and 0923 through 0926 represent the same vehicle and simulated inertial load exercised through different driving tests. The CO/PM ratios are 22.3, $16.5,14.6,33.8$, and 16.8 respectively. These results suggest that the ratio is driving condition dependant for the same engine, although a larger number of tests would be necessary to verify this observation.

CO/PM Ratios from 1996 DDC Series 50 Engines: 8.5 L 275 hp @ 2010 rpm

\begin{tabular}{|c|c|c|c|c|c|c|c|c|c|c|}
\hline Test \# & $\mathbf{0 9 1 8}$ & $\mathbf{0 9 1 9}$ & $\mathbf{0 9 2 0}$ & $\mathbf{0 9 2 1}$ & $\mathbf{0 9 2 2}$ & $\mathbf{0 9 2 3}$ & $\mathbf{0 9 2 4}$ & $\mathbf{0 9 2 5}$ & $\mathbf{0 9 2 6}$ & $\mathbf{0 9 2 7}$ \\
\hline $\begin{array}{c}\text { Veh. \# } \\
\text { Load \% of GVW }\end{array}$ & $\mathbf{1 6 2 5 9}$ & $\mathbf{1 6 2 6 0}$ & $\mathbf{1 6 2 6 1}$ & $\mathbf{1 6 2 6 1}$ & $\mathbf{1 6 2 6 1}$ & $\mathbf{1 6 2 6 1}$ & $\mathbf{1 6 2 6 1}$ & $\mathbf{1 6 2 6 1}$ & $\mathbf{1 6 2 6 1}$ & $\mathbf{1 6 2 6 2}$ \\
\cline { 2 - 12 } & $\mathbf{8 7 \%}$ & $\mathbf{8 7 \%}$ & $\mathbf{8 7 \%}$ & $\mathbf{7 3 \%}$ & $\mathbf{1 0 0 \%}$ & $\mathbf{8 7 \%}$ & $\mathbf{8 7 \%}$ & $\mathbf{8 7 \%}$ & $\mathbf{8 7 \%}$ & $\mathbf{8 7 \%}$ \\
\hline \hline Run \#Cycle & CBD & CBD & CBD & CBD & CBD & $\mathbf{5 - P e a k}$ & $\mathbf{5 - M i l e}$ & NYCB & D-Cycle & CBD \\
\hline $\mathbf{1}$ & 112 & 16.8 & 20.9 & 21.3 & 192 & 16.6 & 16.3 & 30.1 & 13.9 & 20.4 \\
\hline $\mathbf{2}$ & 11.4 & 15.8 & - & 22.3 & 20. & 16.5 & 12.9 & 38.4 & 19.7 & 23.0 \\
\hline $\mathbf{3}$ & 10.0 & 19.7 & 26.3 & - & - & - & - & 33.0 & - & 20.5 \\
\hline $\mathbf{4}$ & 12.0 & 15.0 & 22.5 & - & 21.8 & - & - & - & - & 20.0 \\
\hline $\mathbf{5}$ & 11.9 & 13.6 & 19.5 & - & - & - & - & - & - & 18.5 \\
\hline $\mathbf{6}$ & 102 & 13.5 & 22.4 & - & - & - & - & - & - & 20.4 \\
\hline Average & $\mathbf{1 1 . 1}$ & $\mathbf{1 5 . 7}$ & $\mathbf{2 2 . 3}$ & $\mathbf{2 1 . 8}$ & $\mathbf{2 0 . 3}$ & $\mathbf{1 6 . 5}$ & $\mathbf{1 4 . 6}$ & $\mathbf{3 3 . 8}$ & $\mathbf{1 6 . 8}$ & $\mathbf{2 0 . 5}$ \\
\hline Std. Dev. & $\mathbf{0 . 8 3}$ & $\mathbf{2 . 3 1}$ & $\mathbf{2 . 5 2}$ & $\mathbf{0 . 7 3}$ & $\mathbf{1 . 3 3}$ & $\mathbf{0 . 0 7}$ & $\mathbf{2 . 4 1}$ & $\mathbf{4 . 2 0}$ & $\mathbf{4 . 0 5}$ & $\mathbf{1 . 4 8}$ \\
\hline CV\% & $\mathbf{7 . 4 6}$ & $\mathbf{1 4 . 7}$ & $\mathbf{1 1 . 3}$ & $\mathbf{3 . 3 3}$ & $\mathbf{6 . 5 3}$ & $\mathbf{0 . 4 3}$ & $\mathbf{1 6 . 5}$ & $\mathbf{1 2 . 4}$ & $\mathbf{2 4 . 1}$ & $\mathbf{7 . 2 2}$ \\
\hline
\end{tabular}

Table 4-5. CO/PM ratios from four 1996 transit buses exercised through a range of transient driving tests and simulated inertial loads in Flint, MI.

Figure 4-22 shows average PM as a function of average $\mathrm{CO}$ from the transit bus tested through the different driving tests (tests 0920 and 0923 through 0926). Despite the wide range of 
$\mathrm{CO} / \mathrm{PM}$ ratio values the plot shows a strong, linear correlation between PM and CO for the same engine exercised through different driving cycles. A larger number of data may be necessary to better determine the $\mathrm{CO} / \mathrm{PM}$ relation with respect to driving conditions.

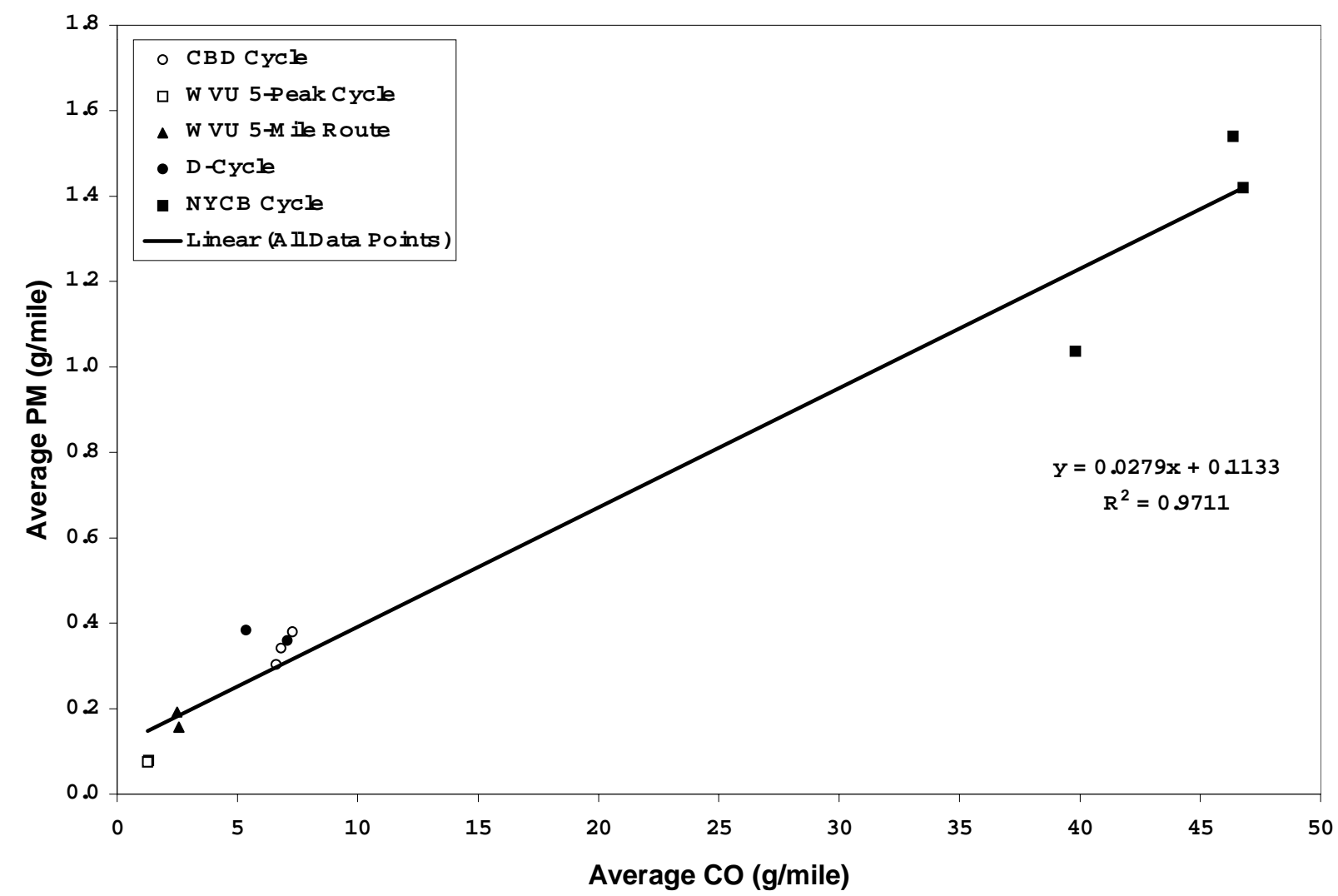

Figure 4-22. Cycle emissions of carbon monoxide and particulate matter for a 1996 transit bus with a 1996 DDC Series 50 engine exercised through five different transient cycles.

Table 4-6 shows the CO/PM ratios from eight 1994 Cummins M11-330E engines exercised through the same transient driving test and simulated inertial loading weights. The transient test used was the WVU 5-Mile route and the simulated inertial load was $19,070 \mathrm{~kg}$ $(42,040 \mathrm{lb}$.$) , or 85 \%$ of GVW [22,680 kg (50,000 lb.)]. As in Table 4-5, the CO/PM ratios were obtained from integrated emission results averaged on a mass per distance basis. These results 
also show a wide range of values for the CO/PM ratio for similar engines exercised through the same transient driving test and same simulated inertial load.

Results from both tables show the CO/PM ratio to be fairly consistent for a specific engine exercised through similar driving conditions under specific loads, and also show that the $\mathrm{CO} / \mathrm{PM}$ relation is unique for each engine, and possibly driving conditions. For Tables 4-5 and 4-6, details of the test site, vehicle, engine, and emission test results (known as a short report) are shown for each test in Appendix A. Short report average emissions are useful in verifying consistency in transient test execution, as well as identification and possible illumination of any erroneous test result though out-lying data values.

CO/PM Ratios from 1994 Cummins M11-330E Engines: 10.8 L $330 \mathrm{hp}$

\begin{tabular}{|c|c|c|c|c|c|c|c|c|}
\hline Test \# & $\mathbf{0 9 6 1}$ & $\mathbf{0 9 6 2}$ & $\mathbf{0 9 6 3}$ & $\mathbf{0 9 6 4}$ & $\mathbf{0 9 7 6}$ & $\mathbf{0 9 7 7}$ & $\mathbf{0 9 7 8}$ & $\mathbf{0 9 7 9}$ \\
\hline Run \# $\backslash$ Route & $\mathbf{5 - M i l e}$ & $\mathbf{5 - M i l e}$ & $\mathbf{5 - M i l e}$ & $\mathbf{5 - M i l e}$ & $\mathbf{5 - M i l e}$ & 5-Mile & 5-Mile & 5-Mile \\
\hline \hline $\mathbf{1}$ & - & 1.20 & 2.50 & 5.48 & - & 4.86 & 2.50 & 5.12 \\
\hline $\mathbf{2}$ & 5.48 & 1.37 & 2.41 & 5.81 & 1.57 & 5.00 & 2.74 & 5.12 \\
\hline $\mathbf{3}$ & 5.23 & 1.43 & 2.39 & 5.45 & 1.50 & 3.08 & 2.63 & 5.38 \\
\hline $\mathbf{4}$ & 5.24 & 1.31 & 2.88 & 6.18 & 1.48 & 3.47 & 2.53 & 5.50 \\
\hline $\mathbf{5}$ & 5.11 & 2.02 & 2.36 & 6.56 & 1.50 & - & - & - \\
\hline $\mathbf{6}$ & 5.51 & 1.82 & - & 5.48 & - & - & - & - \\
\hline $\mathbf{7}$ & 3.53 & 2.19 & - & - & - & - & - & - \\
\hline Average & $\mathbf{5 . 0 1}$ & $\mathbf{1 . 6 2}$ & $\mathbf{2 . 5 1}$ & $\mathbf{5 . 8 3}$ & $\mathbf{1 . 5 1}$ & $\mathbf{4 . 1 0}$ & $\mathbf{2 . 6 0}$ & $\mathbf{5 . 2 8}$ \\
\hline Std. Dev. & $\mathbf{0 . 7 4}$ & $\mathbf{0 . 3 9}$ & $\mathbf{0 . 2 1}$ & $\mathbf{0 . 4 6}$ & $\mathbf{0 . 0 4}$ & $\mathbf{0 . 9 7}$ & $\mathbf{0 . 1 1}$ & $\mathbf{0 . 1 9}$ \\
\hline CV\% & $\mathbf{1 4 . 8}$ & $\mathbf{2 3 . 9}$ & $\mathbf{8 . 5 2}$ & $\mathbf{7 . 8 2}$ & $\mathbf{2 . 4 4}$ & $\mathbf{2 3 . 7}$ & $\mathbf{4 . 1 5}$ & $\mathbf{3 . 6 1}$ \\
\hline
\end{tabular}

Table 4-6. CO/PM ratio from eight 1994 Kenworth trucks powered by 1994 Cummins M11-330E engines exercised through the WVU 5-Mile route.

Table 4-7 contains test cell data from a 1994 Navistar T-444E engine with fuel injection regulated by two different stock electronic engine controllers. The engine was exercised through the Federal transient heavy-duty certification schedule (known as the Federal Test Procedure or FTP) of torque and speed and the data presented were collected after the engine had achieved standard operating temperature. For these tests, the average CO/PM ratio was 13.4 and 16.0, indicating that the CO/PM ratio for the same engine is also a function of the electronic controller. 
Average Emission Results from a 1994 Navistar T-444E Engine: 7.4L 195hp @ 2600 rpm

\begin{tabular}{|c|c|c|c|c|c|c|}
\hline & HC & CO & CO2 & NOx & PM & CO/PM \\
\hline Test Number & (g/Bhp-hr) & (g/Bhp-hr) & (g/Bhp-hr) & (g/Bhp-hr) & (g/Bhp-hr) & \\
\hline \hline $\mathbf{1 2 1 0 9 6 0 2 - N - E - S ~}$ & 0.353 & 1.10 & 625 & 5.00 & 0.081 & 13.5 \\
\hline $\mathbf{1 2 1 0 9 6 0 3 - N - E - S ~}$ & 0.338 & 1.09 & 614 & 4.97 & 0.078 & 14.0 \\
\hline $\mathbf{1 2 1 0 9 6 0 4 - N - E - S ~}$ & 0.325 & 1.01 & 611 & 4.98 & 0.079 & 12.8 \\
\hline 12109605-N-E-S & 0.353 & 1.04 & 627 & 5.01 & 0.079 & 13.2 \\
\hline Average & $\mathbf{0 . 3 4 2}$ & $\mathbf{1 . 0 6}$ & $\mathbf{6 1 9}$ & $\mathbf{4 . 9 9}$ & $\mathbf{0 . 0 7 9}$ & $\mathbf{1 3 . 4}$ \\
\hline Std. Dev. & $\mathbf{0 . 0 1 4}$ & $\mathbf{0 . 0 4}$ & $\mathbf{7 . 9 3}$ & $\mathbf{0 . 0 1 7}$ & $\mathbf{0 . 0 0 1}$ & $\mathbf{0 . 5 0 1}$ \\
\hline CV\% & $\mathbf{3 . 9 4}$ & $\mathbf{3 . 8 1}$ & $\mathbf{1 . 2 8}$ & $\mathbf{0 . 3 4}$ & $\mathbf{1 . 5 9}$ & $\mathbf{3 . 7 4}$ \\
\hline \multicolumn{7}{|l|}{} \\
\hline 12189602-N-E-AS & 0.328 & 1.14 & 625 & 4.92 & 0.077 & 14.8 \\
\hline 12189603-N-E-AS & 0.327 & 1.17 & 625 & 4.89 & 0.078 & 14.9 \\
\hline 12189604-N-E-AS & 0.360 & 1.17 & 628 & 4.89 & 0.072 & 16.2 \\
\hline Average & $\mathbf{0 . 3 3 8}$ & $\mathbf{1 . 1 6}$ & $\mathbf{6 2 6}$ & $\mathbf{4 . 9 0}$ & $\mathbf{0 . 0 7 6}$ & $\mathbf{1 5 . 3}$ \\
\hline Std. Dev. & $\mathbf{0 . 0 1 9}$ & $\mathbf{0 . 0 1 6}$ & $\mathbf{1 . 7 3 2}$ & $\mathbf{0 . 0 2 0}$ & $\mathbf{0 . 0 0 3}$ & $\mathbf{0 . 7 8 7}$ \\
\hline CV\% & $\mathbf{5 . 5 5}$ & $\mathbf{1 . 3 8}$ & $\mathbf{0 . 2 8}$ & $\mathbf{0 . 4 1}$ & $\mathbf{4 . 2 5}$ & $\mathbf{5 . 1 4}$ \\
\hline
\end{tabular}

Table 4-7. Average emission results from a 1994 Navistar T-444E engine exercised through an FTP engine test with fuel injection provided by two different stock electronic controllers.

A final evaluation examines the $\mathrm{CO} / \mathrm{PM}$ relation with respect to environmental conditions. Figure 4-23 shows data, taken at various locations, from a 1985 Freightliner tandem-axle, line-haul tractor with a mechanically injected Caterpillar $350 \mathrm{hp}, 3406 \mathrm{~B}$ engine. This truck was tested in each case at $19,050 \mathrm{~kg}(42,000 \mathrm{lb}$.) of simulated gross vehicle weight using the WVU 5-Mile route. In this case $\mathrm{CO}$ and PM vary due to atmospheric conditions, changing quality of pump fuel, and possible changes in engine condition due to wear and/or maintenance which may have occurred over the course of the tests. Figure 4-23 underlines the importance of determining a $\mathrm{CO} / \mathrm{PM}$ ratio from a series of tests where engine, driving cycle, and fuel are maintained constant and changes in atmospheric conditions are kept at a minimum. 


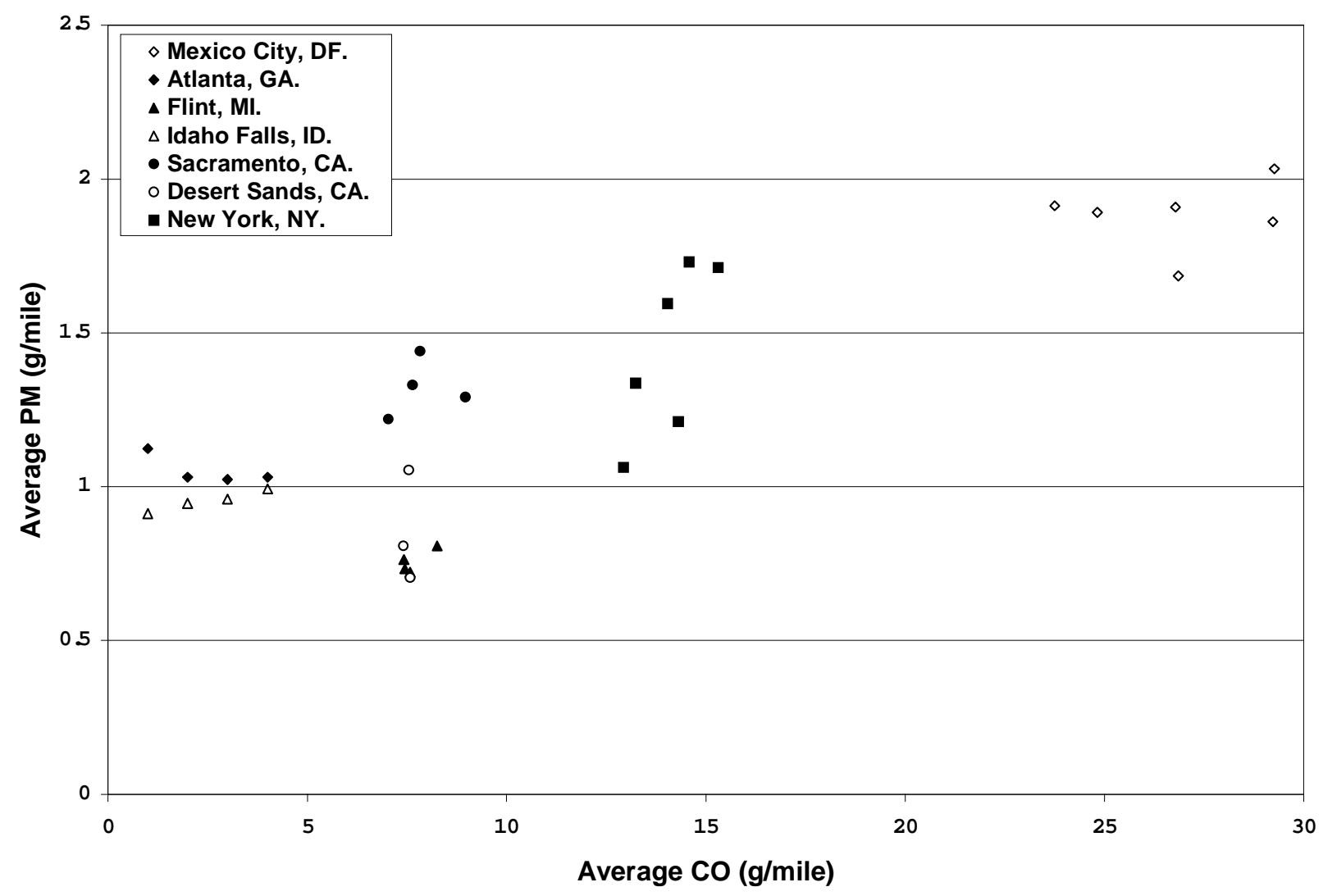

Figure 4-23. Emissions from a 1985 Freightliner tractor, with a Caterpillar 3406B engine tested exercised through the WVU 5-Mile Route at a test weight of $19,050 \mathrm{~kg}(42,000 \mathrm{lb}$.) at various locations. Altitude, atmospheric conditions, and fuel variations will influence emissions.

Data in Tables 4-5 through 4-7 and in Figures 4-21 through 4-23 clearly show that the $\mathrm{CO} / \mathrm{PM}$ ratio is a function of each specific engine, injection controller, environmental conditions, and possible load and driving conditions. But the data also show the CO/PM relation to be consistent for each engine operated within a specific load and driving condition using the same fuel within the same general environmental conditions. The wide range of average CO/PM ratios is too great to allow the inference of $\mathrm{PM}$ directly from $\mathrm{CO}$, but the consistency of average $\mathrm{CO} / \mathrm{PM}$ ratios for a single engine exercised through similar driving and loading conditions suggests that continuous CO may still offer itself for apportionment of filter-captured PM measured gravimetrically as proposed in Equation 2-1. 


\section{CHAPTER 5: CONCLUSIONS AND RECOMMENDATIONS}

\subsection{Conclusions}

Evaluation of the electromagnetic theory which governs the absorption and scattering of an electromagnetic wave by a particle cloud reveals a gray area in terms of quantifying the extinction effects. The absorptive index $(k)$ of the complex index of refraction $(m)$ is a parameter which quantifies the absorptive properties of a material and is found to be a function of particle shape, composition, and size, the three of which are known to vary during transient operating conditions of diesel engine. Thus the extinction effects of a diesel particle cloud will vary during the course of transient operation. Most of the particle size range from modern diesel engines is smaller than the wavelength of the light sourced used by commercial opacity meters, making optical detection less predictable.

Data were collected from two different opacity meters (Bosch RT 100 and Wager 650CP) during snap-acceleration test as prescribed by the SAE J1667 publication. Considerable differences in peak opacity readings were recorded, with the Bosch meter measuring values almost twice that of the Wager. Peak opacity values were generally between $2 \%$ and $12 \%$ and the percent difference between the two meters would probably be less for readings in the higher opacity ranges. Differences between sampling methods may explain in part the differences in opacity readings between the two meters, as well as differences in frequency of data acquisition. The exhaust gas sample drawn by the Bosch meter travels through a sample line for about $1 / 3$ of a second, where as the Wager takes a reading instantaneously. Other research has shown this time difference to be sufficient for measurable differences in particle count and size due to nucleation, adsorption, and condensation. The Bosch meter samples opacity data at a frequency of $100 \mathrm{~Hz}$ where as the Wager output was sampled at a frequency of $10 \mathrm{~Hz}$. Research has shown 
a small increase in opacity readings of a specific exhaust sample when the opacity meter sample rate was increased.

Continuous opacity data and filter-captured PM were collected during snap-acceleration tests and transient chassis dynamometer tests from the same vehicles. Results showed that the PM/opacity ratio was smaller for the snap-acceleration test than for the transient chassis dynamometer tests. This suggests that opacity readings taken during non-loaded snap-acceleration tests do not fully quantify PM emissions during loaded transient operation. In general, results showed a weak correlation between integrated opacity and filter-captured PM taken during transient chassis dynamometer tests. A fairly strong correlation was found between integrated opacity and filter-captured PM for a single vehicle exercised through a series of different transient tests and loaded at the same simulated inertial weight. The same vehicle was exercised through the same transient test at different inertial loads resulting in no correlation between opacity and PM. This suggests that the relation between opacity and PM is engine and loading specific at least and may include fuel and environmental conditions as well. Thus, any relation found between opacity and PM for a series of tests can not be inferred to other engines, even of the same model.

Early observations of continuous opacity and continuous $\mathrm{CO}$ concentrations data from transient tests found similarities between the two data. Further analysis found a mild to good correlation between respective peak magnitudes of opacity and CO data. Due to differences in sampling location a dispersion model was developed to apply to continuous opacity data before evaluating it with continuous $\mathrm{CO}$ data. Correlation between opacity and $\mathrm{CO}$ was found to be good for most tests evaluated for this research. This also encourages the use of continuous CO data to apportion total PM over a cycle. The dispersion model developed for opacity may be 
useful in comparing continuous engine or axial data such as torque and power with continuous emissions collected during transient tests.

Data taken using a variety of test schedules, vehicles, engines, and geographic locations have shown that there is generally no reliable or unique relationship between CO and PM integrated over the test cycle. However, data taken from a single bus exercised through five different cycles showed a strong relationship between CO and PM. This encourages the author to believe that continuous $\mathrm{CO}$ may serve as a tool for apportioning total PM over a cycle to predict instantaneous PM, thereby increasing the value of existing emissions data banks. This argument would encourage the development of neural network or modal models that can be used to predict PM for untried driving cycles. This approach will not hold true for alternative fuel engines, where $\mathrm{CO}$ and PM production mechanisms may be disparate.

In conclusion, it is evident that the relationships between $\mathrm{CO}$ and PM and between opacity and PM are tenuous. However, in the absence of detailed continuous PM data, the need to develop models for inventory prediction may require that integrated PM is apportioned over the length of a test cycle with respect to continuous opacity or continuous CO. 


\subsection{Recommendations}

Given that the relation between opacity and PM mass is weak at best, it is not recommended that opacity and snap-acceleration tests be used as a basis for PM regulation enforcement. However, it is acknowledged that opacity data from snap-acceleration is a convenient method for in-field identification of vehicles that may be high emitters of PM. Thus, it is recommended that opacity data from snap-acceleration tests be used to identify vehicles for more accurate PM testing. In addition, it is recommended that an opacity meter with a smaller wavelength be developed for more accurate detection of PM. The need for this will become more essential if average particle size continues to fall.

For future research at WVU, more testing is recommended to evaluate the dispersive effects of the exhaust transport system. This should be done for each of the laboratories at different tunnel flow rates to determine the relation between the modified dispersion model variables (VDN, $a$, and $b$ ) and tunnel flow rate. 


\section{REFERENCES}

1. Grumet, J.; Levin, R.; Marin, A., Ed. Heavy-Duty Engine Emissions in the Northeast; Northeast States for Coordinated Air Use Management: Washington, DC, 1997.

2. Diez-Sanchez, D., "The role of diesel exhaust particles and their associated polyaromatic hydrocarbons in the induction of allergic airway disease", Allergy. 1997, vol. 52, p 52-56.

3. Watson, J. G.; Fujita, E. M.; Chow, J. C.; Zielinska, B.; Richards, L. W.; Neff, W.; Dietrich, D., Northern Front Range Air Quality Study Final Report; Prepared for the Office of the Vice President for Research and Information Technology, Colorado State University: Fort Collins, CO, June 30, 1998.

4. Cass, G. R., Contribution of Vehicle Emissions to Ambient Carbonaceous Particulate Matter-A Review and Synthesis of the Available Data in the South Coast Air Basin; Prepared for Coordinating Research Council National Technical Information Service, U.S. Department of Commerce: Springfield, VA, February 1997.

5. Becker, R. F.; Ndiomu, P.; Hoskin, D. H., "Reduction in Particulate and Black Smoke in Diesel Exhaust Emissions”, SAE Technical Paper 972903, 1997.

6. Clark, N. N.; Gautam, M.; Lyons, D. W.; Bata, R. M.; Wang, W., "Natural Gas and Diesel Transit Bus Emissions: review and recent data”, SAE Technical Paper 973203, 1997.

7. Moore, T., The Efficacy of the New PM 2.5 Secondary NAAQS in Three Western Urban Areas, Conference on $\mathrm{PM}_{2.5}$ : A Fine Particle Standard, Long Beach, CA. 1998

8. U.S. Environmental Protection Agency. EPA's Revised Particulate Matter Standards, Office of Air and Radiation, Office of air Quality Planning and Standards, http://www.epa.com (accessed July 1997). 
9. Scheepers, P. T. J.; Bos, R. P., "Combustion of diesel fuel from a toxicological perspective", Occupational Environmental Health: 1989, vol. 64, p 163-177.

10. Bagley, S.T.; Baumfard, K. J.; Fratz, L. D.; Johnson, J.G.; Leddy, D. G., Characterization of Fuel and Aftertreatment Device Effects on Diesel Emissions; Research Report No. 76; Health Effects Institute: Cambridge, MA, September 1996.

11. Tsien, A.; Diaz-Sanchez, D.; Ma, J.; Saxon, A., "The Organic Component Of Diesel Exhaust Particles and Phenanthrene, a Major Polyaromatic Hydrocarbon Constituent, Enhances IgE Production By IgE-Secreting EBV-Transformed Human B Cells in Vitro", Toxicology and Applied Pharmacology, 1997, vol. 142, p 256-263.

12. Dockery, W. D.; Arden, C. P.; Xu, X.; Spengler, J. D.; Ware, J. H.; Fay, M. E.; Ferris, B. G.; Speizer, F. E., “An Association Between Air Pollution And Mortality In Six U.S. Cities"; The New England Journal of Medicine, Massachusetts Medical Society, Massachusetts, December 1993, vol. 329, no. 24, p 1753-59.

13. Delfino, R. J.; Murphy-Moulton, A. M.; Burnett, R. T.; Brook, J. R.; Becklake, M. R., "Effects of Air Pollution on Emergency Room Visits For Respiratory Illnesses in Montreal, Quebec", American Journal of Respiratory Critical Care Medicine, 1997, vol. 155, p 568576.

14. U.S. Environmental Protection Agency, "Guidance to States on Smoke Opacity Cutpoints To Be Used With the SAE J1667 In-Use Smoke Test Procedure" Office of Air and Radiation, Publication \# EPA420-F-99-024, February 25, 1999.

15. SAE "Surface Vehicle Recommended Practice”, SAE J1667, 1996.

16. Robert H. Wager Co. Inc. website, State (Province) Regulations, http://www.wagerusa.com/regulations.html (accessed May 2000). 
17. Code of Federal Regulations: Protection of Environment, Office of the Federal Register, National Archives and Records; U.S. Government Printing Office: Washington, DC, 1996; 40 CFR 86.1, Subpart N.

18. Clark, N.N.; Gautam, M.; Bata, R..M.; Loth, J.L.; Palmer, G.M.; Wang, W.G.; Lyons, D.W., "Design and Operation of a New Transportable Laboratory For Emissions Testing of Heavy Duty Trucks and Buses" Int. J. Vehicle Design (Heavy Vehicle Sys.) 1995, 2 (3/4), p 285299.

19. Atkinson, C. M.; Long, T. M.; Hanzevack, E.L., "Virtual Sensing: A Neural Network-Based Intelligent Performance and Emissions Prediction System for On-Board Diagnostics and Engine Control”, SAE Technical Paper 980516, 1998.

20. Kittelson, D.B.; Johnson, J. H., "Variability in Particulate Emission Measurements in the Heavy Duty Transient Test”, SAE Technical Paper 910738, 1991.

21. Schaberg, P.W.; Nyburgh, I.S.; Botha, J.J.; Roets, P.N.; Viljoen, C.L.; Dancuart, L.P.; Starr, M.E., "Diesel Exhaust Emissions Using Sasol Slurry Phase Distillate Process Fuels" SAE Technical Paper No. 972898, 1997.

22. Ariga, S.; Sui, P.C.; Shahed, S.M., "Instantaneous Unburned Oil Consumption Measurement in a Diesel Engine Using $\mathrm{SO}_{2}$ Tracer Technique" SAE Technical Paper No. 922196, 1992.

23. Gerke, D. H., "Real-Time Measurement of Diesel Particulate Emissions with a Light Extinction Opacity Meter", SAE Technical Paper 830183, 1983.

24. Roessler, D. M., "Opacity and Photoacoustic Measurements of Diesel Particle Mass Emissions", SAE Technical Paper 820460, 1982.

25. Arcoumanis, C.; Megaritis, A., "Real-Time Measurement of Particulate Emissions in a Turbocharged DI Diesel Engine”, SAE Technical Paper 922390, 1992. 
26. Saito, K., "Development of Diesel Opacimeter for Real-Time Measurement of Low Concentration Smoke”, SAE Technical Paper 881319, 1988.

27. Levenspiel, O., Chemical Reaction Engineering, $2^{\text {nd }}$ ed.; Wiley J. and Sons; New York, 1972, p 253-308.

28. Modest, M. F., Radiative Heat Transfer; McGraw Hill, Inc.; New Jersey, 1993, p 385-400.

29. Rickeard, D. J.; Bateman, J. R.; Kwon, Y. K., "Exhaust Particulate Size Distribution: Vehicle and Fuel Influences in Light Duty Vehicles”, SAE Technical Paper 96198, 1996.

30. Dalzell, W. H.; Sarofim, A. F., "Optical Constants of Soot and Their Application to Heat-Flux Calculations", ASME Journal of Heat Transfer, 1969, vol. 91, no. 1, p 100-104.

31. Hunt, A.J.; Quinby-Hunt, M.S.; and Shepherd, I.G., "Diesel Exhaust Particle Characterization by Polarized Light Scattering”, SAE Technical Paper 982629, 1998.

32. Van de Hulst, H. C., "Light Scattering by Small Particles", John Wiley \& Sons, Inc. New York, 1957.

33. Abramowitz, M. and Stegun, I. A., "Handbook of Mathematic Functions", Applied Mathematics Series 55, U.S. Department of Commerce, National Bureau of Standards, March 1965.

34. Wiscombe, W. J., "Improved Mie Scattering Algorithms”, Applied Optics, 1980, vol. 19, p 1505-1509.

35. Abdul-Khalek, S. I. and Kittelson, D. B., "Diesel Trap Performance: Particle Size Measurements and Trends” SAE Technical Paper 982599, 1998.

36. Jones, B. L.; Stollery, J. D.; Clifton, M. J.; and Wylie, T. F., "In-Service Smoke and Particulate Measurements", SAE Technical Paper 970748, 1997. 
37. Byrd, R. L., 1996, "Measurement of Smoke Opacity and Particulate Matter from Heavy Duty In-Use Diesel Powered Vehicles", M.S. Thesis, Dept. of Mech. and Aero. Eng., West Virginia University, Morgantown, WV.

38. Clark, N. N.; Messer, J. T.; McKain, D. L.; Wang, W.; Bata, R. M.; Gautam, M.; Lyons, D. W., "Use of the West Virginia University Truck Test Cycle to Evaluate Emissions from Class 8 Trucks", SAE Technical Paper 951016, 1995.

39. Messer, J. T.; Clark, N. N.; Lyons D. W., "Measurement Delays and Modal Analysis for a Heavy Duty Transportable Emissions Testing Laboratory", SAE Technical Paper 951016, 1995. 
APPENDIX A

VEHICLE SPECIFICATIONS AND TEST RESULTS FOR VEHICLES

TESTED BY THE WEST VIRGINIA UNIVERSITY TRANSPORTABLE HEAVY DUTY VEHICLE EMISSION TESTING LABORATORY 
Test Sequence Number: 0918

WVU Test Reference Number: MTA-1133-D2

Fleet Owner Full Name

Fleet Address

Fleet Address (City, State, Zip)

Vehicle Type

Vehicle ID Number (VIN)

Vehicle Manufacturer

Vehicle Model Year

Gross Vehicle Weight (GVW) (lb.)

Vehicle Total Curb Weight (lb.)

Vehicle Tested Weight (lb.)

Odometer Reading (mile)

Transmission Type

Transmission Configuration

Number of Axles

Engine Type

Engine ID Number

Engine Displacement (Liter)

Number of Cylinders

Engine Rated Power (hp)

Primary Fuel

Test Cycle

Test Date

Engineer

Driver
Flint Mass Transit Authority

1401 South Dort Highway

Flint, MI 48503

Transit Bus

2FYD2LL19TUO16259

New Flyer

1996

37920

27500

32825

27500

Automatic

5-Speed

2

Detroit Diesel Corp. Series 50

04R0013102

8.5

4

275

D2

CBD

5/28/97

J. Kopasko

S. McConnell

Emissions Results (g/mile)

\begin{tabular}{|c|c|c|c|c|c||c|c|c|}
\hline Run Seq. No. & $\mathrm{CO}$ & $\mathrm{NO}_{\mathrm{x}}$ & $\mathrm{FIDHC}$ & $\mathrm{PM}$ & $\mathrm{CO}_{2}$ & mile/gal & $\mathrm{BTU} / \mathrm{mile}$ & Miles \\
\hline $918-1$ & 4.1 & 32.4 & 0.08 & 0.37 & 2723 & 3.73 & 34874 & 2.02 \\
\hline $918-2$ & 4.3 & 31.8 & 0.04 & 0.37 & 2744 & 3.70 & 35144 & 2.00 \\
\hline $918-3$ & 4.7 & 29.4 & 0.04 & 0.40 & 2694 & 3.77 & 34508 & 2.02 \\
\hline $918-4$ & 4.3 & 27.6 & 0.06 & 0.42 & 2811 & 3.61 & 36001 & 2.00 \\
\hline $918-5$ & 3.9 & 27.9 & 0.08 & 0.39 & 2802 & 3.62 & 35879 & 2.02 \\
\hline $918-6$ & 5.0 & 27.3 & 0.08 & 0.42 & 2733 & 3.71 & 35024 & 2.02 \\
\hline & & & & & & & & \\
\hline 918 Average & 4.4 & 29.4 & 0.06 & 0.40 & 2751 & 3.69 & 35238 & 2.01 \\
\hline Std. Dev. & 0.4 & 2.2 & 0.02 & 0.02 & 46 & 0.06 & 585 & 0.01 \\
\hline CV\% & 9.0 & 7.5 & $\mathrm{~d}$ & 5.8 & 1.7 & 1.7 & 1.7 & 0.4 \\
\hline
\end{tabular}

Test Purpose:

Collection of emissions data from diesel powered buses for use in comparison with similar, CNG powered buses in Atlanta, GA.

\section{Special Procedures:}

Exhaust pipe was changed for continuous smoke testing using a Wager opacity meter. This was done for graduate research performed by Ron Jarrett. 
Test Sequence Number: 0919

WVU Test Reference Number: MTA-1134-D2

Fleet Owner Full Name

Fleet Address

Fleet Address (City, State, Zip)

Vehicle Type

Vehicle ID Number (VIN)

Vehicle Manufacturer

Vehicle Model Year

Gross Vehicle Weight (GVW) (lb.)

Vehicle Total Curb Weight (lb.)

Vehicle Tested Weight (lb.)

Odometer Reading (mile)

Transmission Type

Transmission Configuration

Number of Axles

Engine Type

Engine ID Number

Engine Displacement (Liter)

Number of Cylinders

Engine Rated Power (hp)

Primary Fuel

Test Cycle

Test Date

Engineer

Driver
Flint Mass Transit Authority

1401 South Dort Highway

Flint, MI 48503

Transit Bus

2FYD2LL15TUO16260

New Flyer

1996

37920

27500

32825

34300

Automatic

5-Speed

2

Detroit Diesel Corp. Series 50

04R0013337

8.5

4

275

D2

CBD

5/30/97

J. Kopasko

S. McConnell

Emissions Results (g/mile)

\begin{tabular}{|c|c|c|c|c|c||c|c|c|}
\hline Run Seq. No. & $\mathrm{CO}$ & $\mathrm{NO}_{\mathrm{x}}$ & $\mathrm{FIDHC}$ & $\mathrm{PM}$ & $\mathrm{CO}_{2}$ & mile/gal & $\mathrm{BTU} / \mathrm{mile}$ & Miles \\
\hline $919-1$ & 4.3 & 30.9 & 0.16 & 0.27 & 2686 & 3.78 & 34407 & 2.00 \\
\hline $919-2$ & 5.5 & 33.2 & 0.13 & 0.28 & 2624 & 3.86 & 33643 & 2.01 \\
\hline $919-3$ & 4.2 & 27.6 & 0.14 & 0.31 & 2608 & 3.89 & 33406 & 2.01 \\
\hline $919-4$ & 4.4 & 30.8 & 0.12 & 0.29 & 2690 & 3.77 & 34459 & 2.01 \\
\hline $919-5$ & 4.1 & 34.7 & 0.14 & 0.25 & 2654 & 3.82 & 33990 & 2.03 \\
\hline $919-6$ & 4.4 & 30.6 & 0.13 & 0.32 & 2698 & 3.76 & 34564 & 2.03 \\
\hline & & & & & & & & \\
\hline 919 Average & 4.5 & 31.3 & 0.14 & 0.29 & 2660 & 3.82 & 34078 & 2.02 \\
\hline Std. Dev. & 0.5 & 2.4 & 0.01 & 0.03 & 38 & 0.05 & 477 & 0.01 \\
\hline CV\% & 11.5 & 7.8 & 8.6 & 9.5 & 1.4 & 1.4 & 1.4 & 0.6 \\
\hline
\end{tabular}

Test Purpose:

Collection of emissions data from diesel powered buses for use in comparison with similar, CNG powered buses in Atlanta, GA.

\section{Special Procedures:}

Zero-air dropped low between test \#1 and \#2, causing an FIDHC analyzer flame out. The analyzer could not get relit in time, so a warm-up test was run. 
Test Sequence Number: 0920

WVU Test Reference Number: MTA-1135-D2

Fleet Owner Full Name

Fleet Address

Fleet Address (City, State, Zip)

Vehicle Type

Vehicle ID Number (VIN)

Vehicle Manufacturer

Vehicle Model Year

Gross Vehicle Weight (GVW) (lb.)

Vehicle Total Curb Weight (lb.)

Vehicle Tested Weight (lb.)

Odometer Reading (mile)

Transmission Type

Transmission Configuration

Number of Axles

Engine Type

Engine ID Number

Engine Displacement (Liter)

Number of Cylinders

Engine Rated Power (hp)

Primary Fuel

Test Cycle

Test Date

Engineer

Driver
Flint Mass Transit Authority

1401 South Dort Highway

Flint, MI 48503

Transit Bus

2FYD2LL17TUO16261

New Flyer

1996

37920

27500

32825

40900

Automatic

5-Speed

2

Detroit Diesel Corp. Series 50

04R0013097

8.5

4

275

D2

CBD

6/2/97

J. Kopasko

S. McConnell

Emissions Results (g/mile)

\begin{tabular}{|c|c|c|c|c|c||c|c|c|}
\hline Run Seq. No. & $\mathrm{CO}$ & $\mathrm{NO}_{\mathrm{x}}$ & FIDHC & $\mathrm{PM}$ & $\mathrm{CO}_{2}$ & mile/gal & $\mathrm{BTU} / \mathrm{mile}$ & Miles \\
\hline $920-1$ & 4.8 & 32.5 & 0.09 & 0.23 & 2434 & 4.17 & 31200 & 2.03 \\
\hline $920-3$ & $\mathrm{a}$ & 33.3 & 0.13 & 0.24 & 2496 & 4.06 & 32018 & 2.02 \\
\hline $920-4$ & 4.5 & 32.5 & 0.15 & 0.20 & 2906 & 3.49 & 37219 & 2.04 \\
\hline $920-5$ & 4.1 & 30.8 & 0.16 & 0.21 & 2612 & 3.89 & 33462 & 2.03 \\
\hline $920-6$ & 4.7 & 32.2 & 0.15 & 0.21 & 2513 & 4.04 & 32202 & 2.02 \\
\hline & & & & & & & & \\
\hline 920 Average & 4.51 & 32.2 & 0.14 & 0.22 & 2592 & 3.93 & 33220 & 2.03 \\
\hline Std. Dev. & 0.31 & 0.9 & 0.03 & 0.01 & 187 & 0.26 & 2378 & 0.01 \\
\hline CV\% & 6.9 & 2.8 & 20.0 & 6.8 & 7.2 & 6.7 & 7.2 & 0.4 \\
\hline
\end{tabular}

Test Purpose:

Collection of emissions data from diesel powered buses for use in comparison with similar, CNG powered buses in Atlanta, GA.

\section{Special Procedures:}

A slight rain began during testing, requiring a tarpaulin to be placed over the dilution tunnel.

\section{Observations:}

Antifreeze fluid was found leaking before and during the test. The transit agency was notified, however the engine remained within operational temperature range during the entire test. 
Test Sequence Number: 0921

WVU Test Reference Number: MTA-1135-D2

Fleet Owner Full Name

Fleet Address

Fleet Address (City, State, Zip)

Vehicle Type

Vehicle ID Number (VIN)

Vehicle Manufacturer

Vehicle Model Year

Gross Vehicle Weight (GVW) (lb.)

Vehicle Total Curb Weight (lb.)

Vehicle Tested Weight (lb.)

Odometer Reading (mile)

Transmission Type

Transmission Configuration

Number of Axles

Engine Type

Engine ID Number

Engine Displacement (Liter)

Number of Cylinders

Engine Rated Power (hp)

Primary Fuel

Test Cycle

Test Date

Engineer

Driver
Flint Mass Transit Authority

1401 South Dort Highway

Flint, MI 48503

Transit Bus

2FYD2LL17TUO16261

New Flyer

1996

37920

27500

27650

40900

Automatic

5-Speed

2

Detroit Diesel Corp. Series 50

04R0013097

8.5

4

275

D2

CBD

$6 / 2 / 97$

J. Kopasko

S. McConnell

Emissions Results (g/mile)

\begin{tabular}{|c|c|c|c|c|c||c|c|c|}
\hline Run Seq. No. & $\mathrm{CO}$ & $\mathrm{NO}_{\mathrm{x}}$ & $\mathrm{FIDHC}$ & $\mathrm{PM}$ & $\mathrm{CO}_{2}$ & mile/gal & BTU/mile & Miles \\
\hline $921-1$ & 4.6 & 28.2 & 0.13 & 0.21 & 2244 & 4.52 & 28760 & 2.01 \\
\hline $921-2$ & 4.5 & 29.2 & 0.15 & 0.20 & 2288 & 4.43 & 29322 & 2.02 \\
\hline & & & & & & & & \\
\hline 921 Average & 4.6 & 28.7 & 0.14 & 0.21 & 2266 & 4.48 & 29041 & 2.01 \\
\hline Std. Dev. & 0.0 & 0.8 & 0.01 & 0.01 & 31 & 0.06 & 397 & 0.00 \\
\hline CV\% & 0.2 & 2.6 & 9.7 & 3.5 & 1.4 & 1.4 & 1.4 & 0.2 \\
\hline
\end{tabular}

\section{Test Purpose:}

Collection of emissions data from diesel powered buses under different conditions and using different cycles for use in cycle development. This test will not be reported.

\section{Special Procedures:}

The test weight was set to the curb weight plus $150 \mathrm{lbs}$.

\section{Observations:}

Driver noted that it was hard to hold vehicle at steady state due to the fact that there was a small-simulated load, causing the accelerator to respond more quickly. 
Test Sequence Number: 0922

WVU Test Reference Number: MTA-1135-D2-FW

Fleet Owner Full Name

Fleet Address

Fleet Address (City, State, Zip)

Vehicle Type

Vehicle ID Number (VIN)

Vehicle Manufacturer

Vehicle Model Year

Gross Vehicle Weight (GVW) (lb.)

Vehicle Total Curb Weight (lb.)

Vehicle Tested Weight (lb.)

Odometer Reading (mile)

Transmission Type

Transmission Configuration

Number of Axles

Engine Type

Engine ID Number

Engine Displacement (Liter)

Number of Cylinders

Engine Rated Power (hp)

Primary Fuel

Test Cycle

Test Date

Engineer

Driver
Flint Mass Transit Authority

1401 South Dort Highway

Flint, MI 48503

Transit Bus

2FYD2LL17TUO16261

New Flyer

1996

37920

27500

38000

40900

Automatic

5-Speed

2

Detroit Diesel Corp. Series 50

04R0013097

8.5

4

275

D2

CBD

6/2/97

J. Kopasko

S. McConnell

Emissions Results (g/mile)

\begin{tabular}{|c|c|c|c|c|c||c|c|c|}
\hline Run Seq. No. & $\mathrm{CO}$ & $\mathrm{NO}_{\mathrm{x}}$ & FIDHC & $\mathrm{PM}$ & $\mathrm{CO}_{2}$ & mile/gal & $\mathrm{BTU} / \mathrm{mile}$ & Miles \\
\hline $922-1$ & 7.3 & 30.0 & 0.15 & 0.38 & 2698 & 3.75 & 34621 & 2.03 \\
\hline $922-2$ & 6.8 & 30.0 & 0.15 & 0.34 & 2720 & 3.73 & 34889 & 2.01 \\
\hline $922-3$ & $\mathrm{c}$ & 29.8 & 0.13 & 0.32 & 2614 & 3.89 & 33392 & 2.03 \\
\hline $922-4$ & 6.6 & 32.8 & 0.12 & 0.30 & 2695 & 3.76 & 34572 & 2.01 \\
\hline & & & & & & & & \\
\hline 922 Average & 6.9 & 30.7 & 0.14 & 0.34 & 2682 & 3.78 & 34368 & 2.02 \\
\hline Std. Dev. & 0.3 & 1.5 & 0.02 & 0.03 & 46 & 0.07 & 665 & 0.01 \\
\hline CV\% & 5.0 & 4.7 & 11.1 & 10.0 & 1.7 & 2.0 & 1.9 & 0.6 \\
\hline
\end{tabular}

Test Purpose:

Collection of emissions data from diesel powered buses under different conditions and using different cycles for use in cycle development. This test will not be reported.

\section{Special Procedures:}

The test weight was set to the $100 \% \mathrm{GVW}$. 
Test Sequence Number: 0923

WVU Test Reference Number: MTA-1135-D2-5P

Fleet Owner Full Name

Fleet Address

Fleet Address (City, State, Zip)

Vehicle Type

Vehicle ID Number (VIN)

Vehicle Manufacturer

Vehicle Model Year

Gross Vehicle Weight (GVW) (lb.)

Vehicle Total Curb Weight (lb.)

Vehicle Tested Weight (lb.)

Odometer Reading (mile)

Transmission Type

Transmission Configuration

Number of Axles

Engine Type

Engine ID Number

Engine Displacement (Liter)

Number of Cylinders

Engine Rated Power (hp)

Primary Fuel

Test Cycle

Test Date

Engineer

Driver
Flint Mass Transit Authority

1401 South Dort Highway

Flint, MI 48503

Transit Bus

2FYD2LL17TUO16261

New Flyer

1996

37920

27500

32825

40900

Automatic

5-Speed

2

Detroit Diesel Corp. Series 50

04R0013097

8.5

4

275

D2

WVU-Trk

$6 / 3 / 97$

J. Kopasko

S. McConnell

Emissions Results (g/mile)

Emissions Results (g/mile)
\begin{tabular}{|c|c|c|c|c|c||c|c|c|}
\hline Run Seq. No. & $\mathrm{CO}$ & $\mathrm{NO}_{\mathrm{x}}$ & $\mathrm{FIDHC}$ & $\mathrm{PM}$ & $\mathrm{CO}_{2}$ & mile/gal & BTU/mile & Miles \\
\hline $923-1$ & 1.3 & 29.3 & 0.06 & 0.08 & 1308 & 7.77 & 16733 & 5.00 \\
\hline $923-2$ & 1.3 & 27.8 & 0.08 & 0.08 & 1248 & 8.14 & 15972 & 4.99 \\
\hline & & & & & & & & \\
\hline 923 Average & 1.3 & 28.6 & 0.07 & 0.08 & 1278 & 7.95 & 16353 & 5.00 \\
\hline Std. Dev. & 0.0 & 1.1 & 0.01 & 0.00 & 42 & 0.26 & 538 & 0.00 \\
\hline CV\% & 2.8 & 3.7 & 22.1 & 2.4 & 3.3 & 3.3 & 3.3 & 0.1 \\
\hline
\end{tabular}

\section{Test Purpose:}

Collection of emissions data from diesel powered buses under different conditions and using different cycles for use in cycle development. This test will not be reported.

\section{Special Procedures:}

The vehicle was tested using a WVU 5-Peak cycle. 
Test Sequence Number: 0924

WVU Test Reference Number: MTA-1135-D2-5MILES

Fleet Owner Full Name

Fleet Address

Fleet Address (City, State, Zip)

Vehicle Type

Vehicle ID Number (VIN)

Vehicle Manufacturer

Vehicle Model Year

Gross Vehicle Weight (GVW) (lb.)

Vehicle Total Curb Weight (lb.)

Vehicle Tested Weight (lb.)

Odometer Reading (mile)

Transmission Type

Transmission Configuration

Number of Axles

Engine Type

Engine ID Number

Engine Displacement (Liter)

Number of Cylinders

Engine Rated Power (hp)

Primary Fuel

Test Cycle

Test Date

Engineer

Driver
Flint Mass Transit Authority

1401 South Dort Highway

Flint, MI 48503

Transit Bus

2FYD2LL17TUO16261

New Flyer

1996

37920

27500

32825

40900

Automatic

5-Speed

2

Detroit Diesel Corp. Series 50

04R0013097

8.5

4

275

D2

5 Mile Route

6/3/97

J. Kopasko

S. McConnell

Emissions Results (g/mile)

\begin{tabular}{|c|c|c|c|c|c||c|c|c|}
\hline Run Seq. No. & $\mathrm{CO}$ & $\mathrm{NO}_{\mathrm{x}}$ & FIDHC & $\mathrm{PM}$ & $\mathrm{CO}_{2}$ & mile/gal & $\mathrm{BTU} / \mathrm{mile}$ & Miles \\
\hline $924-1$ & 2.5 & 25.0 & 0.04 & 0.19 & 1332 & 7.62 & 17069 & 5.01 \\
\hline $924-2$ & 2.6 & 24.4 & 0.07 & 0.16 & 1311 & 7.73 & 16807 & 5.01 \\
\hline & & & & & & & & \\
\hline 924 Average & 2.5 & 24.7 & 0.06 & 0.17 & 1322 & 7.68 & 16938 & 5.01 \\
\hline Std. Dev. & 0.1 & 0.4 & 0.02 & 0.03 & 15 & 0.08 & 185 & 0.00 \\
\hline CV\% & 2.2 & 1.7 & 30.3 & 14.3 & 1.1 & 1.1 & 1.1 & 0.0 \\
\hline
\end{tabular}

\section{Test Purpose:}

Collection of emissions data from diesel powered buses under different conditions and using different cycles for use in cycle development. This test will not be reported.

\section{Special Procedures:}

The vehicle was tested using a WVU 5-Mile route. 
Test Sequence Number: 0925

WVU Test Reference Number: MTA-1135-D2-NYBUS

Fleet Owner Full Name

Fleet Address

Fleet Address (City, State, Zip)

Vehicle Type

Vehicle ID Number (VIN)

Vehicle Manufacturer

Vehicle Model Year

Gross Vehicle Weight (GVW) (lb.)

Vehicle Total Curb Weight (lb.)

Vehicle Tested Weight (lb.)

Odometer Reading (mile)

Transmission Type

Transmission Configuration

Number of Axles

Engine Type

Engine ID Number

Engine Displacement (Liter)

Number of Cylinders

Engine Rated Power (hp)

Primary Fuel

Test Cycle

Test Date

Engineer

Driver
Flint Mass Transit Authority

1401 South Dort Highway

Flint, MI 48503

Transit Bus

2FYD2LL17TUO16261

New Flyer

1996

37920

27500

32825

40900

Automatic

5-Speed

2

Detroit Diesel Corp. Series 50

04R0013097

8.5

4

275

D2

NY-Bus

6/3/97

J. Kopasko

S. McConnell

Emissions Results (g/mile)

Emissions Results (g/mile)
\begin{tabular}{|c|c|c|c|c|c|c|c|c|}
\hline Run Seq. No. & $\mathrm{CO}$ & $\mathrm{NO}_{\mathrm{x}}$ & FIDHC & $\mathrm{PM}$ & $\mathrm{CO}_{2}$ & mile/gal & $\mathrm{BTU} / \mathrm{mile}$ & Miles \\
\hline $925-1$ & 46.4 & 66.0 & 0.58 & 1.54 & 5202 & 1.93 & 67407 & 0.63 \\
\hline $925-2$ & 39.8 & 70.2 & 0.68 & 1.04 & 5196 & 1.93 & 67206 & 0.62 \\
\hline $925-4$ & 46.8 & 73.8 & 0.55 & 1.42 & 5740 & 1.75 & 74297 & 0.63 \\
\hline & & & & & & & & \\
\hline 925 Average & 44.3 & 70.0 & 0.61 & 1.33 & 5379 & 1.87 & 69636 & 0.63 \\
\hline Std. Dev. & 3.9 & 3.9 & 0.07 & 0.26 & 313 & 0.10 & 4037 & 0.00 \\
\hline CV\% & 8.8 & 5.6 & 11.7 & 19.7 & 5.8 & 5.6 & 5.8 & 0.7 \\
\hline
\end{tabular}

Test Purpose:

Collection of emissions data from diesel powered buses under different conditions and using different cycles for use in cycle development. This test will not be reported.

\section{Special Procedures:}

The vehicle was tested using a New York Bus cycle.

\section{Observations:}

Vehicle could not keep up with scheduled acceleration ramp. 
Test Sequence Number: 0926

WVU Test Reference Number: MTA-1135-D2-D

Fleet Owner Full Name

Fleet Address

Fleet Address (City, State, Zip)

Vehicle Type

Vehicle ID Number (VIN)

Vehicle Manufacturer

Vehicle Model Year

Gross Vehicle Weight (GVW) (lb.)

Vehicle Total Curb Weight (lb.)

Vehicle Tested Weight (lb.)

Odometer Reading (mile)

Transmission Type

Transmission Configuration

Number of Axles

Engine Type

Engine ID Number

Engine Displacement (Liter)

Number of Cylinders

Engine Rated Power (hp)

Primary Fuel

Test Cycle

Test Date

Engineer

Driver
Flint Mass Transit Authority

1401 South Dort Highway

Flint, MI 48503

Transit Bus

2FYD2LL17TUO16261

New Flyer

1996

37920

27500

32825

40900

Automatic

5-Speed

2

Detroit Diesel Corp. Series 50

04R0013097

8.5

4

275

D2

Test-D

6/4/97

J. Kopasko

S. McConnell

Emissions Results (g/mile)

\begin{tabular}{|c|c|c|c|c|c||c|c|c|}
\hline Run Seq. No. & $\mathrm{CO}$ & $\mathrm{NO}_{\mathrm{x}}$ & $\mathrm{FIDHC}$ & $\mathrm{PM}$ & $\mathrm{CO}_{2}$ & mile/gal & BTU/mile & Miles \\
\hline $926-1$ & 5.4 & 28.1 & 0.03 & 0.38 & 1826 & 5.55 & 23439 & 5.56 \\
\hline $926-2$ & 7.1 & 25.5 & 0.09 & 0.36 & 1664 & 6.07 & 21402 & 5.52 \\
\hline & & & & & & & & \\
\hline 926 Average & 6.2 & 26.8 & 0.06 & 0.37 & 1745 & 5.81 & 22420 & 5.54 \\
\hline Std. Dev. & 1.2 & 1.9 & 0.04 & 0.02 & 115 & 0.37 & 1440 & 0.03 \\
\hline CV\% & 19.6 & 7.0 & 64.8 & 4.6 & 6.6 & 6.4 & 6.4 & 0.5 \\
\hline
\end{tabular}

\section{Test Purpose:}

Collection of emissions data from diesel powered buses under different conditions and using different cycles for use in cycle development. This test will not be reported.

\section{Special Procedures:}

The vehicle was tested using Test-D cycle. 
Test Sequence Number: 0927

WVU Test Reference Number: MTA-1136-D2

Fleet Owner Full Name

Fleet Address

Fleet Address (City, State, Zip)

Vehicle Type

Vehicle ID Number (VIN)

Vehicle Manufacturer

Vehicle Model Year

Gross Vehicle Weight (GVW) (lb.)

Vehicle Total Curb Weight (lb.)

Vehicle Tested Weight (lb.)

Odometer Reading (mile)

Transmission Type

Transmission Configuration

Number of Axles

Engine Type

Engine ID Number

Engine Displacement (Liter)

Number of Cylinders

Engine Rated Power (hp)

Primary Fuel

Test Cycle

Test Date

Engineer

Driver
Flint Mass Transit Authority

1401 South Dort Highway

Flint, MI 48503

Transit Bus

2FYD2LL19TUO16262

New Flyer

1996

37920

27500

32825

40000

Automatic

5-Speed

2

Detroit Diesel Corp. Series 50

04R0013378

8.5

4

275

D2

CBD

$6 / 5 / 97$

J. Kopasko

S. McConnell

Emissions Results (g/mile)

\begin{tabular}{|c|c|c|c|c|c||c|c|c|}
\hline Run Seq. No. & $\mathrm{CO}$ & $\mathrm{NO}_{\mathrm{x}}$ & $\mathrm{FIDHC}$ & $\mathrm{PM}$ & $\mathrm{CO}_{2}$ & mile/gal & BTU/mile & Miles \\
\hline $927-1$ & 5.34 & 28.3 & 0.07 & 0.26 & 2485 & 4.08 & 31861 & 2.01 \\
\hline $927-2$ & 5.28 & 29.3 & 0.10 & 0.23 & 2420 & 4.19 & 31020 & 2.03 \\
\hline $927-4$ & 5.02 & 30.0 & 0.11 & 0.25 & 2393 & 4.24 & 30677 & 2.01 \\
\hline $927-6$ & 5.46 & 26.4 & 0.13 & 0.27 & 2425 & 4.18 & 31094 & 2.01 \\
\hline & & & & & & & & \\
\hline 927 Average & 5.27 & 28.5 & 0.10 & 0.25 & 2431 & 4.17 & 31163 & 2.01 \\
\hline Std. Dev. & 0.19 & 1.6 & 0.02 & 0.02 & 39 & 0.07 & 499 & 0.01 \\
\hline CV\% & 3.6 & 5.5 & 20.6 & 7.4 & 1.6 & 1.6 & 1.6 & 0.4 \\
\hline
\end{tabular}

Test Purpose:

Collection of emissions data from diesel powered buses for use in comparison with similar, CNG powered buses in Atlanta, GA. 
Test Sequence Number: 0961

WVU Test Reference Number: RDC-1579-D2-5MILES

Fleet Owner Full Name

Fleet Address

Fleet Address (City, State, and Zip Code)

Vehicle Type

Vehicle ID Number (VIN)

Vehicle Manufacturer

Vehicle Model Year

Gross Vehicle Weight (GVW)(lb.)

Vehicle Total Curb Weight (lb.)

Vehicle Tested Weight (lb.)

Odometer Reading (mile)

Vehicle Transmission Type

Vehicle Transmission Configuration

Number of Axles

Engine Type

Engine ID Number

Engine Displacement (liter)

Number of Cylinders

Engine Rated Power (hp)

Primary Fuel

Test Cycle

Test Date

Engineer

Driver

Data Verifier
Raley's Distribution Center

4061 Gateway Park Blvd.

Sacramento, CA 95834

Tractor Truck

1XKBD99X0SS643610

Kenworth

1994

80000

15100

42000

233500

Manual

10-Speed

3

Cummins M11-330E

34735917

10.8

6

330

D2

5Miles

07/18/1997

S. McConnell

L. McGrath

Emissions Results (g/mile)

\begin{tabular}{|c|c|c|c|c|c||c|c|c|}
\hline Run Seq. No. & $\mathrm{CO}$ & $\mathrm{NO}_{\mathrm{x}}$ & $\mathrm{FIDHC}$ & $\mathrm{PM}$ & $\mathrm{CO}_{2}$ & mile/gal & $\mathrm{BTU} / \mathrm{mile}$ & Miles \\
\hline $961-2$ & 2.35 & 26.5 & 1.41 & 0.42 & 1739 & 5.83 & 22316 & 4.00 \\
\hline $961-3$ & 2.28 & 25.9 & 1.33 & 0.44 & 1609 & 6.29 & 20654 & 4.12 \\
\hline $961-4$ & 2.22 & 27.9 & 1.38 & 0.42 & 1587 & 6.38 & 20371 & 4.04 \\
\hline $961-5$ & 2.41 & 24.2 & 1.42 & 0.47 & 1670 & 6.06 & 21436 & 4.05 \\
\hline $961-6$ & 2.65 & 30.2 & 1.43 & 0.49 & 1689 & 5.99 & 21685 & 3.96 \\
\hline $961-7$ & 1.81 & 30.2 & 1.37 & 0.51 & 1523 & 6.65 & 19552 & 3.95 \\
\hline & & & & & & & & \\
\hline 961 Average & 2.29 & 27.5 & 1.39 & 0.46 & 1636 & 6.20 & 21002 & 4.02 \\
\hline Std. Dev. & 0.28 & 2.4 & 0.04 & 0.04 & 78 & 0.30 & 1000 & 0.06 \\
\hline CV\% & 12.1 & 8.8 & 2.6 & 8.2 & 4.8 & 4.8 & 4.8 & 1.5 \\
\hline
\end{tabular}

\section{Test Purpose}

Collection of emissions data from diesel fueled vehicles to establish a data set for use in comparison with LNG emissions.

\section{Special Procedures}

Flywheel driver was found misaligned and broken. It was replaced with a new one and the system loss was recalibrated before this test.

\section{Observations}

The road speed governor was keeping the driver from shifting gears. Driver accelerated more slowly than normal to prevent shifting problem and could not finish five miles during the test cycle. Test was invalid. 
Test Sequence Number: 0962

WVU Test Reference Number: RDC-1586-D2-5MILES-R

Fleet Owner Full Name

Fleet Address

Fleet Address (City, State, and Zip Code)

Vehicle Type

Vehicle ID Number (VIN)

Vehicle Manufacturer

Vehicle Model Year

Gross Vehicle Weight (GVW)(lb.)

Vehicle Total Curb Weight (lb.)

Vehicle Tested Weight (lb.)

Odometer Reading (mile)

Vehicle Transmission Type

Vehicle Transmission Configuration

Number of Axles

Engine Type

Engine ID Number

Engine Displacement (liter)

Number of Cylinders

Engine Rated Power (hp)

Primary Fuel

Test Cycle

Test Date

Engineer

Driver

Data Verifier

Emissions Results (g/mile)

Run Seq. No

\begin{tabular}{|c|c|c|c|c|c||c|c|c|}
\hline Run Seq. No. & CO & NOx & FIDHC & PM & CO2 & MPG & BTU/mile & Miles \\
\hline $962-1$ & 2.02 & 28.8 & 1.74 & 1.67 & 1622 & 6.24 & 20834 & 3.70 \\
\hline $962-2$ & 1.95 & 30.5 & 1.74 & 1.46 & 1562 & 6.48 & 20062 & 3.42 \\
\hline $962-3$ & 2.40 & 32.9 & 1.99 & 1.68 & 1597 & 6.33 & 20531 & 3.65 \\
\hline $962-4$ & 1.87 & 32.8 & 1.80 & 1.45 & 1603 & 6.31 & 20590 & 4.03 \\
\hline $962-5$ & 2.19 & 26.2 & 1.38 & 1.09 & 1678 & 6.04 & 21538 & 4.56 \\
\hline $962-6$ & 2.41 & 25.6 & 1.60 & 1.32 & 1644 & 6.16 & 21111 & 4.29 \\
\hline $962-7$ & 2.46 & 24.6 & 1.55 & 1.14 & 1713 & 5.91 & 21991 & 4.10 \\
\hline & & & & & & & & \\
\hline 962 Average & 2.19 & 28.8 & 1.69 & 1.40 & 1631 & 6.21 & 20951 & 3.96 \\
\hline Std. Dev. & 0.24 & 3.4 & 0.20 & 0.23 & 51 & 0.19 & 654 & 0.40 \\
\hline CV\% & 11.1 & 11.9 & 11.6 & 16.6 & 3.1 & 3.1 & 3.1 & 10.1 \\
\hline
\end{tabular}

\section{Test Purpose}

Collection of emissions data from diesel fueled vehicles to establish a data set for use in comparison with LNG emissions.

\section{Special Procedures}

This is a re-test of tractor numbered 1586. (see test number 0951).

\section{Observations}

The road speed governor was keeping the driver from shifting gears. Driver accelerated more slowly than normal to prevent shifting problem and could not finish five miles during the test cycle. Test was invalid. 
Test Sequence Number: 0963

WVU Test Reference Number: RDC-1592-D2-5MILES

Fleet Owner Full Name

Fleet Address

Fleet Address (City, State, and Zip Code)

Vehicle Type

Vehicle ID Number (VIN)

Vehicle Manufacturer

Vehicle Model Year

Gross Vehicle Weight (GVW)(lb.)

Vehicle Total Curb Weight (lb.)

Vehicle Tested Weight (lb.)

Odometer Reading (mile)

Vehicle Transmission Type

Vehicle Transmission Configuration

Number of Axles

Engine Type

Engine ID Number

Engine Displacement (liter)

Number of Cylinders

Engine Rated Power (hp)

Primary Fuel

Test Cycle

Test Date

Engineer

Driver

Data Verifier
Raley's Distribution Center

4061 Gateway Park Blvd.

Sacramento, CA 95834

Tractor Truck

1XKBD99X2TS712783

Kenworth

1995

80000

14960

42000

131000

Manual

10-Speed

3

Cummins M11-330E

34786945

10.8

6

330

D2

5Miles

07/20/1997

S. McConnell

L. McGrath

Emissions Results (g/mile)

Fuel Economy

\begin{tabular}{|c|c|c|c|c|c||c|c|c|}
\hline Run Seq. No. & $\mathrm{CO}$ & $\mathrm{NO}_{\mathrm{x}}$ & FIDHC & $\mathrm{PM}$ & $\mathrm{CO}_{2}$ & mile/gal & $\mathrm{BTU} / \mathrm{mile}$ & Miles \\
\hline $963-1$ & 2.16 & 33.7 & 1.30 & 0.88 & 1847 & 5.49 & 23692 & 3.37 \\
\hline $963-2$ & 1.88 & 33.1 & 1.21 & 0.79 & 1753 & 5.78 & 22481 & 3.72 \\
\hline $963-3$ & 1.73 & 32.5 & 1.18 & 0.71 & 1619 & 6.26 & 20768 & 4.00 \\
\hline $963-4$ & 1.87 & 31.9 & 1.22 & 0.66 & 1600 & 6.33 & 20526 & 4.09 \\
\hline $963-5$ & 1.74 & 32.9 & 1.19 & 0.72 & 1581 & 6.41 & 20281 & 3.88 \\
\hline & & & & & & & & \\
\hline 963 Average & 1.88 & 32.8 & 1.22 & 0.75 & 1680 & 6.05 & 21550 & 3.81 \\
\hline Std. Dev. & 0.17 & 0.7 & 0.05 & 0.09 & 115 & 0.40 & 1477 & 0.29 \\
\hline CV\% & 9.2 & 2.0 & 4.0 & 11.4 & 6.9 & 6.6 & 6.9 & 7.5 \\
\hline
\end{tabular}

\section{$\underline{\text { Test Purpose }}$}

Collection of emissions data from diesel fueled vehicles to establish a data set for use in comparison with LNG emissions.

\section{Observations}

The road speed governor was keeping the driver from shifting gears. Driver accelerated more slowly than normal to prevent shifting problem and could not finish five miles during the test cycle. Test was invalid. 
Test Sequence Number: 0964

WVU Test Reference Number: RDC-1593-D2-5MILES

Fleet Owner Full Name

Fleet Address

Fleet Address (City, State, and Zip Code)

Vehicle Type

Vehicle ID Number (VIN)

Vehicle Manufacturer

Vehicle Model Year

Gross Vehicle Weight (GVW)(lb.)

Vehicle Total Curb Weight (lb.)

Vehicle Tested Weight (lb.)

Odometer Reading (mile)

Vehicle Transmission Type

Vehicle Transmission Configuration

Number of Axles

Engine Type

Engine ID Number

Engine Displacement (liter)

Number of Cylinders

Engine Rated Power (hp)

Primary Fuel

Test Cycle

Test Date

Engineer

Driver

Data Verifier
Raley's Distribution Center

4061 Gateway Park Blvd.

Sacramento, CA 95834

Tractor Truck

1XKBD99X4TS712784

Kenworth

1995

80000

14960

42000

165500

Manual

10-Speed

3

Cummins M11-330E

34787997

10.8

6

330

D2

5Miles

07/21/1997

S. McConnell

L. McGrath

Emissions Results (g/mile)

Fuel Economy

\begin{tabular}{|c|c|c|c|c|c||c|c|c|}
\hline Run Seq. No. & $\mathrm{CO}$ & $\mathrm{NO}_{\mathrm{x}}$ & FIDHC & $\mathrm{PM}$ & $\mathrm{CO}_{2}$ & mile/gal & $\mathrm{BTU} / \mathrm{mile}$ & Miles \\
\hline $964-1$ & 1.70 & 32.9 & 0.97 & 0.31 & 1747 & 5.81 & 22386 & 3.84 \\
\hline $964-2$ & 1.77 & 34.2 & 1.01 & 0.31 & 1736 & 5.84 & 22256 & 3.78 \\
\hline $964-3$ & 1.81 & 33.5 & 1.08 & 0.33 & 1765 & 5.74 & 22629 & 3.51 \\
\hline $964-4$ & 2.09 & 33.7 & 1.10 & 0.34 & 1752 & 5.78 & 22472 & 3.47 \\
\hline $964-5$ & 2.15 & 33.8 & 1.11 & 0.32 & 1730 & 5.86 & 22192 & 3.58 \\
\hline $964-6$ & 1.71 & 34.6 & 1.12 & 0.31 & 1713 & 5.92 & 21968 & 3.68 \\
\hline & & & & & & & & \\
\hline 964 Average & 1.87 & 33.8 & 1.07 & 0.32 & 1741 & 5.83 & 22317 & 3.64 \\
\hline Std. Dev. & 0.20 & 0.6 & 0.06 & 0.01 & 18 & 0.06 & 231 & 0.15 \\
\hline CV\% & 10.6 & 1.7 & 5.9 & 4.3 & 1.0 & 1.0 & 1.0 & 4.2 \\
\hline
\end{tabular}

\section{$\underline{\text { Test Purpose }}$}

Collection of emissions data from diesel fueled vehicles to establish a data set for use in comparison with LNG emissions.

\section{Observations}

The road speed governor was keeping the driver from shifting gears. Driver accelerated more slowly than normal to prevent shifting problem and could not finish five miles during the test cycle. Test was invalid. 
Test Sequence Number: 0976

WVU Test Reference Number: RDC-1586-D2-5MILES-R2

Fleet Owner Full Name

Fleet Address

Fleet Address (City, State, and Zip Code)

Vehicle Type

Vehicle ID Number (VIN)

Vehicle Manufacturer

Vehicle Model Year

Gross Vehicle Weight (GVW)(lb.)

Vehicle Total Curb Weight (lb.)

Vehicle Tested Weight (lb.)

Odometer Reading (mile)

Vehicle Transmission Type

Vehicle Transmission Configuration

Number of Axles

Engine Type

Engine ID Number

Engine Displacement (liter)

Number of Cylinders

Engine Rated Power (hp)

Primary Fuel

Test Cycle

Test Date

Engineer

Driver

Data Verifier
Raley's Distribution Center

4061 Gateway Park Blvd.

Sacramento, CA 95834

Tractor Truck

1XKBD99X9TS690099

Kenworth

1995

80000

14440

42000

162700

Manual

10-Speed

3

Cummins M11-330E

34776206

10.8

6

330

D2

5Miles

08/04/1997

J. Kopasko

L. McGrath

Emissions Results (g/mile)

Fuel Economy

\begin{tabular}{|c|c|c|c|c|c||c|c|c|}
\hline Run Seq. No. & $\mathrm{CO}$ & $\mathrm{NO}_{\mathrm{x}}$ & $\mathrm{FIDHC}$ & $\mathrm{PM}$ & $\mathrm{CO}_{2}$ & mile/gal & $\mathrm{BTU} / \mathrm{mile}$ & Miles \\
\hline $976-2$ & 2.06 & 27.4 & 1.58 & 1.34 & 1527 & 6.63 & 19614 & 5.02 \\
\hline $976-3$ & 1.98 & 28.2 & 1.57 & 1.33 & 1513 & 6.69 & 19426 & 5.01 \\
\hline $976-4$ & 2.03 & 29.9 & 1.55 & 1.35 & 1560 & 6.49 & 20033 & 5.00 \\
\hline $976-5$ & 2.03 & 28.4 & 1.55 & 1.33 & 1592 & 6.36 & 20446 & 5.01 \\
\hline & & & & & & & & \\
\hline 976 Average & 2.02 & 28.5 & 1.56 & 1.34 & 1548 & 6.54 & 19880 & 5.01 \\
\hline Std. Dev. & 0.03 & 1.0 & 0.02 & 0.01 & 36 & 0.15 & 455 & 0.01 \\
\hline CV\% & 1.7 & 3.7 & 1.0 & 0.8 & 2.3 & 2.3 & 2.3 & 0.2 \\
\hline
\end{tabular}

Test Purpose

Collection of emissions data from diesel fueled vehicles to establish a data set for use in comparison with LNG emissions. 
Test Sequence Number: 0977

WVU Test Reference Number: RDC-1593-D2-5MILES-R

Fleet Owner Full Name

Fleet Address

Fleet Address (City, State, and Zip Code)

Vehicle Type

Vehicle ID Number (VIN)

Vehicle Manufacturer

Vehicle Model Year

Gross Vehicle Weight (GVW)(lb.)

Vehicle Total Curb Weight (lb.)

Vehicle Tested Weight (lb.)

Odometer Reading (mile)

Vehicle Transmission Type

Vehicle Transmission Configuration

Number of Axles

Engine Type

Engine ID Number

Engine Displacement (liter)

Number of Cylinders

Engine Rated Power (hp)

Primary Fuel

Test Cycle

Test Date

Engineer

Driver

Data Verifier
Raley's Distribution Center 4061 Gateway Park Blvd.

Sacramento, CA 95834

Tractor Truck

1XKBD99X4TS712784

Kenworth

1995

80000

14960

42000

169400

Manual

10-Speed

3

Cummins M11-330E

34787997

10.8

6

330

D2

5Miles

08/06/1997

J. Kopasko

L. McGrath

Emissions Results (g/mile)

Fuel Economy

\begin{tabular}{|c|c|c|c|c|c||c|c|c|}
\hline Run Seq. No. & $\mathrm{CO}$ & $\mathrm{NO}_{\mathrm{x}}$ & FIDHC & $\mathrm{PM}$ & $\mathrm{CO}_{2}$ & mile/gal & BTU/mile & Miles \\
\hline $977-1$ & 1.70 & 32.4 & 1.00 & 0.35 & 1608 & 6.30 & 20620 & 5.00 \\
\hline $977-2$ & 1.69 & 33.1 & 1.03 & 0.34 & 1636 & 6.20 & 20972 & 5.00 \\
\hline $977-3$ & 1.60 & 31.2 & 1.08 & 0.52 & 1633 & 6.21 & 20933 & 5.00 \\
\hline $977-4$ & 1.71 & 30.8 & 1.07 & 0.49 & 1619 & 6.26 & 20763 & 5.01 \\
\hline & & & & & & & & \\
\hline 977 Average & 1.67 & 31.8 & 1.04 & 0.42 & 1624 & 6.24 & 20822 & 5.00 \\
\hline Std. Dev. & 0.05 & 1.1 & 0.04 & 0.09 & 13 & 0.05 & 162 & 0.01 \\
\hline CV\% & 3.0 & 3.4 & 3.4 & 22.4 & 0.8 & 0.8 & 0.8 & 0.1 \\
\hline
\end{tabular}

\section{$\underline{\text { Test Purpose }}$}

Collection of emissions data from diesel fueled vehicles to establish a data set for use in comparison with LNG emissions.

\section{Special Procedures}

Bees and nest were found in background bag suction tube. They were removed by turning the switch on and off, and filter was replaced. 
Test Sequence Number: 0978

WVU Test Reference Number: RDC-1592-D2-5MILES-R

Fleet Owner Full Name

Fleet Address

Fleet Address (City, State, and Zip Code)

Vehicle Type

Vehicle ID Number (VIN)

Vehicle Manufacturer

Vehicle Model Year

Gross Vehicle Weight (GVW)(lb.)

Vehicle Total Curb Weight (lb.)

Vehicle Tested Weight (lb.)

Odometer Reading (mile)

Vehicle Transmission Type

Vehicle Transmission Configuration

Number of Axles

Engine Type

Engine ID Number

Engine Displacement (liter)

Number of Cylinders

Engine Rated Power (hp)

Primary Fuel

Test Cycle

Test Date

Engineer

Driver

Data Verifier
Raley's Distribution Center 4061 Gateway Park Blvd.

Sacramento, CA 95834

Tractor Truck

1XKBD99X2TS712783

Kenworth

1995

80000

14960

42000

132700

Manual

10-Speed

3

Cummins M11-330E

34786945

10.8

6

330

D2

5Miles

08/07/1997

J. Kopasko

L. McGrath

Emissions Results (g/mile)

Fuel Economy

\begin{tabular}{|c|c|c|c|c|c||c|c|c|}
\hline Run Seq. No. & $\mathrm{CO}$ & $\mathrm{NO}_{\mathrm{x}}$ & FIDHC & $\mathrm{PM}$ & $\mathrm{CO}_{2}$ & mile/gal & $\mathrm{BTU} / \mathrm{mil}$ & Miles \\
\hline $978-1$ & 1.91 & 33.6 & 1.26 & 0.76 & 1736 & 5.84 & 22267 & 5.01 \\
\hline $978-2$ & 2.01 & 34.3 & 1.27 & 0.73 & 1653 & 6.13 & 21213 & 5.01 \\
\hline $978-3$ & 1.97 & 35.9 & $\mathrm{c}$ & 0.76 & 1667 & 6.08 & 21386 & 5.02 \\
\hline $978-4$ & 1.94 & 36.9 & 1.32 & 0.75 & 1695 & 5.98 & 21744 & 5.00 \\
\hline & & & & & & & & \\
\hline 978 Average & 1.96 & 35.2 & 1.28 & 0.75 & 1688 & 6.01 & 21652 & 5.01 \\
\hline Std. Dev. & 0.04 & 1.5 & 0.03 & 0.01 & 36 & 0.13 & 465 & 0.01 \\
\hline CV\% & 2.2 & 4.2 & 2.1 & 1.5 & 2.2 & 2.1 & 2.1 & 0.2 \\
\hline
\end{tabular}

Test Purpose

Collection of emissions data from diesel fueled vehicles to establish a data set for use in comparison with LNG emissions. 
Test Sequence Number: 0979

WVU Test Reference Number: RDC-1579-D2-5MILES-R

Fleet Owner Full Name

Fleet Address

Fleet Address (City, State, and Zip Code)

Vehicle Type

Vehicle ID Number (VIN)

Vehicle Manufacturer

Vehicle Model Year

Gross Vehicle Weight (GVW)(lb.)

Vehicle Total Curb Weight (lb.)

Vehicle Tested Weight (lb.)

Odometer Reading (mile)

Vehicle Transmission Type

Vehicle Transmission Configuration

Number of Axles

Engine Type

Engine ID Number

Engine Displacement (liter)

Number of Cylinders

Engine Rated Power (hp)

Primary Fuel

Test Cycle

Test Date

Engineer

Driver

Data Verifier
Raley's Distribution Center 4061 Gateway Park Blvd.

Sacramento, CA 95834

Tractor Truck

1XKBD99X0SS643610

Kenworth

1994

80000

15100

42000

237800

Manual

10-Speed

3

Cummins M11-330E

34735917

10.8

6

330

D2

5Miles

08/08/1997

J. Kopasko

L. McGrath
Emissions Results (g/mile)

Fuel Economy

\begin{tabular}{|c|l|l|l|l|l||l|l|l|}
\hline Run Seq. No. & \multicolumn{1}{|c|}{$\mathrm{CO}$} & \multicolumn{1}{c|}{$\mathrm{NO}_{\mathrm{x}}$} & \multicolumn{1}{c|}{ FIDHC } & \multicolumn{1}{c|}{$\mathrm{PM}$} & \multicolumn{1}{c|}{$\mathrm{CO}_{2}$} & mile/gal & \multicolumn{1}{c|}{ BTU/mile } & Miles \\
\hline $979-1$ & 2.09 & 34.0 & 1.27 & 0.41 & 1719 & 5.89 & 22058 & 5.00 \\
\hline $979-2$ & 2.12 & 33.7 & 1.22 & 0.41 & 1766 & 5.74 & 22650 & 5.00 \\
\hline $979-3$ & 2.11 & 32.6 & 1.23 & 0.39 & 1720 & 5.89 & 22065 & 5.01 \\
\hline $979-4$ & 2.20 & 33.8 & 1.36 & 0.40 & 1748 & 5.80 & 22432 & 4.99 \\
\hline & & & & & & & & \\
\hline 979 Average & 2.13 & 33.5 & 1.27 & 0.40 & 1738 & 5.83 & 22301 & 5.00 \\
\hline Std. Dev. & 0.05 & 0.6 & 0.06 & 0.01 & 23 & 0.08 & 291 & 0.01 \\
\hline CV\% & 2.3 & 1.9 & 4.9 & 2.3 & 1.3 & 1.3 & 1.3 & 0.2 \\
\hline
\end{tabular}

$\underline{\text { Test Purpose }}$

Collection of emissions data from diesel fueled vehicles to establish a data set for use in comparison with LNG emissions. 


\section{APPENDIX B}

COMPUTER PROGRAMS FOR DATA PROCESSING 


\section{Quick Basic Program For Averaging $10 \mathrm{~Hz}$ Data to $1 \mathrm{~Hz}$ Data}

'This program is for reducing the continuous data take at $10 \mathrm{~Hz}$ and averaging it to one second values.

\section{CLS}

INPUT ; "Inter the length of the test (s)", 1

DIM dat1(12), dat2(12), dat3(12), dat4(12), dat5(12), dat6(12), dat7(12) AS SINGLE

DIM dat8(12), dat9(12), dat10(12) AS SINGLE

OPEN "D:\10Hzdata.csv" FOR INPUT AS \#1

OPEN "D:\Averdat.txt" FOR OUTPUT AS \#2

LINE INPUT \#1, S\$

PRINT \#2, S\$

LINE INPUT \#1, S\$

PRINT \#2, S\$

$\mathrm{k}=0$

DO UNTIL $\mathrm{k}=1$

dat 1 sum $=0$

dat2sum $=0$

dat3sum $=0$

dat 4 sum $=0$

dat5sum $=0$

dat6sum $=0$

dat7sum $=0$

dat 8 sum $=0$

dat9sum $=0$

dat10sum $=0$

$\mathrm{x}=0$

DO UNTIL $x=10$

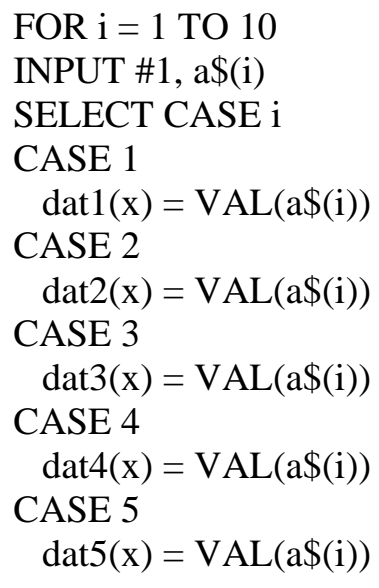




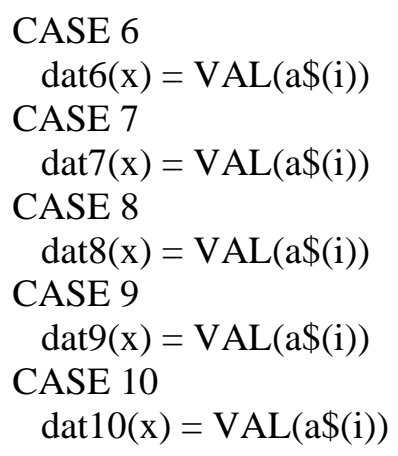

\section{END SELECT}

\section{NEXT i}

$$
\begin{aligned}
& \text { dat } 1 \text { sum }=\text { dat } 1 \text { sum }+ \text { dat } 1(\mathrm{x}) \\
& \text { dat2sum }=\text { dat } 2 \text { sum }+ \text { dat } 2(x) \\
& \text { dat } 3 \text { sum }=\text { dat } 3 \text { sum }+ \text { dat } 3(x) \\
& \text { dat } 4 \text { sum }=\text { dat } 4 \text { sum }+ \text { dat } 4(\mathrm{x}) \\
& \text { dat5sum }=\text { dat5sum }+ \text { dat5 }(\mathrm{x}) \\
& \text { dat6sum }=\text { dat6sum }+ \text { dat6 }(\mathrm{x}) \\
& \text { dat7sum }=\text { dat7sum }+ \text { dat7 }(x) \\
& \text { dat8sum }=\text { dat } 8 \text { sum }+ \text { dat } 8(x) \\
& \text { dat9sum }=\text { dat9sum }+ \text { dat } 9(x) \\
& \text { dat10sum }=\text { dat10sum }+ \text { dat } 10(x)
\end{aligned}
$$

$x=x+1$

\section{LOOP}

dat 1 avg $=$ dat 1 sum $/ 10$
dat2avg $=$ dat 2 sum $/ 10$
dat3avg $=$ dat 3 sum $/ 10$
dat4avg $=$ dat 4 sum $/ 10$
dat5avg $=$ dat5sum $/ 10$
dat6avg $=$ dat6sum $/ 10$
dat7avg $=$ dat 7 sum $/ 10$
dat8avg $=$ dat8sum $/ 10$
dat9avg $=$ dat9sum $/ 10$
dat10avg $=$ dat 10 sum $/ 10$

PRINT \#2, USING "\#\#\#\#\#.\#\#\#, "; dat1avg; dat2avg; dat3avg; dat4avg; dat5avg; dat6avg; dat7avg; dat8avg; dat9avg; dat10avg

$$
\mathrm{k}=\mathrm{k}+1
$$

\section{LOOP}

\section{END}




\section{Quick Basic Program For Determining Time-Shift Between Continuous Data}

'This program uses the cross correlation method to determine the time shift of continuous emission data 'readings with that of the engine (or axial) torque to provide maximum correlation. The program is "designed to read from an Excel spread sheet saved as a "CSV" file. The program uses the first column as 'a reference point. This column should be power (engine or axial), hub speed, or engine speed. The 'output convention ( + or - ) pertains to the direction that the data columns should be shifted. Positive 'indicates shifting the column 'up' (back in time) and negative indicates shifting the column 'down' '(forward in 'time).

CLS

INPUT ; "Inter the time range for shift evaluation (even \#'s only) "; tr

CLS

DIM dat(2000, 7), t(7) AS SINGLE

OPEN "d:Itshift.csv" FOR INPUT AS \#1

$\mathrm{i}=0$

sum $=0$

$\mathrm{x}=0$

DO WHILE NOT EOF(1)

INPUT \#1, var1, var2, var3, var4, var5, var6, var7

$\operatorname{dat}(\mathrm{x}, 1)=\operatorname{var} 1$

$\operatorname{dat}(\mathrm{x}, 2)=\operatorname{var} 2$

$\operatorname{dat}(\mathrm{x}, 3)=\operatorname{var} 3$

$\operatorname{dat}(\mathrm{x}, 4)=\operatorname{var} 4$

$\operatorname{dat}(\mathrm{x}, 5)=\operatorname{var} 5$

dat $(\mathrm{x}, 6)=\operatorname{var} 6$

$\operatorname{dat}(\mathrm{x}, 7)=\operatorname{var} 7$

$\mathrm{x}=\mathrm{x}+1$

LOOP

CLOSE \#1

FOR $\mathrm{z}=2 \mathrm{TO} 7$

$$
\begin{aligned}
& 1=0 \\
& \text { tot }=0 \\
& \text { FOR } \mathrm{k}=1 \text { TO tr } \\
& \operatorname{prod}=0 \\
& \operatorname{sum}=0 \\
& \begin{array}{l}
1=1+1 \\
\text { FOR } \mathrm{j}=0 \text { TO } \mathrm{x}-\operatorname{tr} \\
\operatorname{prod}=\operatorname{dat}(\operatorname{tr} / 2+\mathrm{j}, 1) * \operatorname{dat}(\mathrm{j}+\mathrm{k}, \mathrm{z}) \\
\quad \operatorname{sum}=\operatorname{sum}+\operatorname{prod}
\end{array}
\end{aligned}
$$


NEXT $j$

IF (sum $>$ tot) THEN tot $=$ sum: $\mathrm{t}=\mathrm{k}-\mathrm{tr} / 2$

NEXT k

$\mathrm{t}(\mathrm{z})=\mathrm{t}$

NEXT z

PRINT "Shift HC"; t(2); "seconds"

PRINT "Shift CO"; t(3); "seconds"

PRINT "Shift CO2"; t(4); "seconds"

PRINT "Shift NOx"; t(5); "seconds"

PRINT "Shift TEOM"; t(6); "seconds"

PRINT "Shift Vmx"; t(7); "seconds"

END 


\section{Quick Basic Program for Applying the Levenspiel Dispersion Model To}

\section{Continuous Opacity Data}

'This program applies the Levenspiel theoretical axial dispersion equation to engine power data and then 'applies cross correlation to properly align the dispersed power data with NOx data.

\section{CLS}

DIM Cn(1000), theta(1000), DF(2000), dat(-30 TO 2000, 2), Ci(1000), disp(2000, 2), test(2000, 3), $\operatorname{dif}(1000)$ AS SINGLE

INPUT "Enter the modified variable 'a' (enter 1 for original model)", MODa

INPUT "Enter the modified variable 'b' (enter 1 for original model", MODb

INPUT "Enter the vessel dispersion number", VDNum

INPUT "Enter the spreading range (Ti)", Ti

INPUT "Enter the delay time (Tbar)", Tb

INPUT "Enter the range for cross correlation (even integers) ", tr

$\mathrm{Tb}=20$

OPEN "c:|co2inj.csv" FOR INPUT AS \#1

OPEN "c:Idispdat.txt" FOR OUTPUT AS \#2

LINE INPUT \#1, s\$

PRINT \#2, s\$

LINE INPUT \#1, $\mathrm{s} \$$

PRINT \#2, s\$

sum $=0$

$\mathrm{i}=0$

$\mathrm{x}=0$

Tstart $=\operatorname{INT}(.725 * \mathrm{~Tb})$

Tfinish $=\operatorname{INT}(1.527 * \mathrm{~Tb})$

DO WHILE NOT EOF(1)

FOR $\mathrm{i}=1 \mathrm{TO} 2$

INPUT \#1, a\$(i)

SELECT CASE i

CASE 1

dat $(\mathrm{x}, 1)=\operatorname{VAL}(\mathrm{a} \$(\mathrm{i}))$ 'This is the reference data for cross correlation

CASE 2

dat $(x, 2)=\operatorname{VAL}(a \$(i))$ 'This is the data to be dispersed

END SELECT

NEXT i

$\mathrm{x}=\mathrm{x}+1$ 
CLOSE \#1

$\mathrm{k}=0$

'The following loop calculates the incremental concentrations along the dispersed curve.

PRINT Tstart

PRINT Tfinish

Ctot $=0$

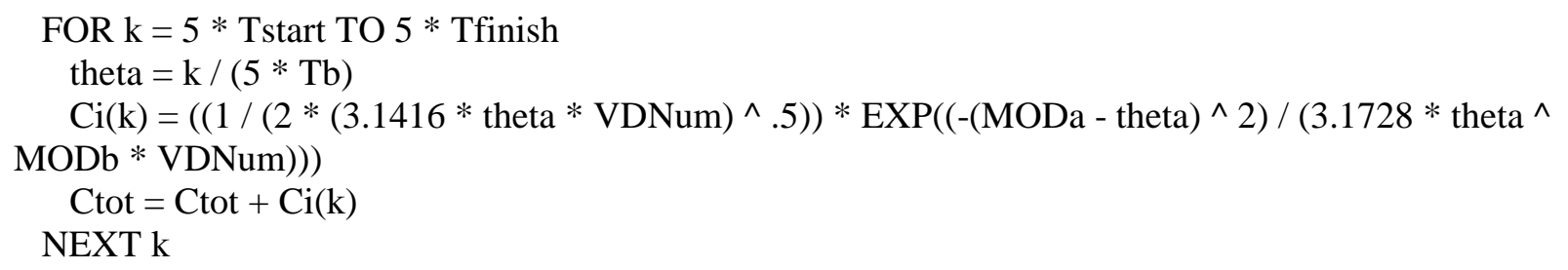

'This loop is for applying the dispersion model to each data point. Each dispersed curve will be added to 'the previous.

$\begin{aligned} \text { FOR } \mathrm{j} & =0 \text { TO } \mathrm{x} \\ \text { sum } & =0\end{aligned}$

'The following nested loop normalizes the dispersion curve and then applies the curve to each of the data 'points.

$$
\begin{aligned}
& \text { FOR } \mathrm{k}=5 * \text { Tstart TO } 5 * \text { Tfinish } \\
& \begin{array}{c}
\text { Cn }(\mathrm{k})=\mathrm{Ci}(\mathrm{k}) / \text { Ctot } \\
\operatorname{dif}(\mathrm{k})=\mathrm{Cn}(\mathrm{k}) * \operatorname{dat}(\mathrm{j}, 2)
\end{array}
\end{aligned}
$$

\section{NEXT k}

'This nested loop adds all of the dispersed curves together.

$$
\begin{aligned}
& \text { FOR } \mathrm{k}=5 * \text { Tstart TO } 5 * \text { Tfinish } \\
& \text { DF }(\mathrm{j}+\mathrm{k})=\mathrm{DF}(\mathrm{j}+\mathrm{k})+\operatorname{dif}(\mathrm{k}) \\
& \text { NEXT } \mathrm{k}
\end{aligned}
$$

PRINT \#2, DF(j)

NEXT $j$

CLOSE \#1, \#2

END 


\section{APPENDIX C}

\section{DRIVING CYCLES AND SUPLIMENTAL PLOTS}




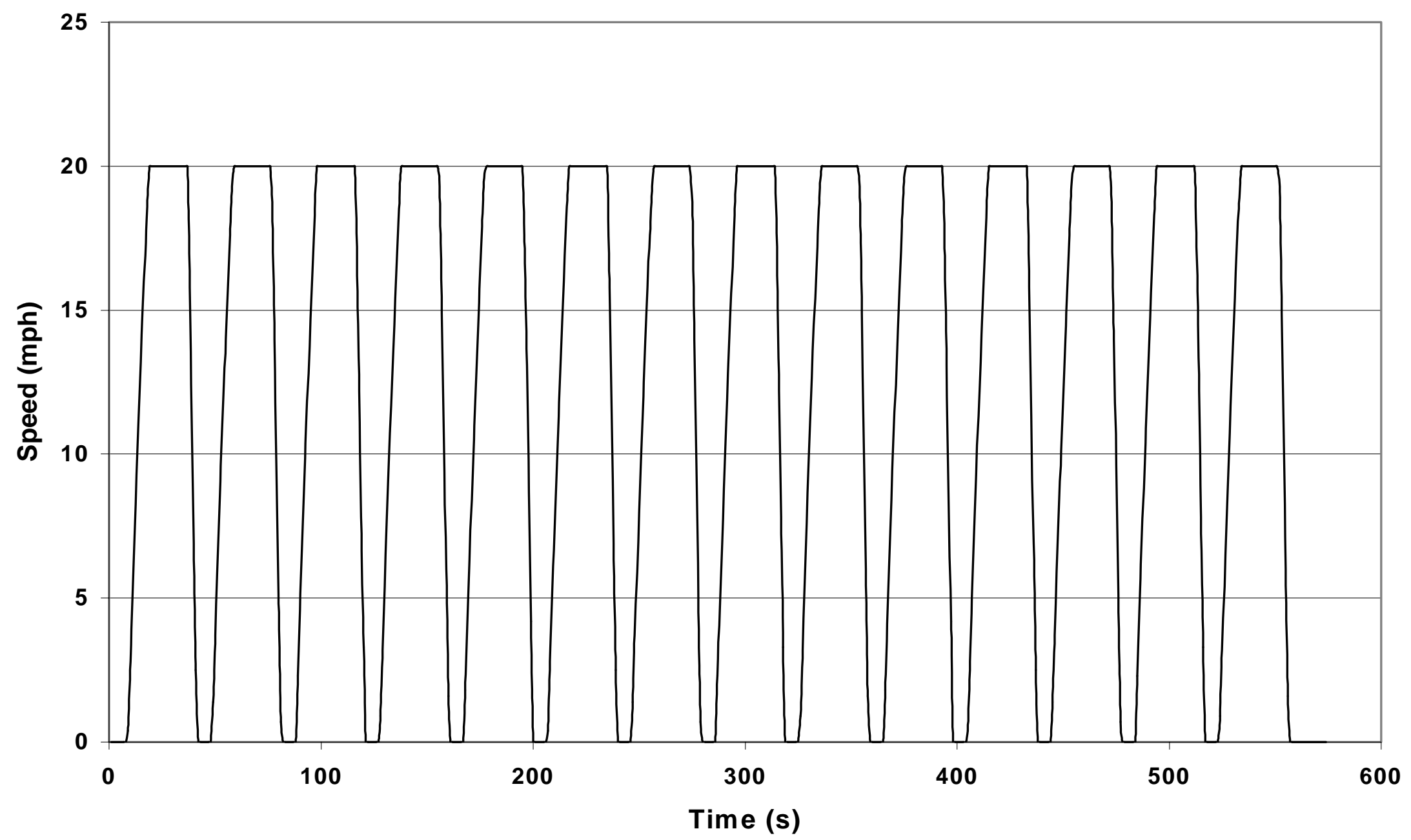

Figure C-1. A speed-time plot for the Central Business District (CBD) Cycle, which is a transient driving cycle for chassis testing of heavy-duty trucks. 


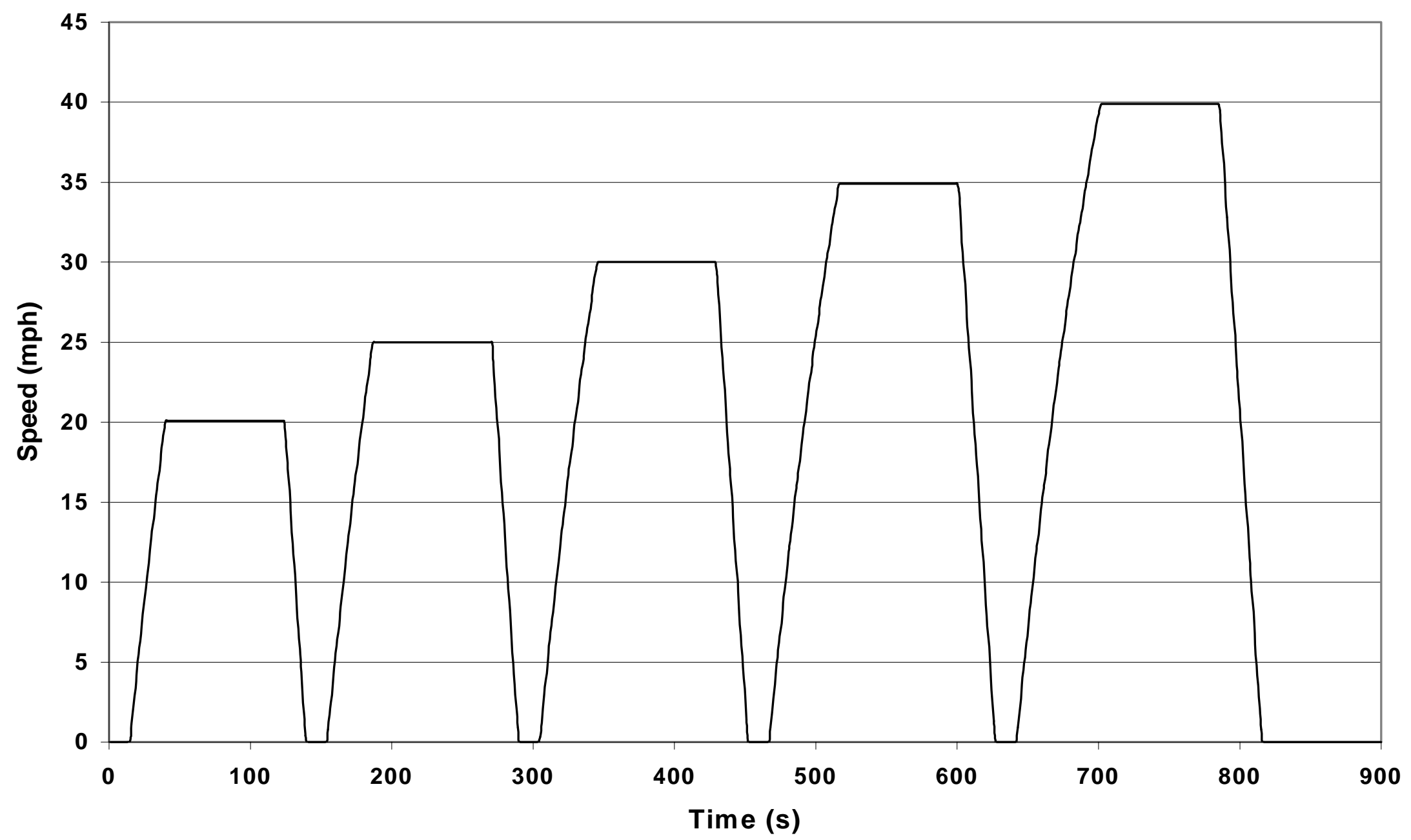

Figure C-2. A speed-time plot of the West Virginia University Five Peak (WVU 5-Peak) transient driving cycle for chassis testing of heavy-duty trucks. 




Figure C-3. A speed-time trace example of a vehicle exercised through the West Virginia University Five Mile (WVU 5-Mile) Route, which is a distance-based transient chassis test for heavy-duty trucks. The WVU 5-Mile Route is similar to the WVU 5-Peak Cycle but allows for free acceleration of the test vehicle. 


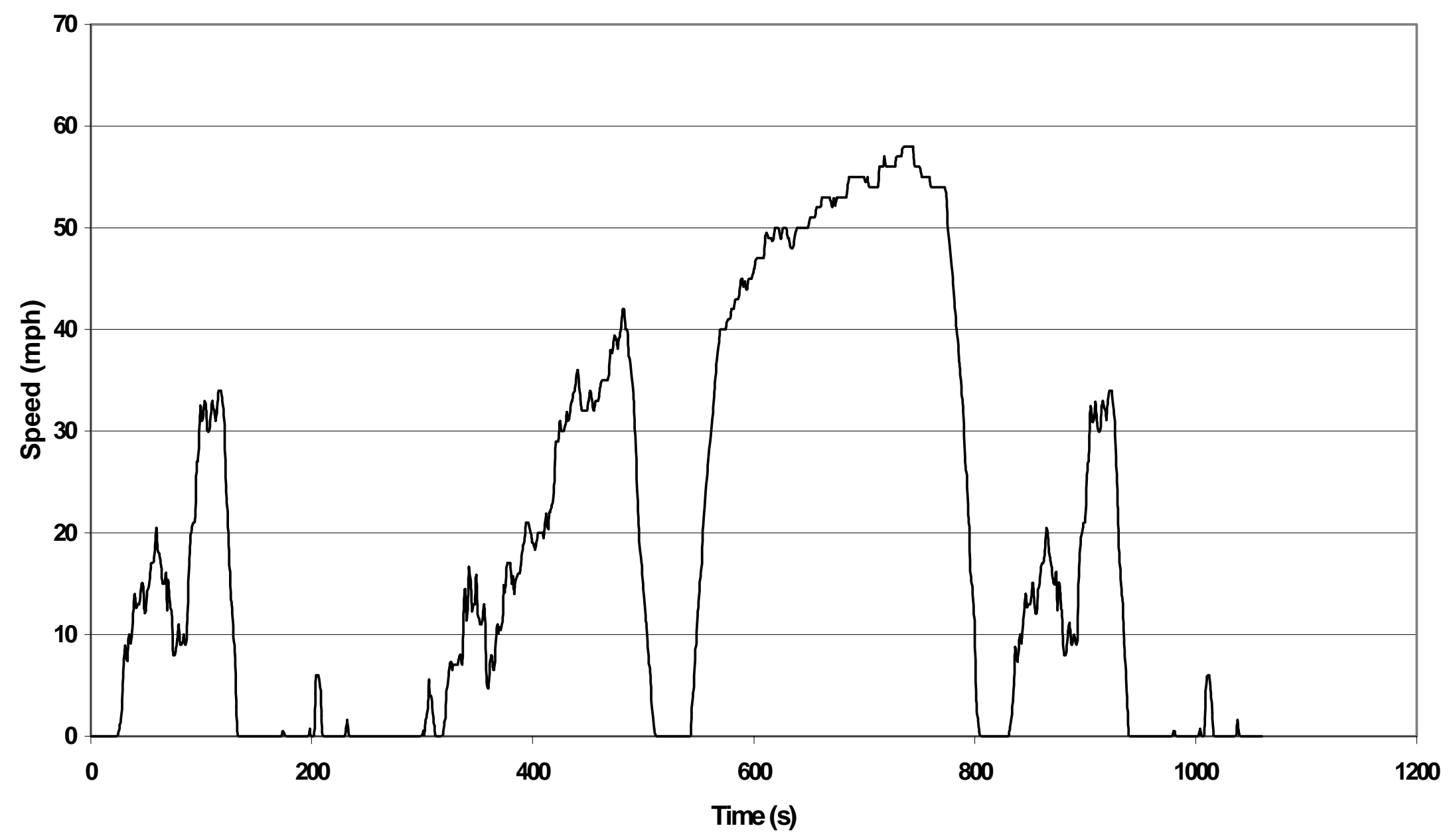

Figure C-4. A speed-time plot of the EPA Urban Dynamometer Driving Schedule for Heavy-Duty Vehicles (Test D). 


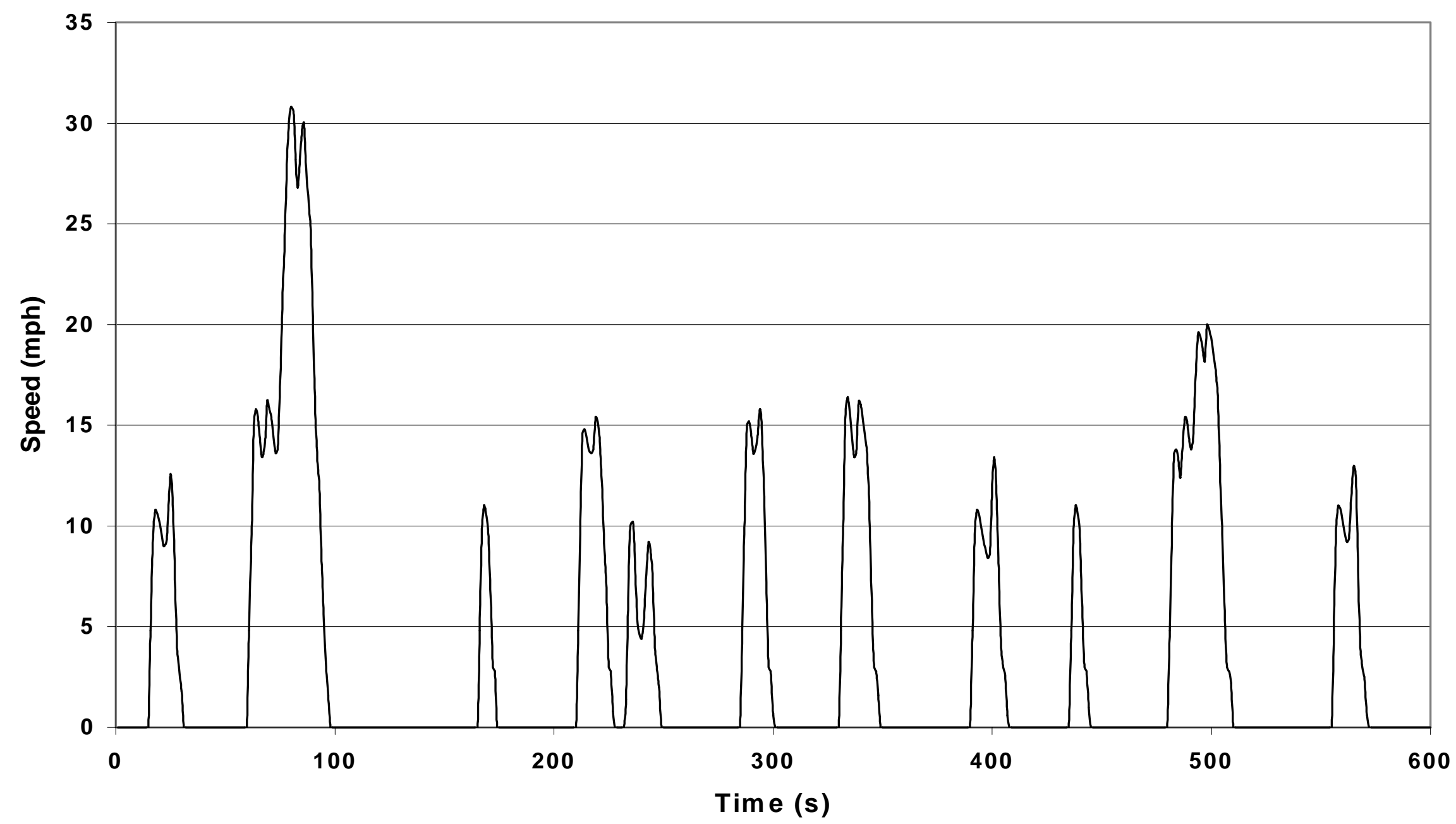

Figure C-5. A speed-time plot of the New York City Bus (NYCB) transient driving cycle for chassis testing of heavy-duty trucks. 


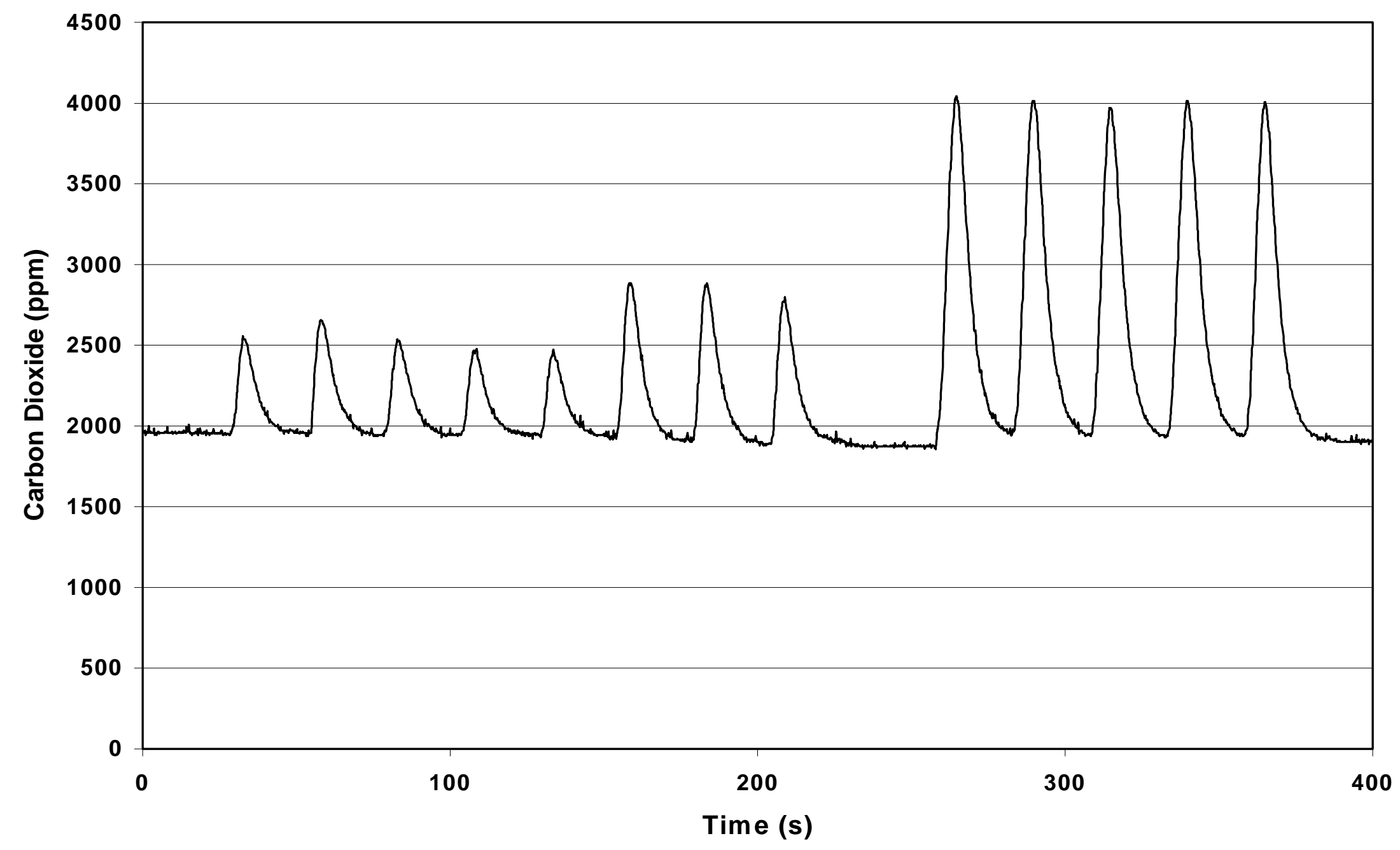

Figure C-6. Initial data from the first of three tests where pulses of $\mathrm{CO}_{2}(99.9 \%$ pure) were injected into the exhaust transfer pipe to evaluate axial dispersion in the exhaust transport system of THDVETL \#2. In this test there were five one-second pulse injections, three two-second pulse injections, and five five-second pulse injections. The vehicle used for this test was a 1995 Mack tractor powered by an E7, 12 liter, turbo-charged engine. The engine was operated at idle throughout the test (approximately $750 \mathrm{rpm}$ ) with the transmission in neutral. 


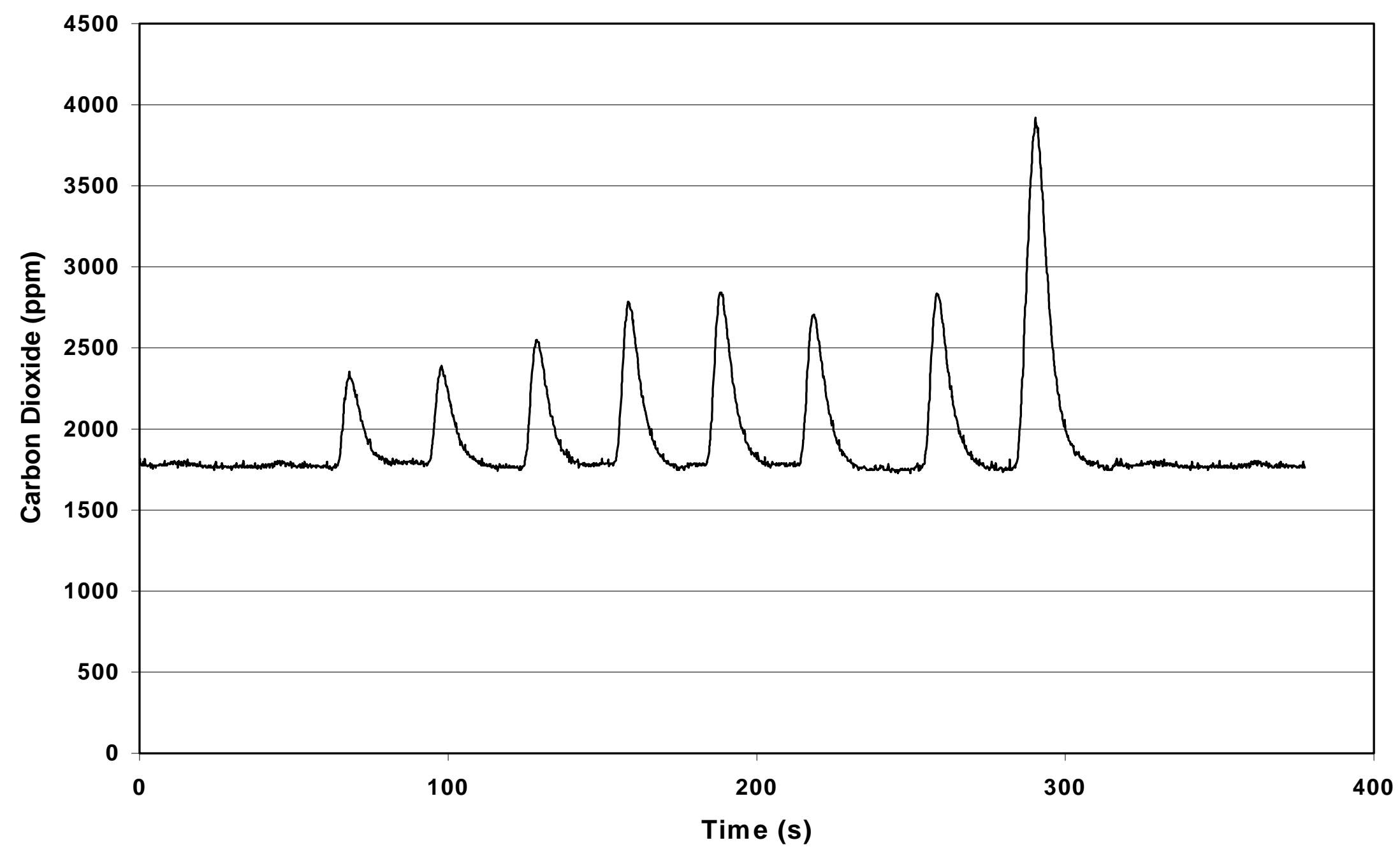

Figure C-7. Initial data from the second of three tests where pulses of $\mathrm{CO}_{2}$ gas $(99.9 \%$ pure) were injected into the exhaust transfer pipe to evaluate axial dispersion in the exhaust transport system of THDVETL \#2. In this test there were three one-second pulse injections, four two-second pulse injections, and one five-second pulse injections. The vehicle used for this test was a 1995 Mack tractor powered by an E7, 11 liter, turbo-charged engine. The engine was operated at idle throughout the test (approximately $750 \mathrm{rpm}$ ) with the transmission in neutral. 


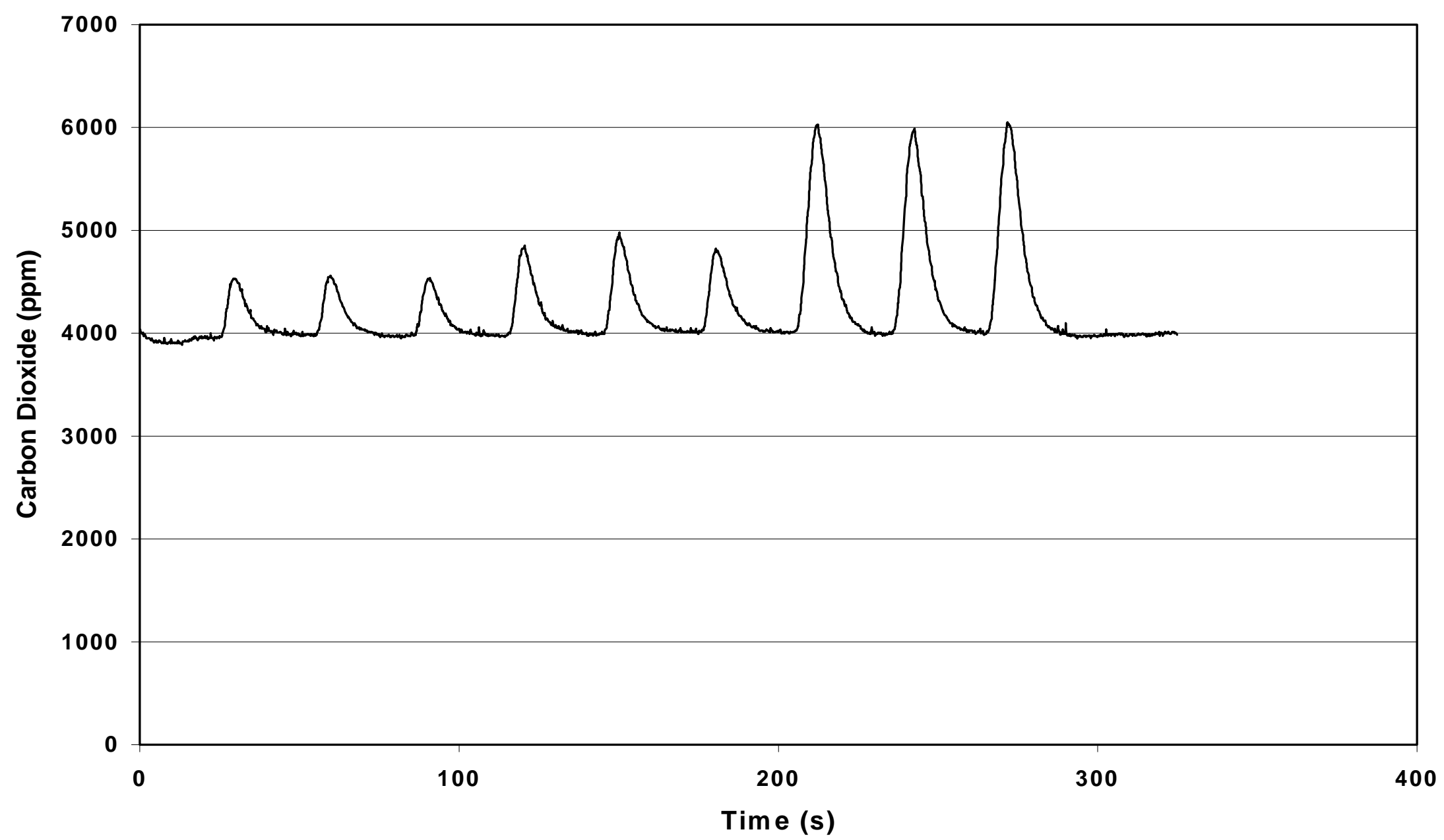

Figure C-8. Initial data from the third of three tests where pulses of $\mathrm{CO}_{2}$ gas $(99.9 \%$ pure) were injected into the exhaust transfer pipe to evaluate axial dispersion in the exhaust transport system of THDVETL \#2. This test consisted of three one-second pulse injections, three two-second pulse injections, and three five-second pulse injections. The vehicle used for this test was a 1995 Mack tractor powered by an E7, 11-liter, turbo-charged engine. The engine was operated at 1500 rpm with the transmission in neutral. 


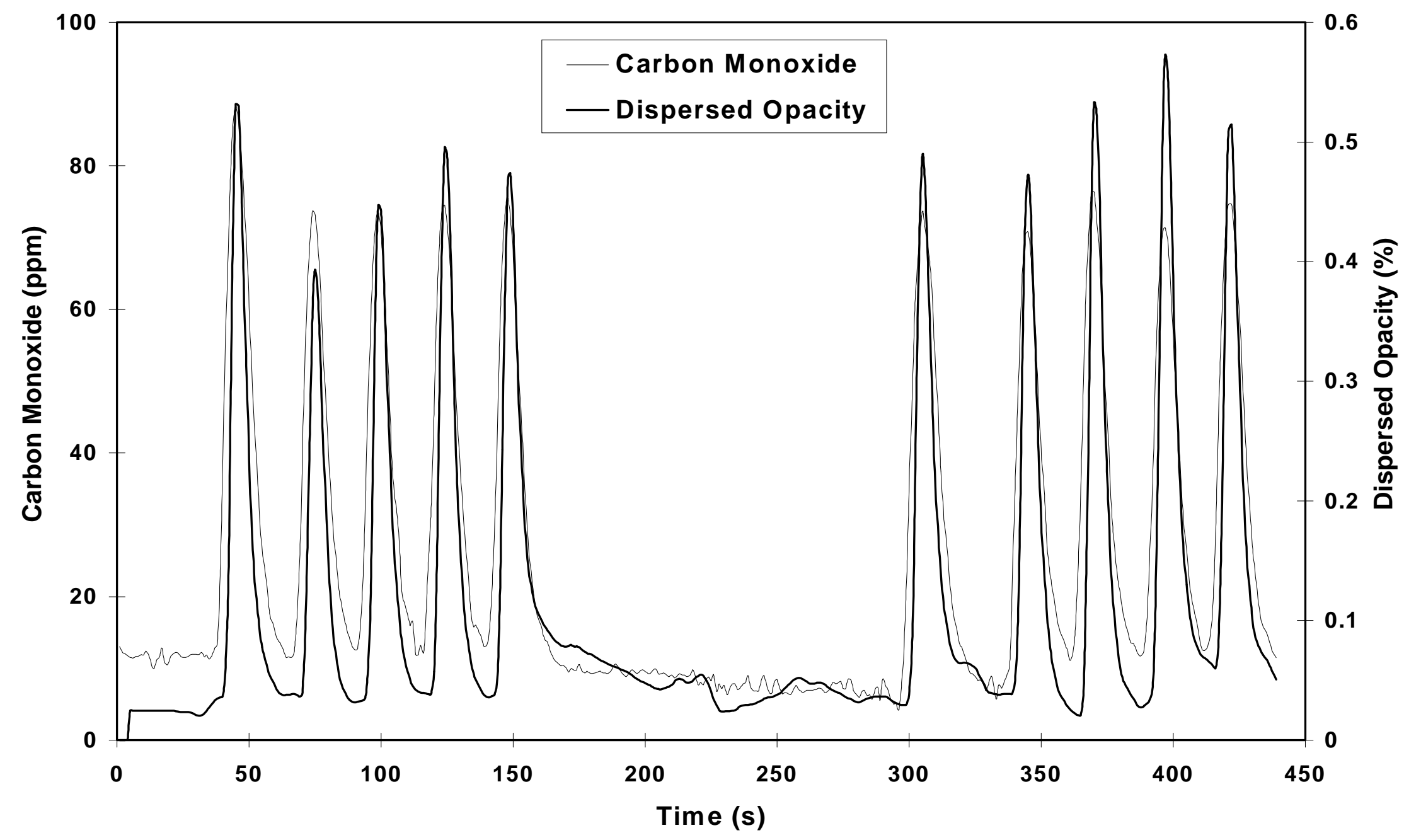

Figure C-9. Continuous carbon monoxide concentration and dispersed opacity from a 1996 transit bus powered by a 1996 DDC Series 50 engine exercised through a snap-acceleration test (test number 0919-snap). These data were collected in Flint, MI and are also shown in Figure C-10 as carbon monoxide plotted as a function of dispersed opacity. 


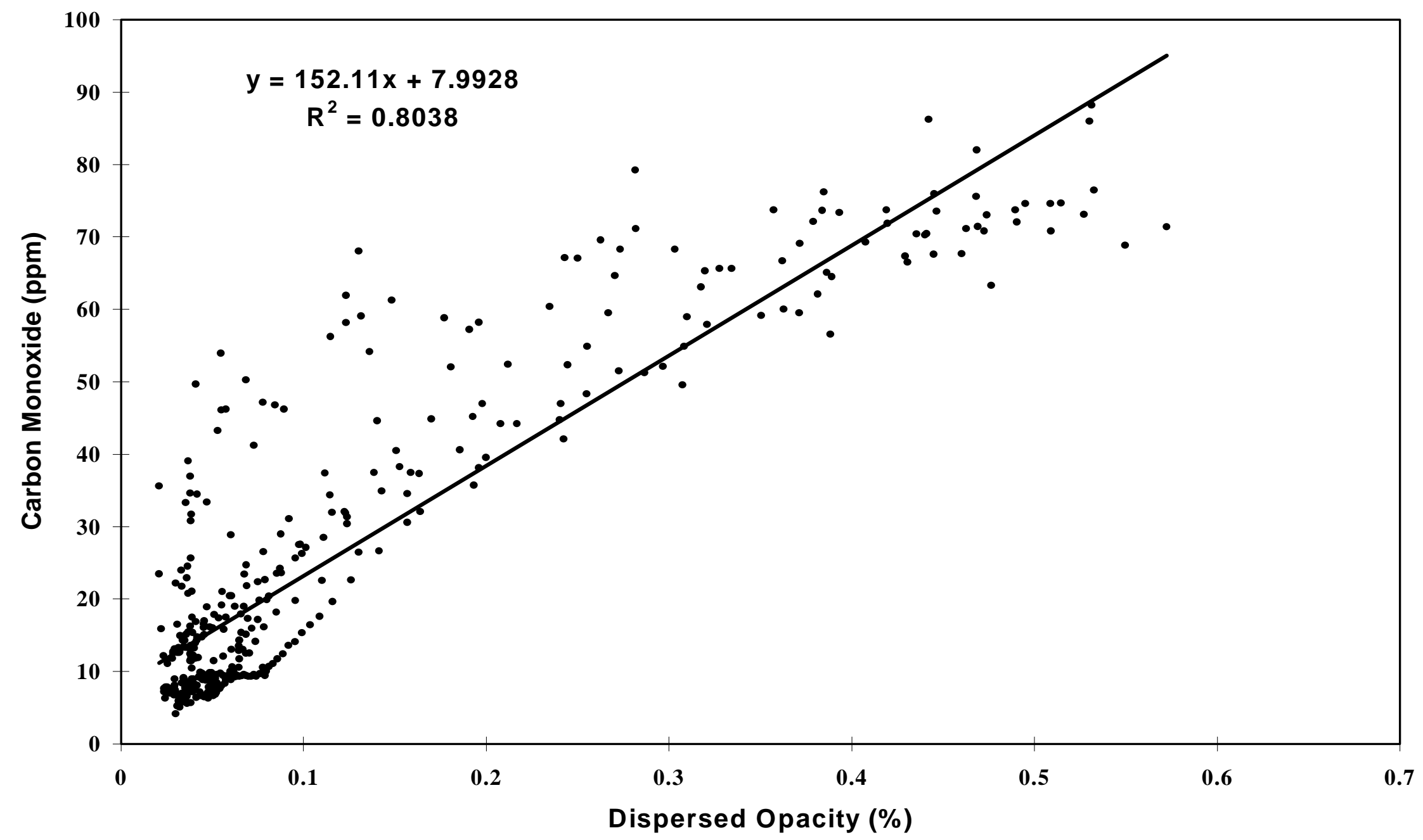

Figure C-10. Continuous carbon monoxide concentration plotted as a function of dispersed opacity from a 1996 transit bus powered by a 1996 DDC Series 50 engine exercised through a snap-acceleration test (test number 0919-snap). These data were collected in Flint, MI and are also shown in Figure C-9 as continuous carbon monoxide and continuous dispersed opacity. 


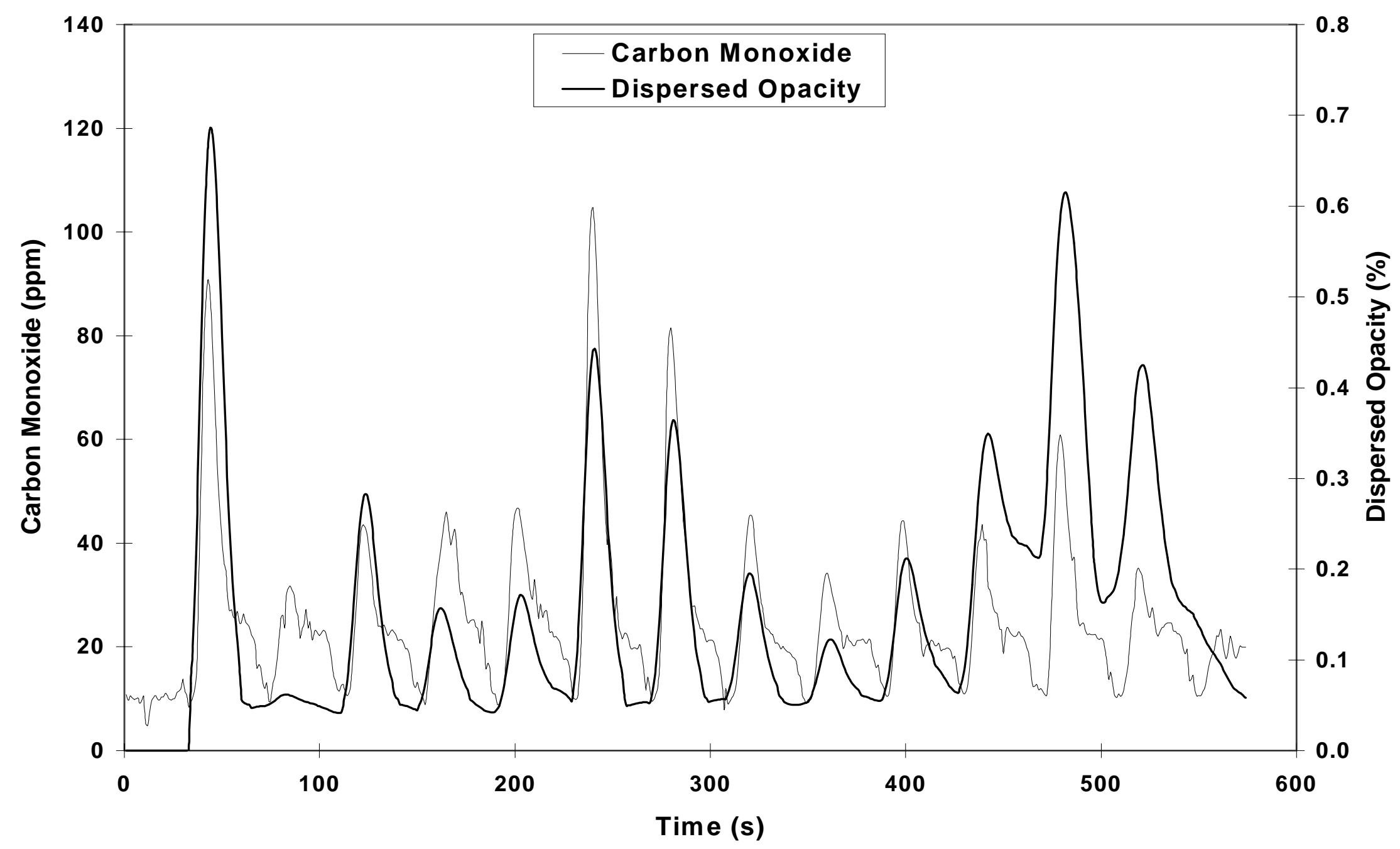

Figure C-11. Continuous carbon monoxide concentration and dispersed opacity from a 1996 transit bus powered by a 1996 DDC Series 50 engine exercised through a CBD cycle (test number 0920-4). This data represents the worst correlation between carbon monoxide and dispersed opacity data in this research. These data were collected in Flint, MI and are also shown in Figure C-12 as carbon monoxide plotted as a function of dispersed opacity. 


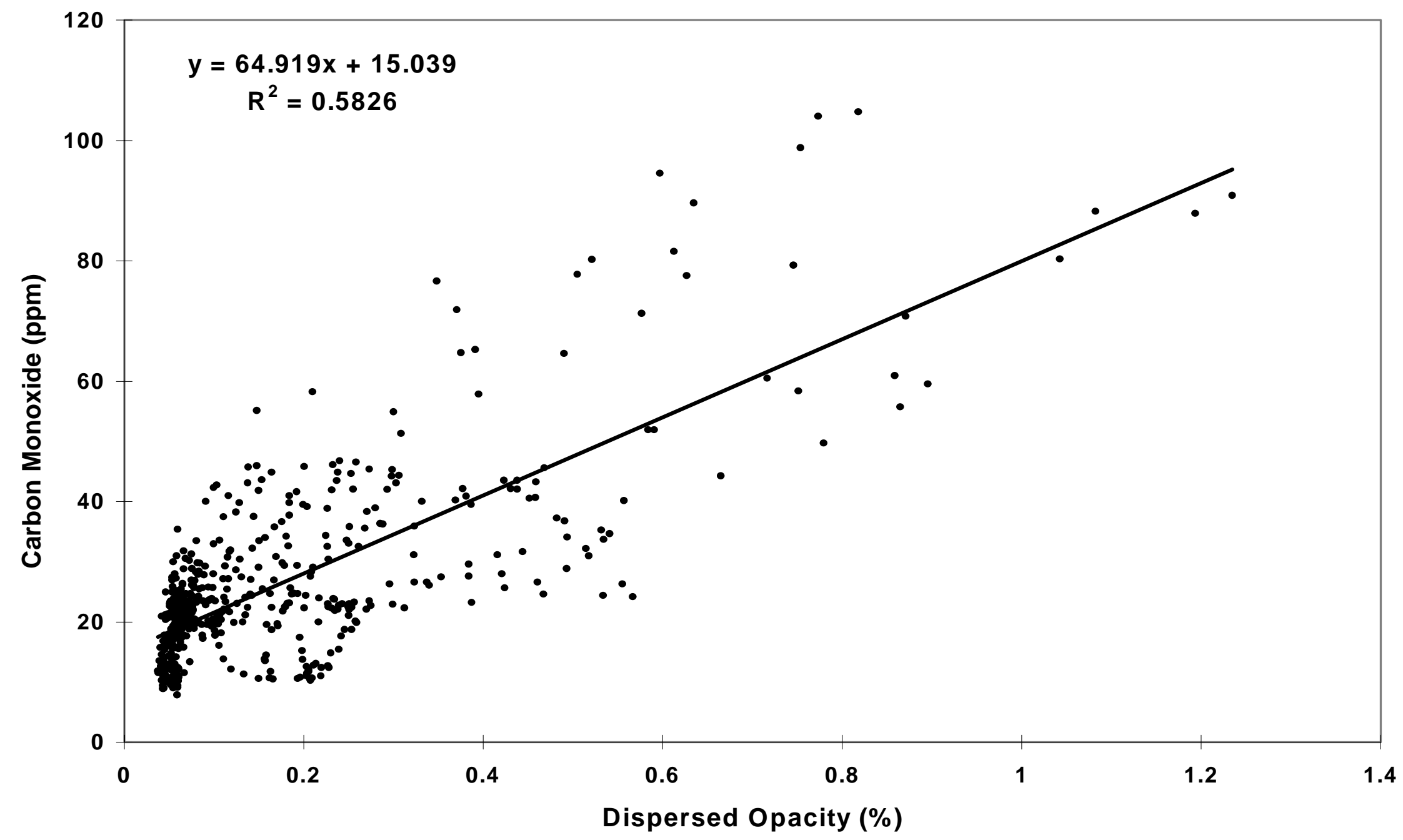

Figure C-12. Continuous carbon monoxide concentration plotted as a function of dispersed opacity from a 1996 transit bus powered by a 1996 DDC Series 50 engine exercised through a CBD cycle (test number 0920-4). These data were collected in Flint, MI and are also shown in Figure C-11 as continuous carbon monoxide and continuous dispersed opacity. 


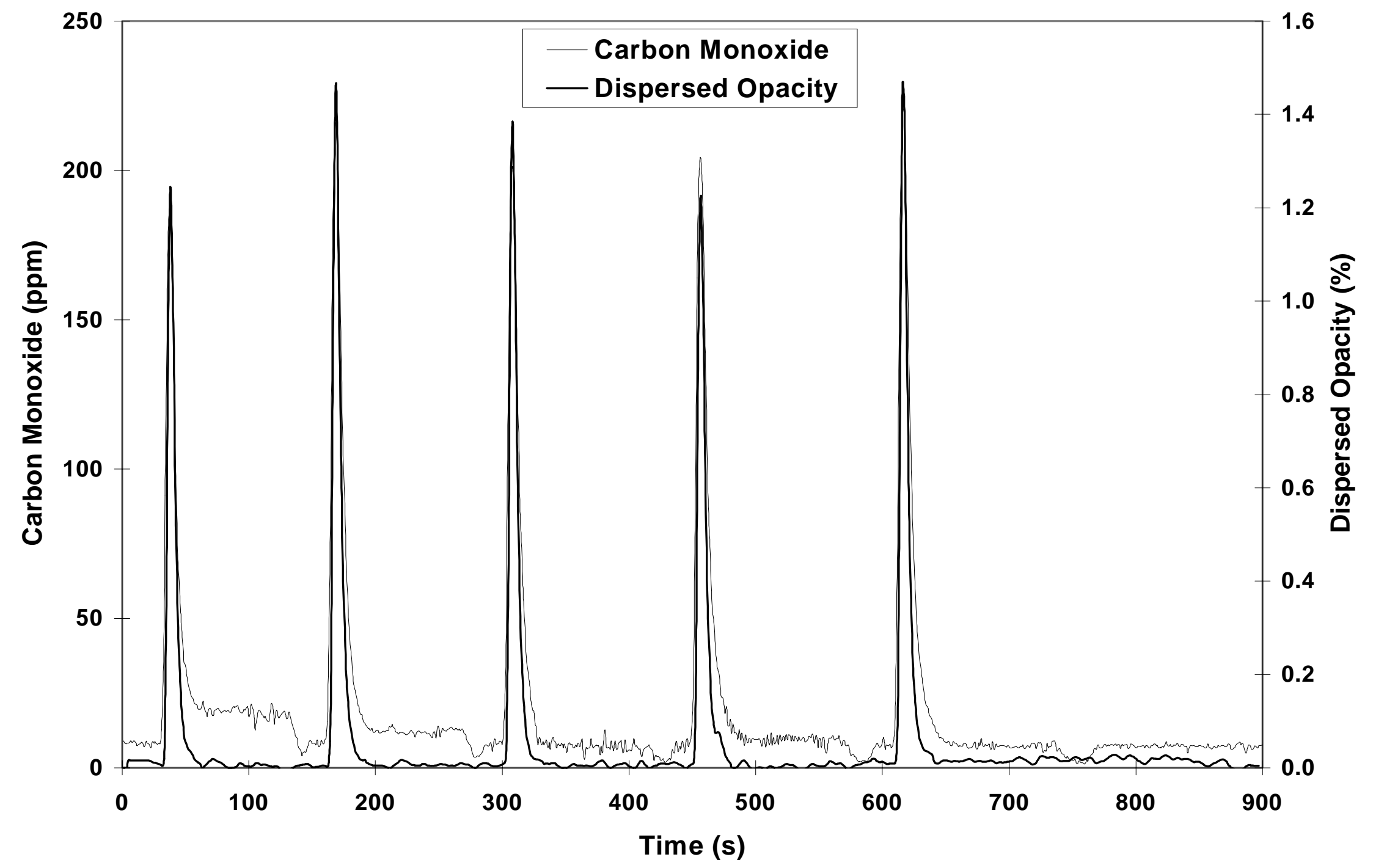

Figure C-13. Continuous carbon monoxide concentration and dispersed opacity from a 1996 transit bus powered by a 1996 DDC Series 50 engine exercised through a 5-Mile route (test number 0924-1). These data were collected in Flint, MI and are also shown in Figure C-14 as carbon monoxide plotted as a function of dispersed opacity. 


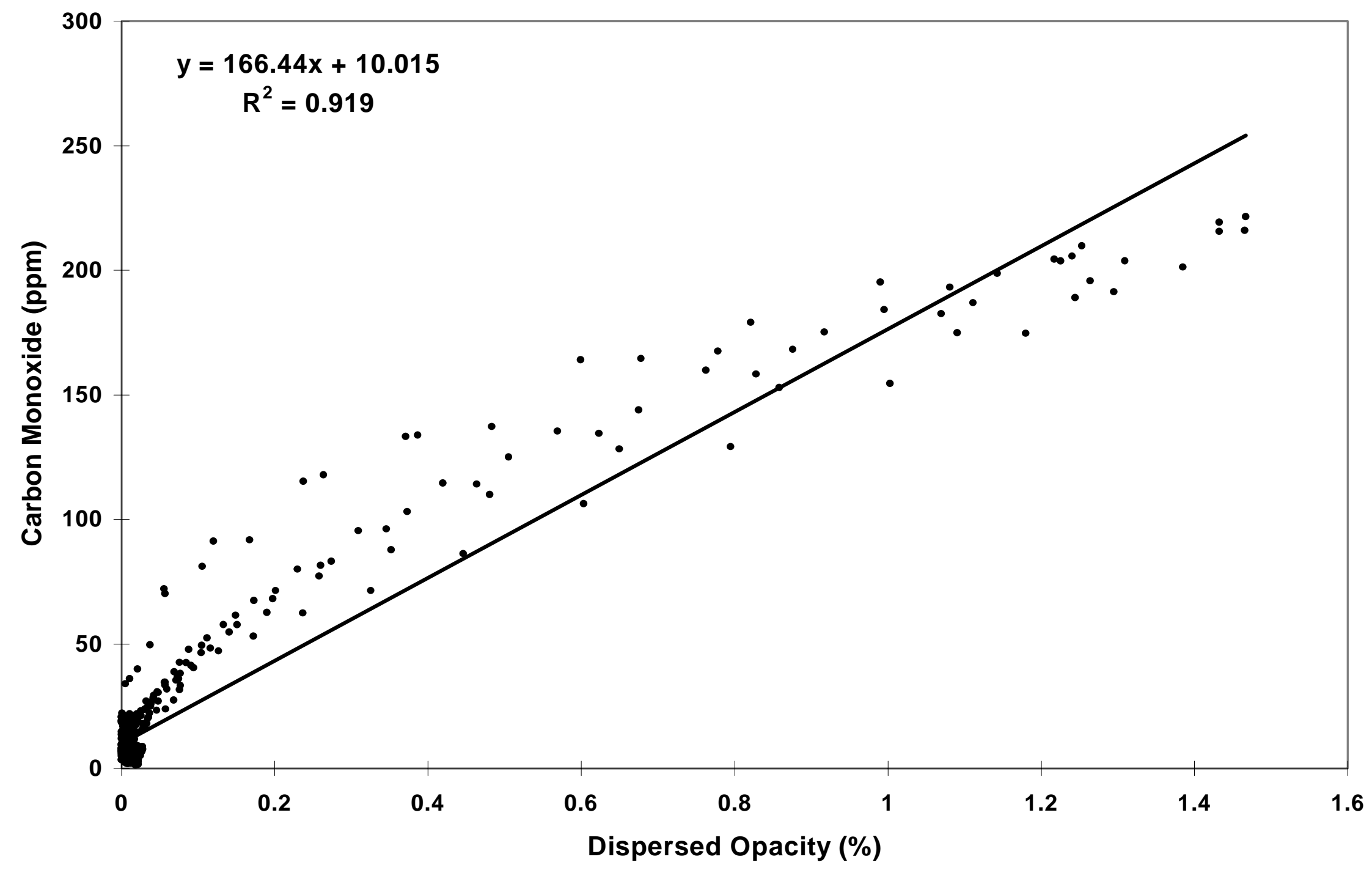

Figure C-14. Continuous carbon monoxide concentration plotted as a function of dispersed opacity from a 1996 transit bus powered by a 1996 DDC Series 50 engine exercised through a 5-Mile route (test number 0924-1). These data were collected in Flint, MI and are also shown in Figure C-13 as continuous carbon monoxide and continuous dispersed opacity. 


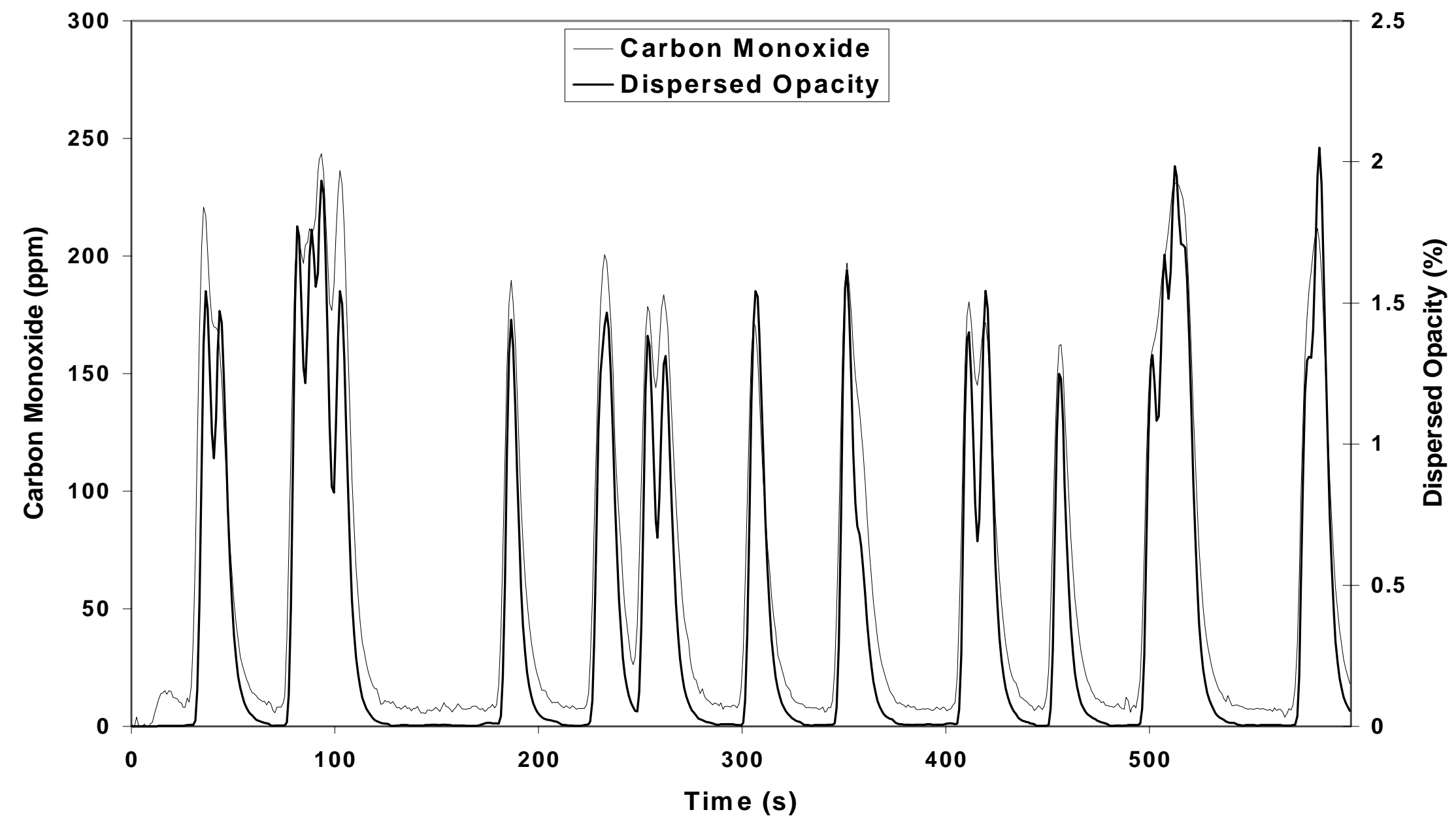

Figure C-15. Continuous carbon monoxide concentration and dispersed opacity from a 1996 transit bus powered by a 1996 DDC Series 50 engine exercised through a NYCB cycle (test number 0925-1). These data were collected in Flint, MI and are also shown in Figure C-16 as carbon monoxide plotted as a function of dispersed opacity. This figure is also shown in Section 4.4.3 as Figure 4-19. 


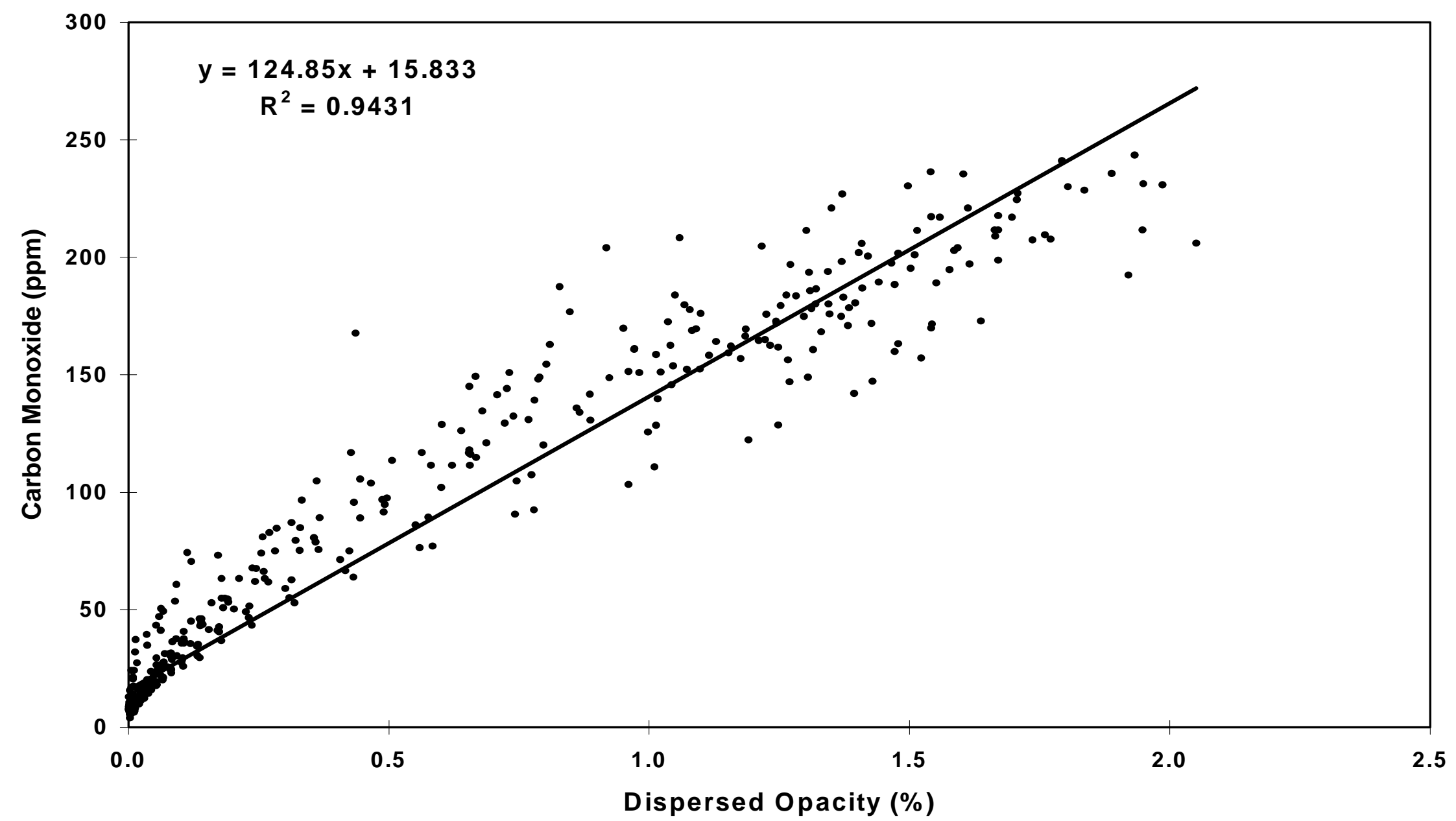

Figure C-16. Continuous carbon monoxide concentration plotted as a function of dispersed opacity from a 1996 transit bus powered by a 1996 DDC Series 50 engine exercised through a NYCB cycle (test number 0925-1). These data were collected in Flint, MI and are also shown in Figure C-15 as continuous carbon monoxide and continuous dispersed opacity. This figure is also shown in Section 4.4.3 as Figure 4-20. 


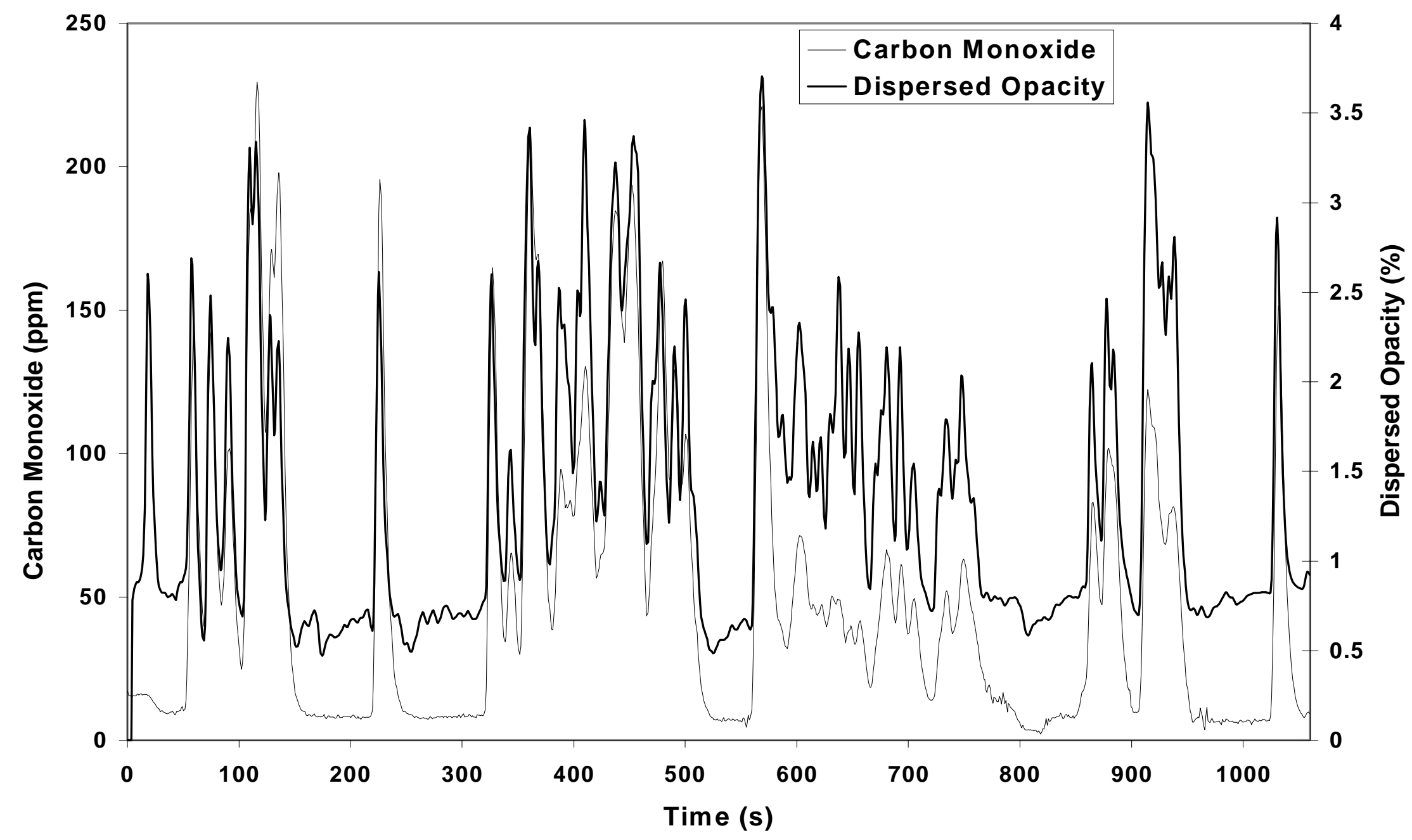

Figure C-17. Continuous carbon monoxide concentration and dispersed opacity from a 1996 transit bus powered by a 1996 DDC Series 50 engine exercised through a Test D (test number 0926-2). These data were collected in Flint, MI and are also shown in Figure C-18 as carbon monoxide plotted as a function of dispersed opacity. 


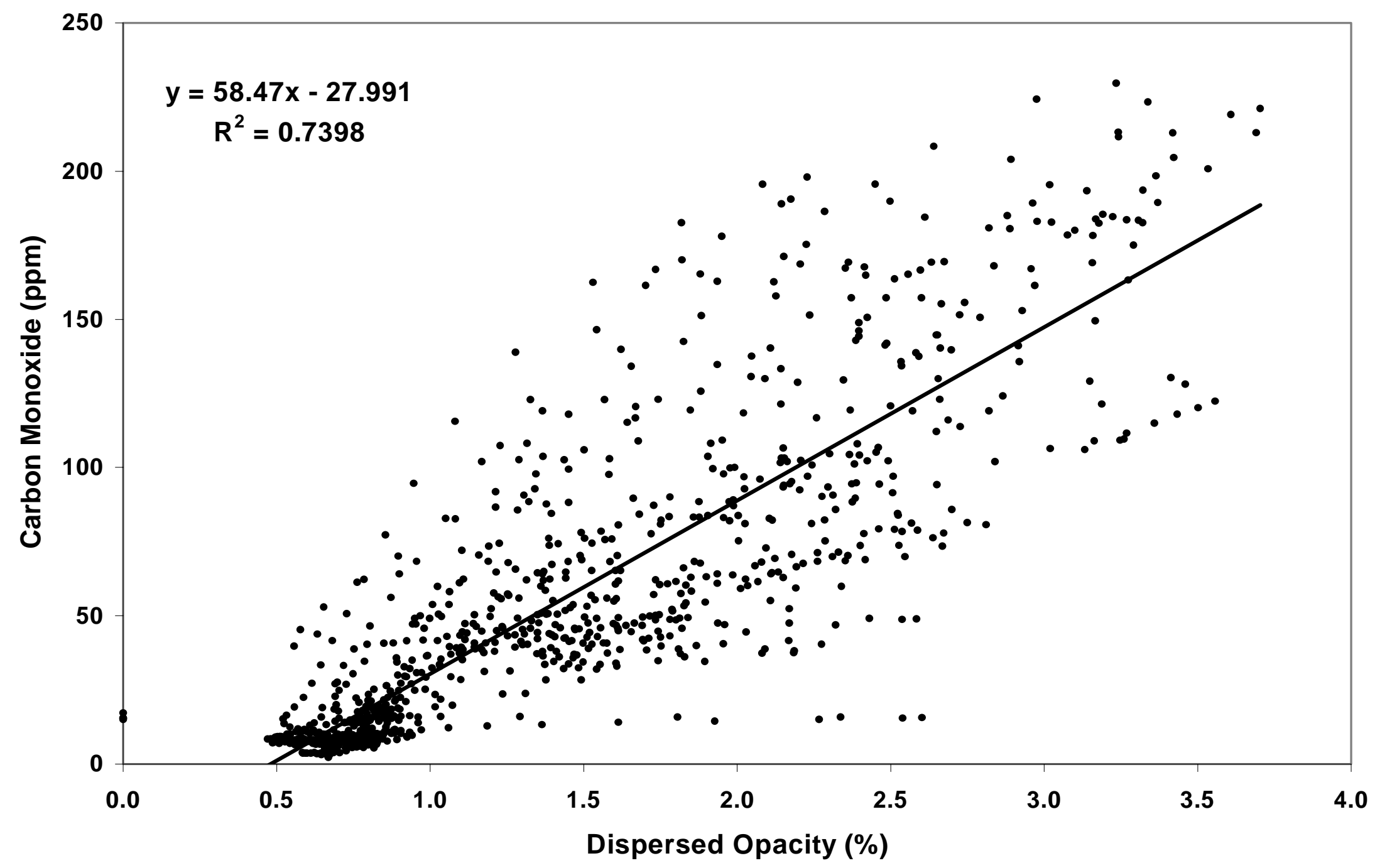

Figure C-18. Continuous carbon monoxide concentration plotted as a function of dispersed opacity from a 1996 transit bus powered by a 1996 DDC Series 50 engine exercised through a Test $D$ (test number 0926-2). These data were collected in Flint, MI and are also shown in Figure C-17 as continuous carbon monoxide and continuous dispersed opacity. 


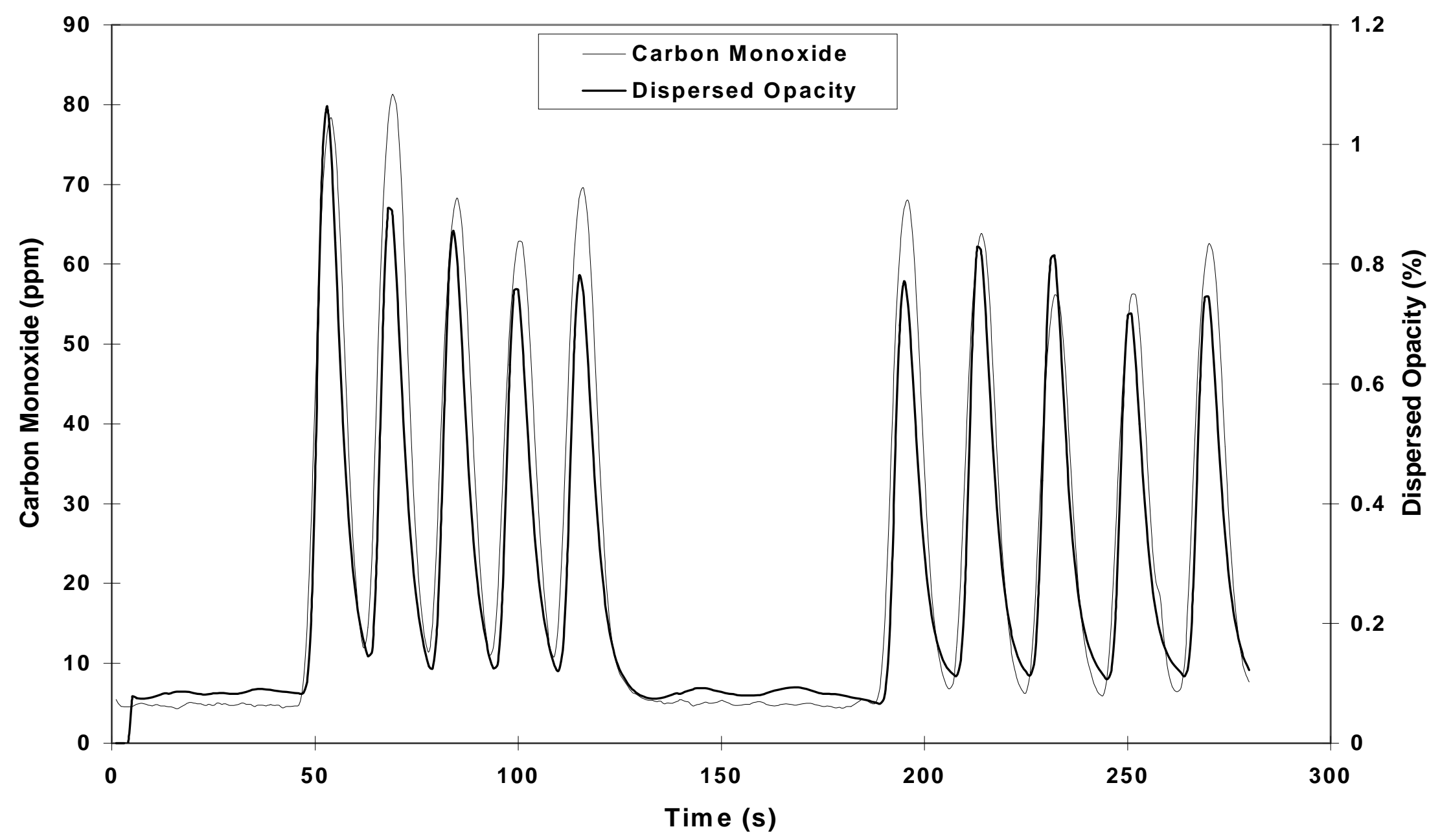

Figure C-19. Continuous carbon monoxide concentration and dispersed opacity from a 1996 Kenworth tractor truck powered by a 1996 Cummins M11 280-E engine exercised through a snap-acceleration test (test number 0964-snap). These data were collected in Sacramento, CA and are also shown in Figure C-20 as carbon monoxide plotted as a function of dispersed opacity. 


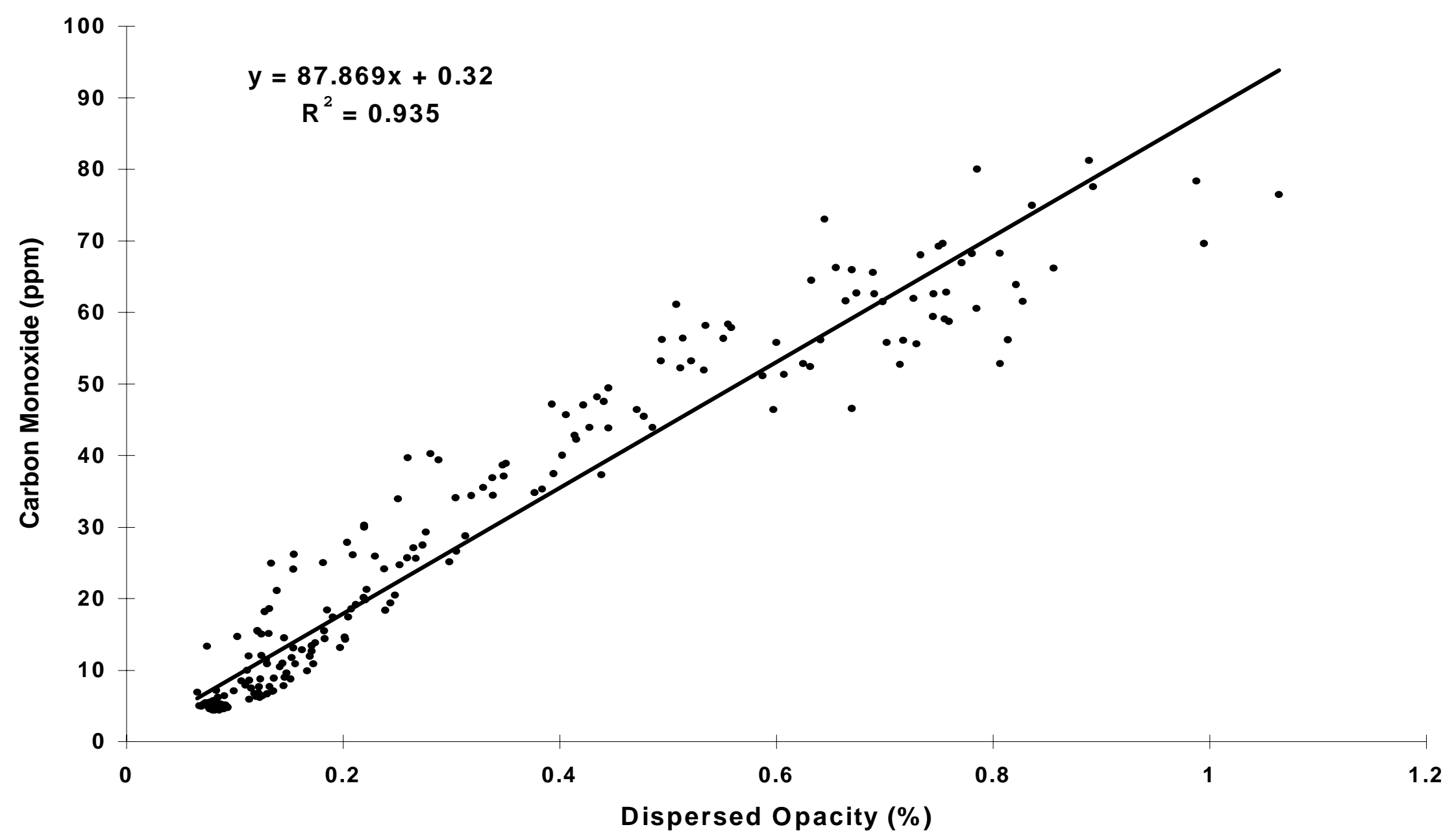

Figure C-20. Continuous carbon monoxide concentration plotted as a function of dispersed opacity from a 1996 Kenworth tractor truck powered by a 1996 Cummins M11 280-E engine exercised through a snap-acceleration test (test number 0964-snap). These data were collected in Sacramento, CA and are also shown in Figure C-19 as continuous carbon monoxide and continuous dispersed opacity. 